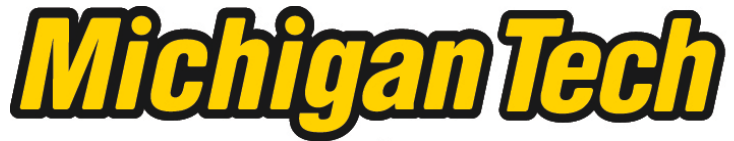 \\ Michigan Technological University Create the Future Digital Commons @ Michigan Tech
}

2013

\section{Production of Recombinant Trichoderma Reesei Endoglucanase Protein CEL7B by Using Kluyveromyces Lactis}

Zainab Ibrahim Alshoug

Michigan Technological University

Follow this and additional works at: https://digitalcommons.mtu.edu/etds

Part of the Chemical Engineering Commons

Copyright 2013 Zainab Ibrahim Alshoug

\section{Recommended Citation}

Alshoug, Zainab Ibrahim, "Production of Recombinant Trichoderma Reesei Endoglucanase Protein CEL7B by Using Kluyveromyces Lactis", Master's Thesis, Michigan Technological University, 2013.

https://doi.org/10.37099/mtu.dc.etds/617

Follow this and additional works at: https://digitalcommons.mtu.edu/etds

Part of the Chemical Engineering Commons 
PRODUCTION OF RECOMBINANT TRICHODERMA REESEI ENDOGLUCANASE PROTEIN CEL7B BY USING KLUYVEROMYCES LACTIS

\author{
By \\ Zainab Ibrahim Alshoug
}

\begin{abstract}
A THESIS
Submitted in partial fulfillment of the requirements for the degree of MASTER OF SCIENCE

In Chemical Engineering
\end{abstract}

MICHIGAN TECHNOLOGICAL UNIVERSITY

2013

(C) 2013 Zainab I. Alshoug 
This thesis has been approved in partial fulfillment of the requirements for the Degree of MASTER OF SCIENCE in Chemical Engineering.

Department of Chemical Engineering

Thesis Advisor: $\quad$ Dr. David Shonnard

Committee Member: Dr. Susan Bagley

Committee Member: Dr. Ching-An Peng

Department Chair: $\quad$ Dr. Komar Kawatra 


\section{Table of contents}

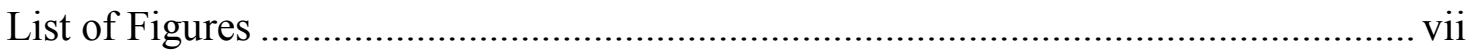

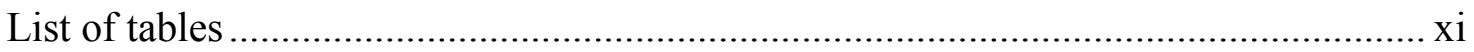

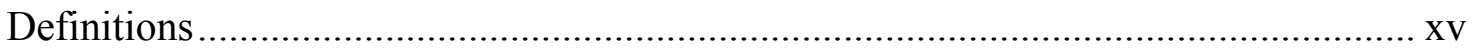

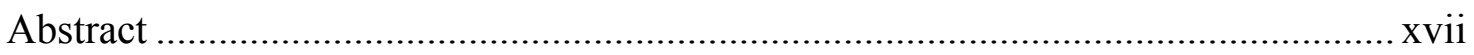

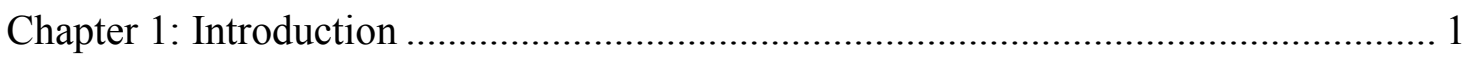

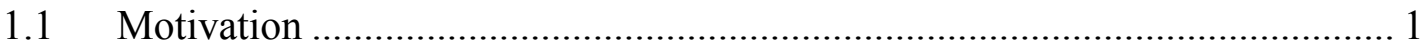

1.2 Biofuel production from woody biomass …………..................................... 2

1.2.1 Thermochemical conversion of plant woody biomass .............................. 2

1.2.2 Biochemical conversion of woody biomass........................................... 2

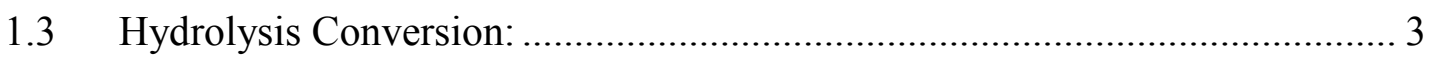

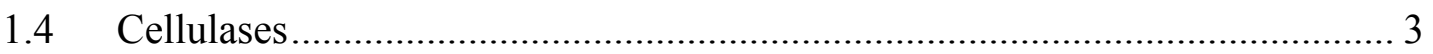

1.4.1 Cellulases in endoglucanase structure .................................................. 4

1.4.2 Measuring cellulase activity.............................................................. 4

Chapter 2: Kluyveromyces lactis: Properties and culture conditions ............................. 5

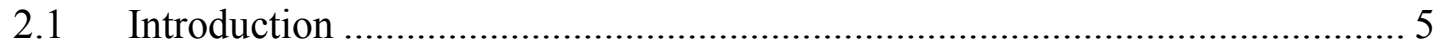

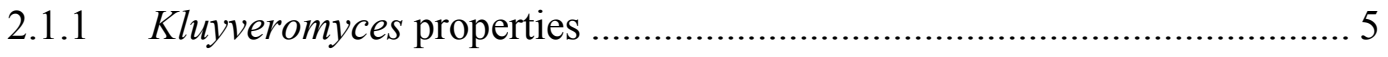

2.1.2 Kluyveromyces lactis features ............................................................ 5

2.1.3 Industrial application of $K$. lactis in dairy and food products................... 6

2.1.4 Advantages of Kluyveromyces lactis as expression host .......................... 6

2.1.5 Comparisons of $K$. lactis to S. cerevisiae............................................... 7

2.2 Growth conditions and environments......................................................... 7

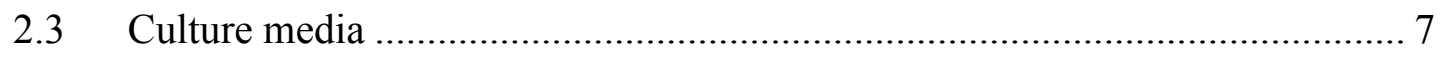

2.3.1 Overnight/Inoculum medium ............................................................. 7 


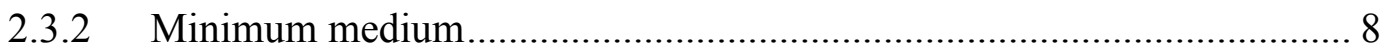

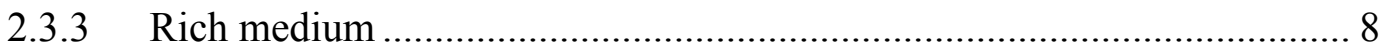

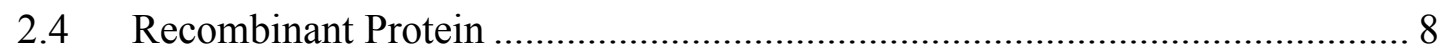

Chapter 3: Flask Culture for Recombinant Cel7B Production....................................... 10

3.1 Research Objectives ............................................................................ 10

3.2 Source of Yeast and Laboratory Equipment................................................. 10

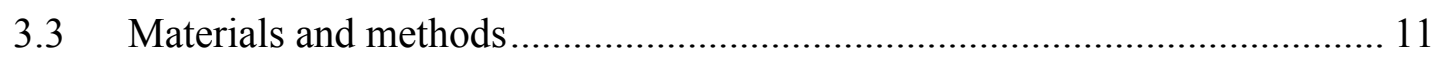

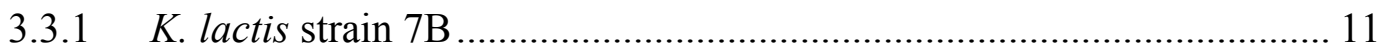

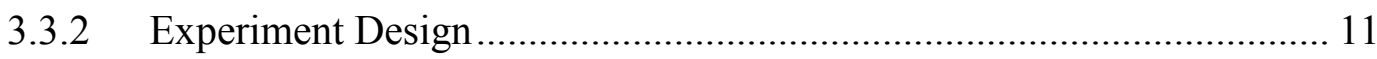

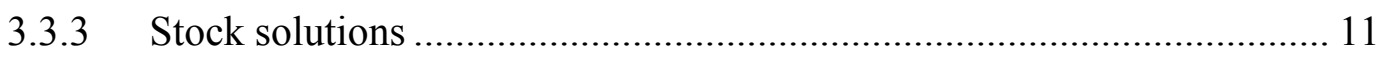

3.3.4 Types of agar and culture media .......................................................... 15

3.3.5 Cell culture conditions ...................................................................... 16

3.3.6 DNS assay for galactose and Cel7B activity ............................................ 19

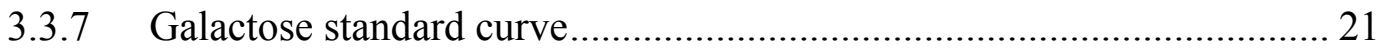

3.3.8 Gel electrophoresis method................................................................ 21

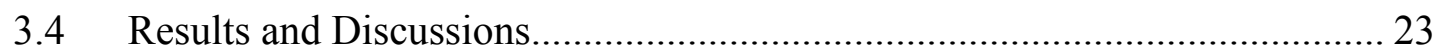

3.4.1 Result of the galactose calibration standard ........................................ 23

3.4.2 Effect of media on K. lactis-Cel7B growth density at $2 \%$ of galactose.. 24

3.4.3 Effect of initial galactose concentration on growth density of K. lactis-

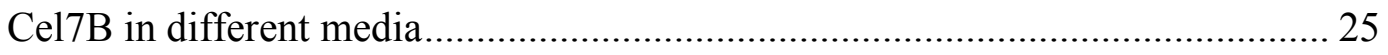

3.4.4 Effect of $1 \%$ galactose concentration on growth density of $K$. lactis-

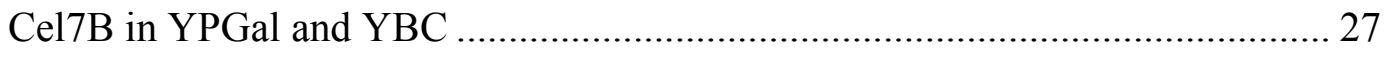

3.4.5 Effect of culture media on biosynthesis of recombinant enzyme Cel7B 29

3.4.6 Effect of initial concentration of galactose on recombinant enzyme Cel7B volumetric activity during flask culture in complex medium YPGal .................... 31 
3.4.7 Effect of initial concentration of galactose on recombinant enzyme Cel7B activity during flask culture in minimal medium YBC ................................... 33

Chapter 4: Bioreactor Culture of Recombinant Cel7B Production............................. 38

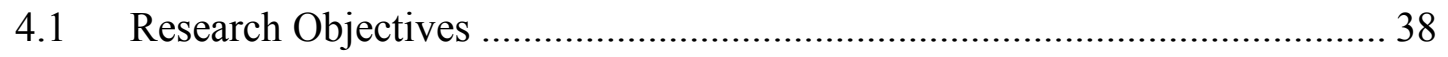

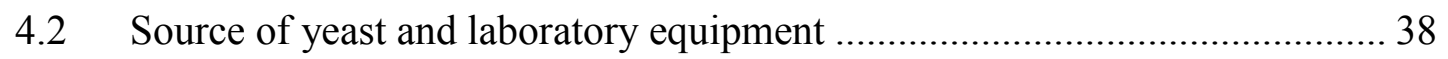

4.3 Materials and methods ....................................................................... 38

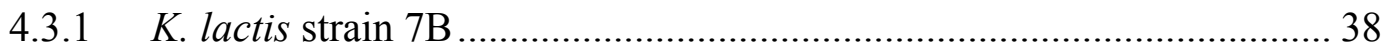

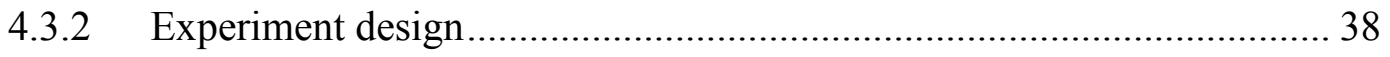

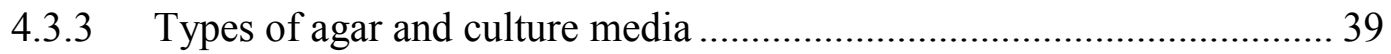

4.3.4 Stock solutions ......................................................................... 40

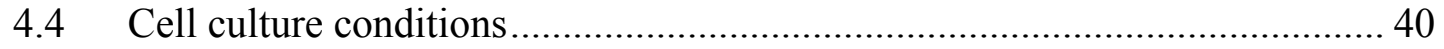

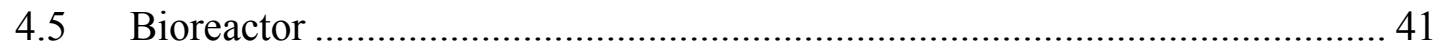

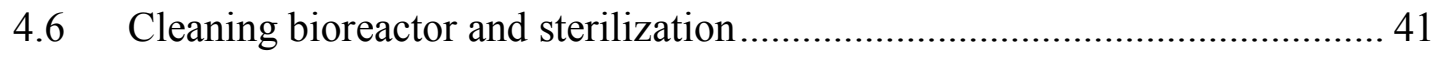

4.7 Starting up bioreactor ..................................................................... 41

4.8 Pumping up media into bioreactor.................................................... 42

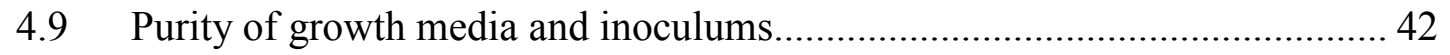

4.10 DNS assay for galactose concentration and Cel7B activity ........................ 42

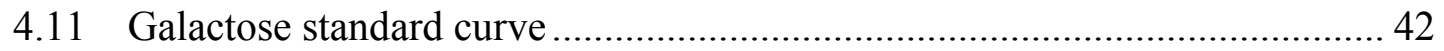

4.12 Results and discussion of bioreactor experiments .................................. 42

4.12.1 Recombinant Cel7B activity and galactose concentration in complex media YPGal-1\% Galactose, May23, 2012 .................................................... 43

4.12.2 Recombinant Cel7B activity and galactose concentration in complex medium YPGal-1\% Galactose, June13, 2012 ............................................... 46

4.13 Convert unit of volumetric activity of recombinant enzyme Cel7B of K. lactis

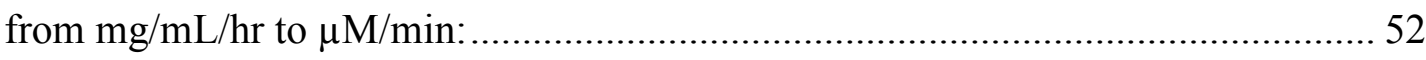


Chapter 5: Conclusions

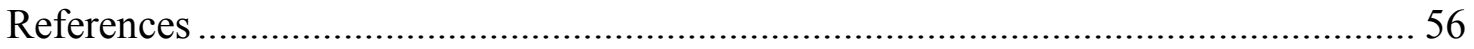

Appendix A: Small Scale "Shake Flask” Experiments ............................................... 59

Appendix B: Large Scale “Bioreactor/Fermenter” Experiments .............................. 92

Appendix C: Tools and devices were used in this study research .............................. 97 


\section{List of Figures}

Figure 3-1 The main steps of analyzing recombinant protein samples by using the $\mathrm{CMC} / \mathrm{DNS}$ assay

Figure 3-2 The growth conditions and environments of producing recombinant Cel7B protein 20

Figure 3-3 Galactose calibration standard using the DNS assay, June 13, 2012 _.......... 23 Figure 3-4 Growth density of $\mathrm{K}$. lactis-Cel7B yeast on three different media in flask culture: YPGal, YNB, and YBC with concentration of galactose (2\%) .......................... 25 Figure 3-5 Growth of K. lactis-Cel7B yeast in flask culture of YPGal media with two

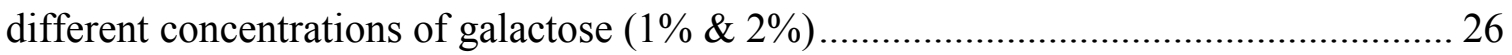

Figure 3-6 Growth density of $K$. lactis-Cel7B yeast in flask culture of YBC media with $1 \%$ and $2 \%$ initial concentration of galactose 27

Figure 3-7 Comparison between cells growth density of $\mathrm{K}$. lactis-Cel7B yeast in different media (YPGal and YBC) with initial 1\% concentration of galactose .28 Figure 3-8 Comparison between cells growth density of $K$. lactis-Cel7B in different media (YPGal and YBC) with $2 \%$ initial concentration of galactose 29

Figure 3-9 Gel electrophoresis of recombinant enzyme Cel7B produced in different media and with 1\% initial galactose concentrations: complex medium YPGal and minimal medium YNB without casamino acids and with (YBC) 30 Figure 3-10 Complex medium YPGal-1\% galactose samples, cell growth, galactose consumption, and Cel7B volumetric activity, March 28, 2012 32 Figure 3-11 Complex medium YPGal-2\% Galactose, cell growth, galactose consumption, and Cel7B volumetric activity, November 4, 2011

Figure 3-12 Minimal medium with casamino acid YBC-1\%, cell growth, galactose consumption, and Cel7B volumetric activity, March 28, 2012 34

Figure 3-13 Minimal medium with casamino acid YBC-2\%, cell growth, galactose consumption, and Cel7B volumetric activity, March 6, 2012 36 
Figure 4-1 K. lactis-Cel7B yeast growth, galactose consumption, and volumetric activity into complex medium YPGal-1\% Galactose samples "Large Scale”, May 23, 2012 ..... 45 Figure 4-2 K. lactis-Cel7B log growth curve on complex medium YPGal-1\% Galactose "Bioreactor Scale", May 23, 2012. 46

Figure 4-3 K. lactis- Cel7B yeast growth, galactose consumption, and volumetric activity into YPGal-1\% Galactose samples "Bioreactor Scale”, June 13, 2012.

Figure 4-4 K. lactis- Cel7B log growth curve on YPGal-1\% Galactose "Bioreactor

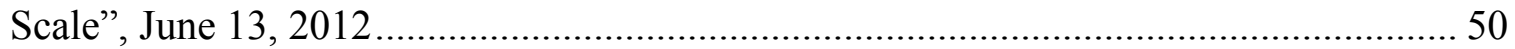

Figure 4-5 K. lactis- Cel7B average growth data on YPGal-1\% Galactose samples "Bioreactor Scale", June 13 and May 23, 2012 52 Figure 4-6 Comparison Endoglucanase Volumetric Activity of K. lactis-Cel7B Yeast versus Pichia Pastoris Yeast (Generoso et al. 2012). 53

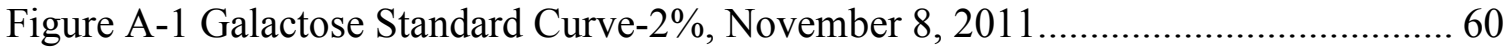
Figure A-2 Galactose Standard Curve into experiment of growing yeast Cel7B intoYNB2\% Galactose, December 12, 2011 63

Figure A-3 K. lactis-Cel7B yeast growth density into YNB-2\% Galactose "Shake FlaskSmall Scale", December 12, 2011 64

Figure A-4 Galactose Concentration into YNB-2\% Galactose "Shake Flask-Small Scale",

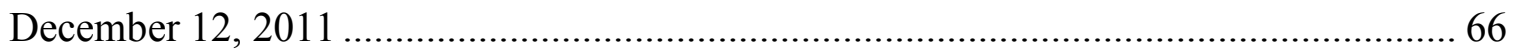

Figure A-5 K. lactis-Cel7B yeast growth density into YPGal.-2\% Galactose "Shake Flask-Small Scale", January 9, 2012 68

Figure A-6 K. lactis-Cel7B yeast growth density into YNB-2\% Galactose "Shake FlaskSmall Scale", January 9, 2012 69

Figure A-7 K. lactis-C17B yeast growth density into YBC-2\% Galactose "Shake Flask-

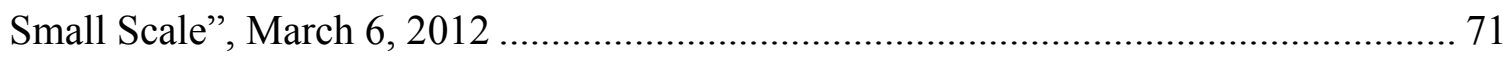

Figure A-8 Galactose Standard Curve into experiment of growing yeast Cel7B intoYBC-

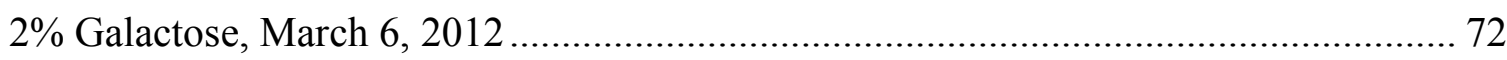

Figure A-9 Galactose calibration standard using the DNS assay, March 28, 2012 ....... 75 
Figure A-10 K. lactis- Cel7B yeast growth density into YPGal-1\% Galactose samples (Day) "Shake Flask-Small Scale”, March 27, 2012 ................................................. 76

Figure A-11 K. lactis-Cel7B yeast growth density into YBC-1\% Galactose samples (Day) "Shake Flask-Small Scale”, March 27, 2012 77

Figure A-12 K. lactis-Cel7B yeast growth density into YPGal-1\% Galactose samples (Hour) "Shake Flask-Small Scale”, March 27, 2012 78

Figure A-13 K. lactis-Cel7B yeast growth density into YBC-1\% Galactose samples (Hour) "Shake Flask-Small Scale”, March 27, 2012. 79

Figure A-14 Galactose Standard Curve into experiment of growing yeast Cel7B into YPGal-1\% Galactose "Shake Flask-Small Scale”, July 9, 2012 85

Figure A-15 K. lactis-Cel7B yeast growth density into YPGal-1\% Galactose samples

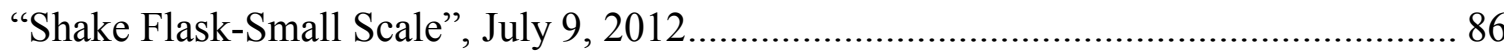

Figure A-16 Galactose concentration into YPGal.-1\% Galactose samples by using

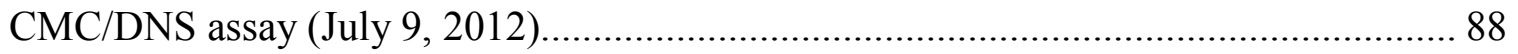

Figure A-17 Volumetric activity of enzyme into YPGal.-1\% Galactose samples by using CMC/DNS assay (July 9, 2012). 89

Figure A-18 Comparison between growth densities of $K$. lactis-Cel7B yeast into different medum: YNB-2\% Gal., YPGal-2\% Gal., YBC-2\% Gal., YPGal-1\% Gal., and YBC-1\% Gal.

Figure B-1 Galactose Standard Curve into experiment into YPGal.-1\% Galactose, (May $23,2012)$

Figure C-1 Gel electrophoresis for the SDS-PAGE 98

Figure C-2 Large flasks (4L) were used to transfer YPGal 1\% media in this research into

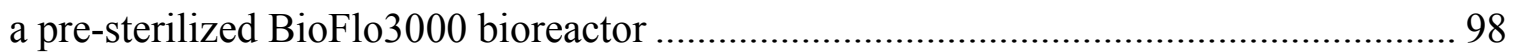

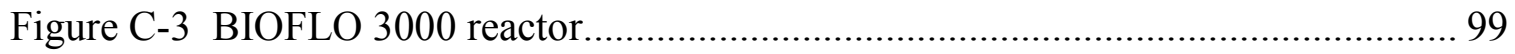

Figure C-4 YPD agar media plate with many single colonies of $K$. lactis-Cel7B........ 100 Figure C-5 Side-arm flasks (small scale) with different medium: YPGal, YNB, and YBC 100 
Figure C-6 The original yeast "Kluyveromyces lactis" was developed at New England

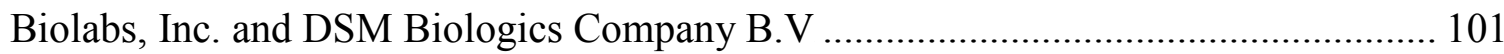

Figure C-7 The transformed yeast "Kluyveromyces lactis" Cel7B was developed by (Brodeur-Campbel 2012) ........................................................................................... 101 


\section{List of tables}

Table 3-1 Experiments Conducted in Small-Scale Culture of K. lactis Cel7B 14

Table 4-1 Experiments Conducted in Large-Scale Culture of K. lactis Cel7B ................ 39

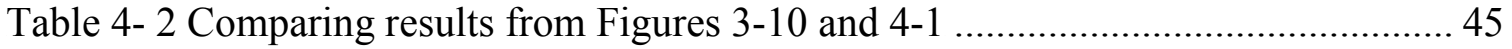

Table 4- 3 Comparing results from Figures 3-10 and 4-3 ........................................ 48

Table A-1 Measurement of Galactose Concentration by using DNS assay into Galactose

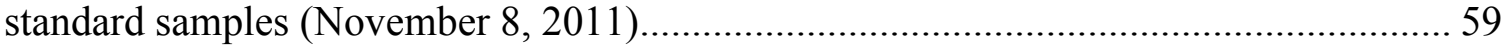

Table A-2 Measurement of Galactose Concentration into YPGal-2\% Galactose samples by using DNS tool (November 4, 2011) 61

Table A-3 Measurement of Galactose Concentration by using DNS assay into Galactose standard samples (December 12, 2011).....

Table A-4 Measurement of yeast growth density into YNB-2\% Galactose by using spectrometer (absorbance) at $600 \mathrm{~nm}$ (December 12, 2011) 63 Table A-5 Measurement of Galactose Concentration into YNB-2\% Galactose samples by

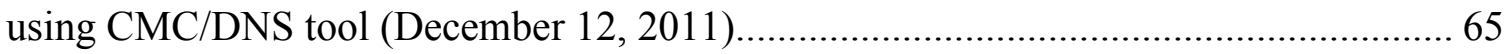

Table A- 6 Experiments Conducted in Small-Scale Culture of K. lactis Cel7B ............. 67 Table A-7 Measurement of yeast growth density into YNB-2\% Galactose and YPGal.-2\% Galactose by using spectrometer (absorbance) at $600 \mathrm{~nm}$ (January 9, 2012).....

Table A-8 Measurement of yeast growth density into YBC-2\% Galactose by using spectrometer (absorbance) at $600 \mathrm{~nm}$ (March 6, 2012) 70

Table A-9 Measurement of Galactose Concentration by using CMC/DNS assay into Galactose standard samples (March 6, 2012) 71

Table A-10 Measurement of Galactose Concentration and Net Activity of Enzyme into YBC-2\% Galactose samples by using CMC/DNS tool (March 6, 2012) ....................... 73

Table A-11 Experiments Conducted in Small-Scale Culture of K. lactis Cel7B ............ 74 Table A-12 Measurement of Galactose Concentration by using CMC/DNS assay into Galactose standard samples (March 28, 2012) 
Table A-13 Measurement of yeast growth density into YBC-1\% Galactose samples and YPGal.-1\% Galactose samples (Day) by using spectrometer (absorbance) at $600 \mathrm{~nm}$ (March 28, 2012) 75

Table A-14 Measurement of yeast growth density into YBC-1\% Galactose samples and YPGal.-1\% Galactose samples (Hour) by using spectrometer (absorbance) at $600 \mathrm{~nm}$ (March 27, 2012) 77

Table A-15 Samples Sheet for CMC/DNS assay experiment (March 28, 2012) ............ 79 Table A-16 Measurement of Galactose Concentration and Net activity of enzyme into YPGal-1\% Galactose samples by using CMC/DNS tool (March 28, 2012) ................... 82 Table A-17 Measurement of Galactose Concentration and Net activity of enzyme into YBC-1\% Galactose samples by using CMC/DNS tool (March 28, 2012) ...................... 83

Table A-18 Experiment Conducted in Small-Scale Culture of K. lactis Cel7B .............. 84 Table A-19 Measurement of Galactose Concentration by using CMC/DNS assay into

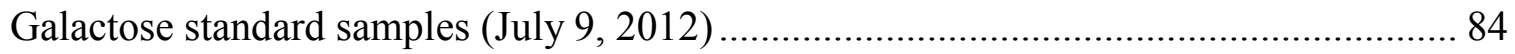

Table A-20 Measurement of yeast growth density into YPGal.-1\% Galactose samples by

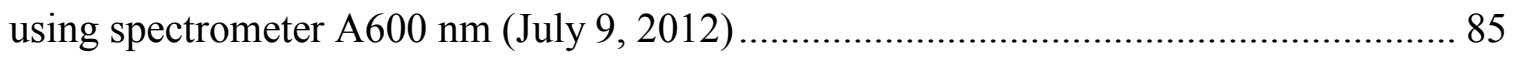

Table A-21 Measurement of Galactose Concentration and Net activity of enzyme into YPGal-1\% Galactose samples by using CMC/DNS tool (July 9, 2012) ......................... 87 Table A-22 Measurement of yeast growth density into YBC-1\% Galactose and YPGal.$1 \%$ Galactose by using spectrometer (absorbance) at $600 \mathrm{~nm}$. 90

Table B-1 Measurement of Galactose Concentration by using CMC/DNS assay into

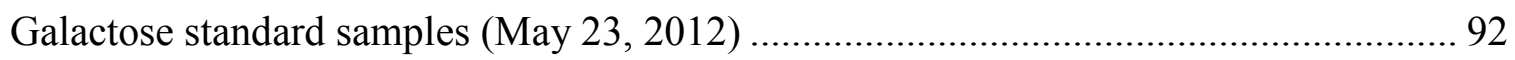
Table B-2 Measurement of yeast growth density into YPGal.-1\% Galactose samples by using spectrometer (absorbance) at $600 \mathrm{~nm}$ (May 23, 2012).... 93 Table B-3 Measurement of Galactose Concentration and Net activity of enzyme into YPGal-1\% Galactose samples by using CMC/DNS tool (May 23, 2012) ...................... 94 Table B-4 Measurement of Galactose Concentration by using CMC/DNS assay into

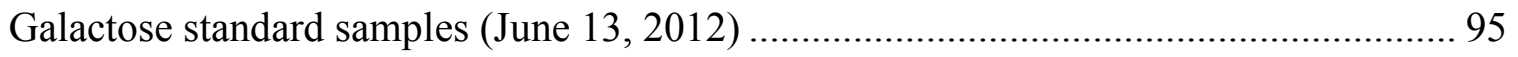


Table B-5 Measurement of yeast growth density into YPGal.-1\% Galactose samples by using spectrometer (absorbance) at $600 \mathrm{~nm}$ (June 13, 2012)..................................... 95 Table B-6 Measurement of Galactose Concentration and Net activity of enzyme into YPGal-1\% Galactose samples by using CMC/DNS tool (June 13, 2012) ..................... 96 


\section{Acknowledgements}

I would like to acknowledge the King Abdullah Scholarship Program (KASP) for his financial support of Master of Science (MS) degree study research project. I would like to acknowledge the Saudi Arabia Ministry of Higher Education and Saudi Arabian Cultural Mission to the U.S. (SACM) for their financial support, understanding and sponsorship. I would like to acknowledge the understanding, support, and guidance of my advisor Dr. David R. Shonnard. I would like to acknowledge the guidance of my laboratory mate Dr. Michael Brodeur-Campbell and Jordan Klinger. I would like to acknowledge Dr. Susan Bagley and Dr. Ching-An Peng for their serving on my advisory committee. I would like to conclude this acknowledgement by a lot of thanks to my family and specially my mother and my sisters Zahra and Bushra for their support to achieve my dream as a woman engineer, understanding to let me study abroad, and prayers to light my way. 


\section{Definitions}

"Cellulose is a linear homopolymer of the six-carbon sugar glucose". "Hemicellulose is a branched heteropolymer of five- and six-carbon sugars, primarily xylose, arabinose, galactose, glucose, and mannose". Six-carbon (hexose) sugars are usually fermented by many strains of microorganisms, while the five-carbon (pentose) sugars are fermented by a few of them (Shonnard et al. 2012)

"Separate hydrolysis and fermentation (SHF) is when enzymatic hydrolysis takes place separately from fermentation. Simultaneous saccharification and fermentation (SSF) is the term for hydrolysis taking place in the presence of fermenting microorganisms. Simultaneous saccharification and co-fermentation (SSCF) means the SSF reduces the effect of product inhibition during hydrolysis as the fermenting organisms consume the products (sugars) as they hydrolysis"(Shonnard et al. 2012).

\section{Carboxymethyl cellulose (CMC):}

This substance is a cellulose derivative, containing a carboxymethyl group $\left(-\mathrm{CH}_{2}-\mathrm{COOH}\right)$ which can bond to hydroxyl groups in some glucopyranose monomers. This reaction is what leads to the construction of the cellulose backbone. The usage of the carboxymethyl cellulose is usually as sodium salt and sodium carboxymethyl cellulose.

\section{3,5-Dinitrosalicylic-acid (DNS or DNSA, IUPAC name 2-hydroxy-3,5-dinitrobenzoic acid)/deoxyribonucleic acid:}

The DNS solution contains: phenol, dinitrosalicyclic acid, sodium sulfite, Rochelle salt, sodium hydroxide " $\mathrm{NaOH}$ ", and distilled water. It reacts with reducing sugars and molecules to produce 3-amino-5-nitrosalicylic acid, the concentration of which can be easily measured on a spectrometer set to $540 \mathrm{~nm}$. 


\section{List of abbreviations}

$\begin{array}{ll}\text { AFEX } & \text { Ammonia Fiber Expansion } \\ \text { CMC } & \text { Carboxymethyl cellulose } \\ \text { DNS } & \text { 3,5-Dinitrosalicylic acid } \\ \text { DO } & \text { Dissolved oxygen } \\ \text { FPU } & \text { Filter Paper Unit } \\ \text { OD } & \text { Optical density } \\ \text { SDS-PAGE } & \text { Sodium Dodecyl Sulfate Polyacrylamide Gel Electrophoresis } \\ \text { YBC } & \text { Yeast nitrogen base with casamino acid } \\ \text { YCB-Acetamide } & \text { Yeast carbon base with acetamide } \\ \text { YNB } & \text { Yeast nitrogen base } \\ \text { YPD } & \text { Yeast extract, peptone, glucose } \\ \text { YPGal } & \text { Yeast extract, peptone, galactose }\end{array}$




\section{Abstract}

This research is about producing recombinant Trichoderma reesei endoglucanase Cel7B by using Kluyveromyces lactis, transformed with chromosomally integrated Cel7B cDNA, as a host cell (K. lactis Cel7B). Cel7B is one of the glycoside hydrolyze family of proteins that are produced by $T$. reesei. Cel7B together with other endoglucanases, exoglucanases, and $\beta$-glucosidases hydrolyze cellulose to glucose, which can then be fermented to biofuels or other value-added products.

The research objective of this MS project is to examine favorable fermentation conditions for recombinant Cel7B enzyme production and improved activity. Production of enzyme on different types of media was examined, and the activity of the enzyme was measured by using different tools or procedures. The first condition tested for was using different concentrations of galactose as a carbon and energy source; however galactose also acts as a potent promoter of recombinant Cel7B expression in K. lactis Cel7B. The purpose of this method is to determine the relationship between production of enzyme with increasing sugar concentration. The second culture condition test was using different types of media: a complex medium-yeast extract, peptone, galactose (YPGal); a minimal medium-yeast nitrogen base (YNB) with galactose; and a minimal medium with supplement-yeast nitrogen base with casamino acid (YBC), a nitrogen source, with galactose. The third condition was using different types of reactors or fermenters: a small reactor (shake flask) and a larger automated bioreactor (BioFlo 3000 fermenter). The purpose of this method is to determine the quantity of the protein produced by using different environments of production.

Different tools to determine the presence and activity of Cel7B enzyme were used. For the presence of enzyme, sodium dodecyl sulfate polyacrylamide gel electrophoresis (SDS-PAGE) was used. Secondly, to detect enzyme activity, the carboxymethyl cellulose- 3,5-dinitrosalicylic acid (CMC- DNS) assay was employed. 
SDS-PAGE showed that the enzyme band was at $67 \mathrm{kDa}$, which is larger than native Cel7B (52 kDa.), likely due to over glycolylation during post-translational processing in $K$. lactis. For the different types of media used in our fermentation, recombinant Cel7B was produced from yeast extract peptone galactose (YPGal), and yeast nitrogen base with casamino acid (YBC), but was not produced and no activity was detected from yeast nitrogen base (YNB). This experiment concluded that the Cel7B production requires the amino acid resources as part of fermentation medium.

In experiments where recombinant Cel7B net activity was measured at $1 \%$ galactose initial concentration in YPGal and YBC media, higher enzyme activity was detected for the complex medium YPGal. Higher activity of recombinant Cel7B was detected for flask culture in $2 \%$ galactose compared to $1 \%$ galactose for YBC medium.

Two bioreactor experiments were conducted under these culture conditions at $30^{\circ} \mathrm{C}, \mathrm{pH}$ 7.0 , dissolved oxygen of $50 \%$ of saturation, and $250 \mathrm{rpm}$ agitation (variable depending on DO control) K. lactis-Cel7B yeast growth curves were quite reproducible with maximum optical density (O.D) at $600 \mathrm{~nm}$ of between 7 and 8 (when factoring dilution of 10:1). Galactose was consumed rapidly during the first 15 hours of bioreactor culture and recombinant Cel7B started to appear in the culture at 10-15 hours and increased thereafter up to a maximum of between 0.9 and $1.6 \mathrm{mg} / \mathrm{mL} / \mathrm{hr}$ in these experiments. These bioreactor enzyme activity results are much higher than comparable experiments conducted with flask-scale culture $(0.5 \mathrm{mg} / \mathrm{mL} / \mathrm{hr})$.

In order to achieve the highest recombinant Cel7B activity from batch culture of $K$. lactis-Cel7B, based on this research it is best to use a complex medium, $2 \%$ initial galactose concentration, and an automated bioreactor where good control of temperature, $\mathrm{pH}$, and dissolved oxygen can be achieved. 


\section{Chapter 1: Introduction}

\subsection{Motivation}

The global interest in liquid biofuels has become greater in the past few years. The most common use for the biofuel in the past century was for transportation, especially for automobiles. At that time, automobiles ran on gasoline or ethanol or a mixture of both. There are many reasons for the global interest in biofuels; in the past it was only to address the need for flammable sources of cooking, heating, and engines of vehicles and other industrial engines. Nowadays, the interest for biofuels pertains to addressing global issues like climate warming, rural economic development, domestic jobs, energy security, and balance of trade. There are two types of processing technologies to convert biomass to biofuels: biochemical and thermochemical, which can increase the biomass feedstock that can be converted to biofuels (Shonnard et al. 2012).

These biochemical conversions have two main steps: a decomposition step, and a fermentation step. The purpose of the first step is to break down lignocellulosic biomass into sugars using pretreatment followed by enzyme treatment. The second step uses microorganisms, which convert sugars into oxygenated biofuels. The type of microorganism depends on the desired sugar because there are specific microorganisms that are able to ferment specific sugars, but cannot ferment other types of sugars (Shonnard et al. 2012).

A recent metabolic engineering research project on microorganisms has found a special microorganism that can ferment different types of sugar from woody biomass into oxygenated biofuels while other microorganisms are able to convert these sugars into true hydrocarbon fuel (Shonnard et al. 2012). On the other hand, thermochemical conversion processes utilize chemical catalysts at high temperatures and pressures. Thermochemical reactions occur at higher rates than biochemical reactions, but biochemical reactions occur with higher specificity toward desired products (Mosier et al. 2005). 
Although biofuels can be produced from most plant feedstocks, such as lignocellulosic (woody) feedstocks, unconventional plant oils, and algae, it is more difficult to produce biofuels from these resources compared to biofuels like corn starch ethanol and biodiesel. Furthermore, because these new biofuel conversion technologies are not yet commercial, their cost and their environmental impacts are less known compared to conventional biofuels (Shonnard et al. 2012).

\subsection{Biofuel production from woody biomass}

\subsubsection{Thermochemical conversion of plant woody biomass}

Thermochemical conversion of the woody biomass into biofuels and other high-value chemicals usually happen at high temperature and pressure in the presence of chemical catalysts. There are two main processes for the thermochemical conversion: gasification and pyrolysis of the original biomass. In both processes, the original woody biomass is thermally decomposed into intermediate products, all of which have small molecular weights relative to the main polymeric carbohydrate and lignin wood fractions. The main product of the gasification step of the thermochemical conversion is a synthesis gas (CO, $\mathrm{CO}_{2}$, and $\mathrm{H}_{2}$ ), and the main product of the pyrolysis step is one of these products: a crude bio-oil, a synthesis gas, or a solid carbonaceous char (Torres et al. 2007).

\subsubsection{Biochemical conversion of woody biomass}

Biochemical conversion of the lignocellulosic biomass into fuels and other chemicals mainly focuses on the production of monomer sugars from hemicellulose and cellulose in the wood. There are four main processes of the biochemical conversion: mechanical size reduction, chemical pretreatment, enzymatic hydrolysis, and fermentation (Shonnard et al. 2012).

The purpose of the chemical pretreatment and enzymatic hydrolysis is to break down and recover the monosaccharides from lignocellulosic biomass. The fermentation step converts these monosaccharides to valuable products (Mosier et al. 2005).

The pretreatment step of the biochemical conversion does not only help to break down the easily hydrolyzed hemicellulose to produce monomer sugars, but also helps to open 
the structure of the lignocellulosic biomass to allow the hydrolyzing enzymes access to cellulose. The enzymatic hydrolysis procedure not only produces the necessary glucose from cellulose, but, due to the mild temperatures and $\mathrm{pH}$, also protects the hemicellulose sugars from thermal degradation, and limits the amount of by-product formation (Mosier et al. 2005).

\subsection{Hydrolysis Conversion:}

One of the most costly processes of biochemical processing of lignocellulosic biomass is the pretreatment hydrolysis conversion step. This step is effected by the degree of size reduction and has an effect on enzymatic hydrolysis processes (Wyman et al. 2005a).

The three main methods for the pretreatment process are low $\mathrm{pH}$ pretreatment (strong acid 0.5-3 wt \%), high $\mathrm{pH}$ pretreatment, and solvent pretreatment. Low $\mathrm{pH}$ pretreatment forms two phases of products: a liquid fraction, which contains most of the hemicellulose sugars, and a solid residue, which contains most of the cellulose and lignin. There are two steps for the low $\mathrm{pH}$ method: dilute acid and hot water/steam autolysis. High $\mathrm{pH}$ conditions take off lignin and leave behind the solid residue with only the cellulose and hemicellulose. There are three steps for the high $\mathrm{pH}$ method: AFEX (ammonia fiber expansion), recycle percolation (soaking in aqueous ammonia), and lime treatment. There are two approaches for solvent pretreatments; organic solvent and ionic liquid pretreatments. Organic solvents treat the biomass by using one of these two solutionsethanol/water or methanol/water - to take off $70-90 \%$ of the lignin into the liquid phase. The ionic liquid phase is an extremely expensive pretreatment and still under development. The remaining cellulose and hemicellulose can be treated by using additional enzyme hydrolysis (Wyman et al. 2005b).

\subsection{Cellulases}

Cellulases are classified by basis or sequence. The classification by basis is for groups and classification by sequence is for families. There are three groups of cellulases: exo$1,4-\beta$-D-glucanases, endo-1,4- $\beta$-D-glucanases, and $\beta$-glucosidases. Also there are many families of cellulases: 1, 3, 5-9, 12, 44, 45, 48, 61, and 74 of the glycoside hydrolases (McFarland et al. 2007). 


\subsubsection{Cellulases in endoglucanase structure}

Endoglucanase is a class of enzyme that hydrolyzes bonds at random locations on amorphous (non-crystalline) regions of cellulose. Endoglucanase produces more cellulose chain ends for cellobiohydrolase (exogluconase) attachment (Shonnard et al. 2012). Cellobiohydrolases attach at the ends of cellulose chains, work gradually over the length of the chain, and produce both cellobiose and cellotriose, but mostly cellobiose. $\beta-$ glucosidases break the soluble parts of cellobiohydrolase products, cellotriose and cellobiose, into glucose monomers. Based on the species, these enzymes can be produced as complex and non-complex enzymes (Lynd et al. 2002). Cellulolytic enzymes must be able to contact the insoluble substrate, break the structure, and lead a single polymer chain through the catalytic site (Eijsink et al. 2008).

\subsubsection{Measuring cellulase activity}

There are some substrates that can be used to measure cellulase activity. There are two different types of the substrates - natural and artificial - and each type has its own advantages and disadvantages. The best artificial substrate to measure endoglucanase activity is Carboxy-methyl-cellulose (CMC), which is an amorphous analog to crystalline cellulose and with is susceptible to hydrolysis attach by endogluconases. Measuring exogluconase (cellobiohydrolyase) activity on pure cellulose may not be the same as the measuring activity on biomass (King et al. 2009), which is one disadvantage of artificial substrates such as pure cellulose. While measuring the activity of the cellulose hydrolysis, the following conditions are important for the reaction: temperature being 40 $50^{\circ} \mathrm{C}, \mathrm{pH}$ of the citrate buffer being 4.8-5, 15-60 FPU/g- glucan plus excess $\beta-$ glucosidase, $1-20 \mathrm{wt} \%$ solids , and the reaction time being 24-72h (Shonnard et al. 2012). 


\section{Chapter 2: Kluyveromyces lactis: Properties and culture conditions}

\subsection{Introduction}

After 1984, the name Kluyveromyces lactis replaced Saccharomyces lactis. K. lactis is an important genetic model organism in fungal genetics. This yeast was one of the first yeasts to be transformed by the foreign DNA in the laboratory.

There are two different classifications for Kluyveromyces lactis. The genus classification depends on the ability of $K$. lactis to cross-breed with S. cerevisiae. The taxonomic classification that grouped K. lactis under Saccharomyces lactis and which has now been changed to be classified under the Kluyveromyces marxianus var. lactis (Swinkels et al. 1993).

\subsubsection{Kluyveromyces properties}

$K$. lactis has special properties which make it better than other yeast species in many respects. K. lactis has impressive secretory capacities for large scale production; its fermentation yields enzymes with the desired characteristics (e.g., for food production) and the availability of its two expression vectors: episomal and integrative (Swinkels et al. 1993).

\subsubsection{Kluyveromyces lactis features}

There are some features that make $K$. lactis a better alternative host for foreign gene expression and secretion. K. lactis has a faster growth rate, wider substrate range, lack of hyperglycosylation, and it reduces catabolite repression relative to $S$. cerevisiae $(\mathrm{H}$. Hsieh and Da Silva 1998).

In K. lactis, the processes of sugar metabolism (i.e., lactose and galactose) are controlled by the lac-gal regulon. Galactose then enters into the Leloir catabolic pathway (Wray et al. 1987). Further metabolism occurs via the enzymes galactokinase (K1GAL1), transferase (K1GAL7), and epimerase (KlGAL10). These five genes are co-regulated; transcription is induced by growth in the presence of lactose or galactose (Dickson and Riley 1989) (Huangpin Ben Hsieh and Da Silva 2000). 


\subsubsection{Industrial application of $K$. lactis in dairy and food products}

$K$. lactis is safe to use in the food and dairy industries, especially when it is used as an expression system to regulate processes of the food. It has been used for a long time in the dairy industry and has been a successful industrial microorganism $(\mathrm{H}$. Hsieh and $\mathrm{Da}$ Silva 1998). K. lactis's dried powder was used as a dietary protein supplement for many years. $K$. lactis produces different type of recombinant proteins such as recombinant bovine rennin and recombinant bovine prochymosin, which can be used safely in the food industry. The recombinant protein that was approved to be used in the food applications was rennin. The main use of the recombinant protein rennin is in cheese manufacturing.

Many features make $K$. lactis good for industrial-scale protein production. K. Lactis, which can produce the heterologous protein in any simple growth medium, does not require methanol, which is important usually for the methylotrophic yeast (Read et al. 2007).

There are many selective strategies; one of them is the counter selection. Counter selection is used to structure selection of the marker-free strains that is used in the food productions at the industrial level (Read et al. 2007).

$K$. lactis works to utilize lactose as carbon source, which was one of the advantages to produce the $K$.lactis biomass on the milk, specifically on the "whey" or what is called "milk serum". This process leads to the use of yeast called "alimentary yeast" to supplement food and feed, and to produce the enzyme "lactase" at an industrial scale (Swinkels et al. 1993).

$K$. lactis is a safe organism for human use, which is produced for the industrial production during the protein synthesis process. Nowadays, K. lactis is mostly used in producing low lactose milk for affected populations (Swinkels et al. 1993).

\subsubsection{Advantages of Kluyveromyces lactis as expression host}

$K$. lactis offers four main advantages as an expression system: it reaches a high cell density when grown in the bioreactors, it does not usually require methanol to obtain high gene expression, it has two different support vectors for the protein expression-stable 
episomal and integrative, and lastly, it can be easily grown and transformed with genetic techniques and media already developed for S. cerevisiae.

\subsubsection{Comparisons of $K$. lactis to $S$. cerevisiae}

Another benefit of $K$. lactis versus $S$. cerevisiae, is that $K$. lactis expresses the enzyme, lactase, which breaks lactose into galactose and glucose. Therefore, in dairy production, when the concentration of lactose is very high, $K$. lactis is truly a necessary component of the culture. Wild-type $K$. lactis is usually isolated from dairy products like yogurt, cheese, and buttermilk making. K. lactis, however, does not produce any ethanol aerobically.

\subsection{Growth conditions and environments}

There are two types of fermenters: the batch/fed-batch fermenter and the continuous fermenter. The most popular one is the batch fermenter, which is usually used on small scale. The culturing of the yeast starts by inculcating a new YPD (yeast extract-peptonedextrose (glucose)) ager plate (see next section) with $-80^{\circ} \mathrm{C}$ frozen cells of $K$. lactisCel7B (a transformed $K$. lactis with chromosomally-integrated cDNA from $T$. Reesei endogluconase (Cel7B) obtained from (Brodeur-Campbel 2012), usually about 800 colonies per agar plate of medium (van der Vlugt-Bergmans and van Ooyen 1999). Then, one colony is taken to inoculate $2 \mathrm{~mL}$ of liquid medium (YPD inoculum medium) in a 14 $\mathrm{mL}$ test-tube (Becton Dickinson Company) in $30^{\circ} \mathrm{C}$ water-bath shaker at $200 \mathrm{rpm}$ until the cell mass reaches $0.22-0.43 \mathrm{~g} / \mathrm{L}($ O.D. $=1 @ 600 \mathrm{~nm})$. After that, $50 \mathrm{~mL}$ of a minimum or rich medium (see sections below) in $250 \mathrm{~mL}$ flask is inoculated $(1 \% \mathrm{v} / \mathrm{v})$ and incubated in a $30^{\circ} \mathrm{C}$ shaker table at $200 \mathrm{rpm}$. After 12 hours of incubation, the sample can be taken. Each sample consists of $5 \mathrm{~mL}$ of culture medium every two hours for more than 12 hours. From these samples, the most important variables in this growth and culture are biomass concentration, growth substrate concentration, and enzyme activity over time of production (H. Hsieh and Da Silva 1998).

\subsection{Culture media}

\subsubsection{Overnight/Inoculum medium}


K. lactis strain CBS 2359 grown in YPD (10 g yeast extract, 20 g Bacto-peptone, $20 \mathrm{~g}$ glucose in $1 \mathrm{~L}$ ) at $30^{\circ} \mathrm{C}$ was diluted $3000-, 600-, 300-$ and 100 - fold in $150 \mathrm{~mL}$ of fresh YPD and incubated in $14 \mathrm{~mL}$ test tubes for $6 \mathrm{~h}$ at $30^{\circ} \mathrm{C}, 160 \mathrm{rpm}$ in a rotary shaker. The purpose of these dilutions to choose an overnight culture has a density of growth cells between 0.7-1.0 was used to inoculated growth culture (van der Vlugt-Bergmans and van Ooyen 1999).

\subsubsection{Minimum medium}

SDC medium (also known as the minimum medium yeast nitrogen base (YNB)-casamino acids) contains: nitrogen bases without amino acids ( $6.7 \mathrm{~g} / \mathrm{L}$, Difco), dextrose (glucose) $(20 \mathrm{~g} / \mathrm{L})$, and casamino acids $(5 \mathrm{~g} / \mathrm{L})$ and Bacto-agar $(20 \mathrm{~g} / \mathrm{L}$, Difco) for the plates $(\mathrm{H}$. Hsieh and Da Silva 1998).

SD minimal medium (Sherman et al. 1986) contain yeast nitrogen bases without amino acids (6.7 g/L, Difco Laboratory, Detroit, MI) and dextrose (20 g/L). SG minimal and SGC medium are similar to SD and SDC except that galactose ( $>99.7 \%$ pure) replaces the glucose. SDGC medium contain both glucose and galactose 20\% (w/v) (Huangpin Ben Hsieh and Da Silva 2000).

\subsubsection{Rich medium}

YPD medium (or rich medium) contains: yeast extract (10 g/L, Difco), peptone (20 g/L, Difco), dextrose (glucose) $(10 \mathrm{~g} / \mathrm{L})$ and Bacto-agar $(20 \mathrm{~g} / \mathrm{L}$, Difco) for the plates (Sherman et al. 1986) (H. Hsieh and Da Silva 1998). For induction, a 20\% (w/v) galactose stock solution was added to the SDC medium to the desired galactose concentration. For plates, $20 \mathrm{~g} / \mathrm{L}$ Bacto-agar (Difco) was added (Huangpin Ben Hsieh and Da Silva 2000).

\subsection{Recombinant Protein}

Recombinant protein is a product synthesized from foreign DNA inserted into host organisms such as yeast, bacteria, fungi, plants or mammals (Van Ooyen et al. 2006) depending on the scale of production. 
There are many effective ways to obtain the recombinant protein expression level of high cell density culture: using different promoters, using different host strains, co-expression of various proteins, reduction of culture temperature, and secretion of proteins into the culture medium (Hockney 1994); (Veldboom and Lee 1996); (Makrides 1996). 


\section{Chapter 3: Flask Culture for Recombinant Cel7B Production}

\subsection{Research Objectives}

The purpose of the small-scale (flask) cell culture component of this study was to evaluate favorable conditions for the growth of the yeast $K$. lactis which was previously transformed by chromosomally-integrated gene for Cel7B, and the production of the highest concentration (activity) of the recombinant enzyme. To find the best environment for flask culture, trials with the small scale (flask culture) were performed to determine the bioreactor production ability under different culture conditions. The objectives of using flask culture are:

- Measure recombinant enzyme volumetric activity in flask scale culture on $K$. lactis-Cel7B growth and galactose consumption as a baseline to compare automated bioreactor trials

- Evaluate effects of using YPGal complex medium with $1 \%$ and $2 \%$ galactose concentration on $\mathrm{K}$. lactis-Cel7B growth, galactose consumption and recombinant enzyme volumetric activity

- Study effects of using minimal medium (YNB) and (YBC) on K. lactis-Cel7B cell growth, galactose consumption and recombinant enzyme volumetric activity

- Conduct research into effects of using $1 \%$ and $2 \%$ galactose concentration in YBC minimum medium supplemented with casamino acid on K. lactis-Cel7B yeast cell growth, galactose consumption and recombinant enzyme volumetric activity

\subsection{Source of Yeast and Laboratory Equipment}

The following pieces of laboratory equipment were used in this research; the shaker table was a Lab-Line ${ }^{\circledR}$ Orbit Environ-shaker (model 3528-5), the autoclave was from New Brunswick Scientific (model AC-48), the spectrophotometer was a Milton Roy Spectrometer (model Spectronic 21D UV), the power source for gel electrophoresis was a VWR 300V Power Source (model G82428), and the scale was from Mettler TOLEDO (model VIPER). The side-arm flasks and other glassware used in this lab were mostly from Fisher Scientific. All these devices, equipment, tools, and the experiments done 
were located in Dr. David R. Shonnard's laboratory (rm. 205), in the Chemical Engineering Department of Michigan Technological University.

\subsection{Materials and methods}

\subsubsection{K. lactis strain 7B}

The original (untransformed) yeast "Kluyveromyces lactis" used in this research was obtained from New England Biolabs and the transformed Cel7B K. lactis was obtained from (Brodeur-Campbel 2012).

\subsubsection{Experiment Design}

The experiments listed in Table 3-1 were designed to address the research objectives set forth in section 3.1. The information in Table 3.1 is organized by date of experiment, type of medium concentration of galactose, and purpose of experiment. In each experiment there was a purpose and there were some targeted measurements such as cell growth of K. lactis-Cel7B, galactose concentration, and enzyme activity of cell culture samples over time. Laboratory methods for the cell culture experiments in Table 3.1 are presented below and the results of these experiments are provided in sections to follow.

\subsubsection{Stock solutions}

Glucose $20 \%$ stock solution was made by dissolved $50 \mathrm{~g}$ of glucose powder (AMRESCO ${ }^{\circledR}$ - Biotechnology Grade) into $250 \mathrm{~mL}$ of $\mathrm{dH}_{2} \mathrm{O}$ (distilled water). Glucose was dissolved by using low heat and then stirlized by using a $250 \mathrm{~mL}$ strilized filter system (Corning Incorporated) using vacumm provided by a faucet aspirator and stored at room temperature.

Galactose $20 \%$ stock solution was made by dissolved $50 \mathrm{~g}$ of galactose $98 \%$ (Alfa Aesar) $98 \%$ powder into $250 \mathrm{~mL}$ of $\mathrm{dH}_{2} \mathrm{O}$ distilled water. Galactose was dissolved by using low heat and then stirlized by using a $250 \mathrm{~mL}$ strilized filter system using vacumm provided by a faucet aspirator and stored at room temperature.

YNB 10\% stock solution was made by mixing $25 \mathrm{~g}$ of yeast-nitrogen-base without amino acid (Bacto ${ }^{\mathrm{TM}}$, Becton Dickinson and Company) into $250 \mathrm{~mL}$ of $\mathrm{dH}_{2} \mathrm{O}$. The solution was 
mixed well if necessary by use of low heat for a few minutes and then sterilized by using a $250 \mathrm{~mL}$ sterilized filter system and stored at room temperature.

Citrate buffer (1 M, pH 4.5 (100 mL solution) was created by following these steps; a. dissolve $21 \mathrm{~g}$ citric acid monohydrate (Mallinckrodt CHEMICALS) in $75 \mathrm{~mL}$ distilled water and add $10 \mathrm{~N}$ of $\mathrm{NaOH}$ (VWR) until the $\mathrm{pH}$ is 4.3. Dilute to $100 \mathrm{~mL}$ and check $\mathrm{pH}$. If necessary further $\mathrm{NaOH}$ can be added until $\mathrm{pH}$ is 4.5. This stock solution was stored in the laboratory refrigerator. This solution is $1 \mathrm{M}$ citrate buffer, $\mathrm{pH}$ 4.5: when diluted to $0.05 \mathrm{M}$, the $\mathrm{pH}$ should be 4.8 .

CMC substrate ( $2 \% \mathrm{CMC}$ ) was made by dissolving $2 \mathrm{~g}$ of carboxymethyl celluose (TCIAMERICA) into $100 \mathrm{~mL}$ of distilled water. This stock solution was stored in the laboratory refrigerator.

DNS Reagent (1 Liter solution) was made by mixing all these ingredients; $10 \mathrm{~g} 3,5-$ dinitrosalicyclic acid (SIGMA), a $2 \mathrm{~g}$ phenol (Aldrich Chemical Company, Inc.), a $0.5 \mathrm{~g}$ sodium sulfite (minimum 98\%, SIGMA), and a 200 g Rochelle salt (Potassium Sodium Tartrate, Tetrahydrate-VWR). All are dissolved in 0.5 liters of $2 \%(\mathrm{w} / \mathrm{v}) \mathrm{NaOH}$ solution and then diluted to 1 liter with distilled water. This stock solution was stored in the laboratory refrigerator.

Tris-glycine electrophoresis 5x stock buffer (Sambrook and Reussell 2001) was made by mixing $15.1 \mathrm{~g}$ tris (Base) (J.T.Baker), $94 \mathrm{~g}$ glycine (BDH $\left.{ }^{\circledR}-\mathrm{VWR}\right), 50 \mathrm{~mL}$ of $10 \%(\mathrm{w} / \mathrm{v})$

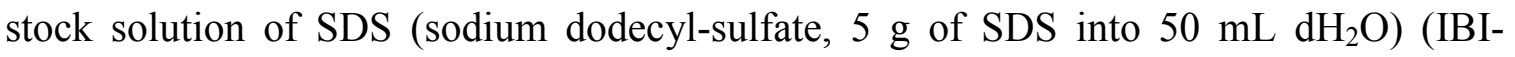
SCIENTIFC), and balance distilled $\mathrm{H}_{2} \mathrm{O}$ (up to $1 \mathrm{~L}$ ) in a volumetric flask by doing the following steps. Prepare solution in a $1 \mathrm{~L}$ volumetric flask (KIMAX). Pour approximately $750 \mathrm{~mL}$ of distilled $\mathrm{H}_{2} \mathrm{O}$ into flask. Add $15.1 \mathrm{~g}$ tris and $94 \mathrm{~g}$ of glycine to flask. Use a funnel to transfer powders and rinse with distilled $\mathrm{H}_{2} \mathrm{O}$ upon completion. Add SDS stock solution to volumetric flask. Add distilled $\mathrm{H}_{2} \mathrm{O}$ to solution until a total volume of $1 \mathrm{~L}$ is achieved.

Fixing buffer was prepared by mixing 30\% pure ethanol, $10 \%$ pure acetic acid solution (i.e., 6:3:1 water:ethanol:acetic acid). Sensitizer working solution was prepared by mixing 1 part Silver Stain Sensitizer with 500 parts ultrapure water (e.g., mix $50 \mu \mathrm{L}$ of 
Sensitizer with $25 \mathrm{~mL}$ water). Stain working solution was prepared by mixing 1 part Stain Enhancer with 50 parts Silver Stain (e.g., mix $0.5 \mathrm{~mL}$ of Enhancer with $25 \mathrm{~mL}$ Stain). Developer working solution was prepared by mixing 1 part Silver Stain Enhancer with 50 parts Silver Developer (e.g., mix $0.5 \mathrm{~mL}$ of Enhancer with $25 \mathrm{~mL}$ of Developer). This Silver Stain Kit was produced by (Thermo Scientific). 
Table 3-1 Experiments Conducted in Small-Scale Culture of $K$. lactis Cel7B

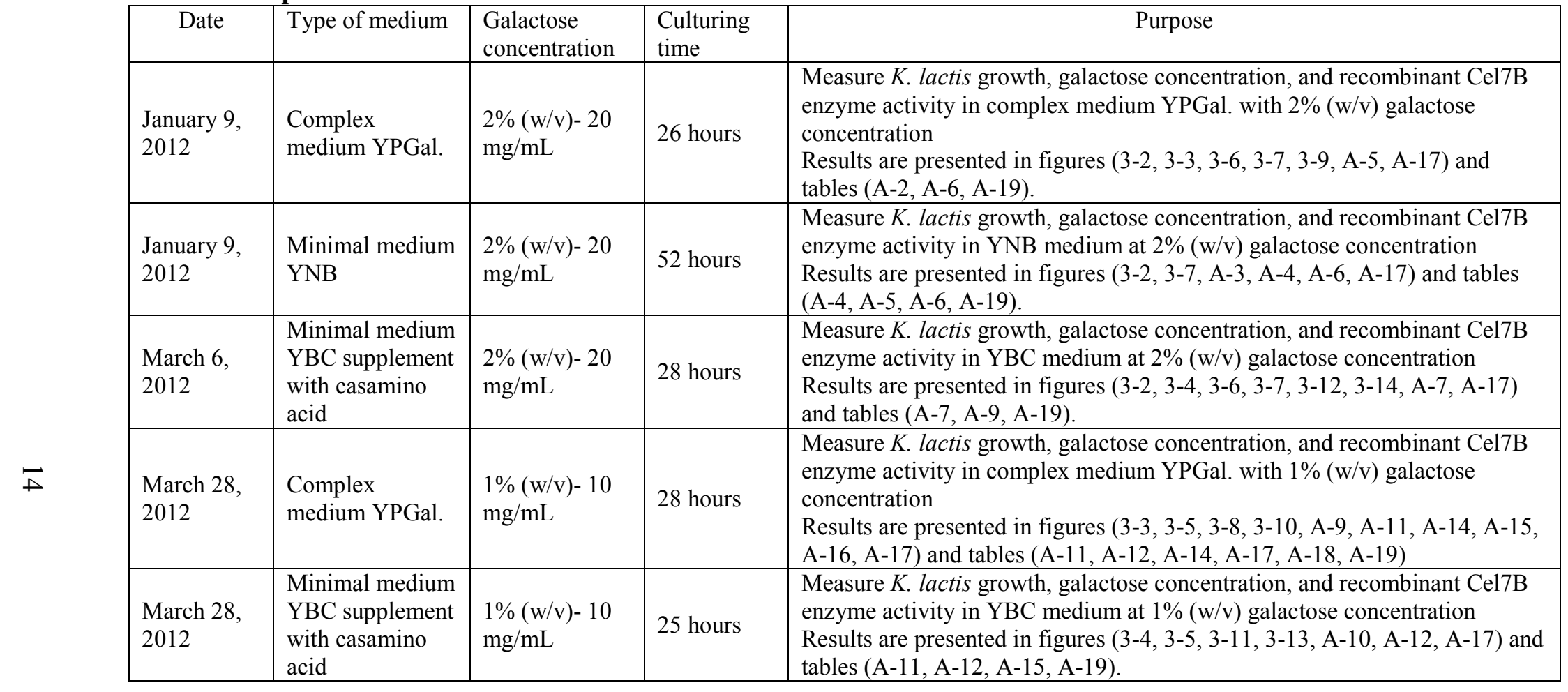




\subsubsection{Types of agar and culture media}

\subsubsection{Agar plate culture media and conditions}

There were two types of agar media: YPD and YBC The agar media were made using $200 \mathrm{~mL}$ of the YPD liquid-medium solution (described next) in a $500 \mathrm{~mL}$ glass bottle (VWR), which contained $200 \mathrm{~mL}$ of distilled water, $2.0 \mathrm{~g}$ of yeast extract (Bacto ${ }^{\mathrm{TM}}$, Becton Dickinson and Company), $4 \mathrm{~g}$ of peptone (Bacto ${ }^{\mathrm{TM}}$, Becton Dickinson and Company), $4 \mathrm{~g}$ of glucose (AMRESCO- Biotechnology Grade), and $2.0 \mathrm{~g}$ of agar (Bacto TM, Becton Dickinson and Company). The $200 \mathrm{~mL}$ of YNB-casamino acid liquid-medium solution was made in a $500 \mathrm{~mL}$ glass bottle (VWR) which contained $180 \mathrm{~mL}$ of $\mathrm{dH}_{2} \mathrm{O}$, $1.0 \mathrm{~g}$ of casamino acid (Bacto ${ }^{\mathrm{TM}}$, Becton Dickinson and Company), $4 \mathrm{~g}$ of glucose, and $2.0 \mathrm{~g}$ of agar for making medium-agar plates, which was autoclaved for 15 minutes at $121^{\circ} \mathrm{C}$ and finally $20 \mathrm{~mL}$ of YNB $10 \%$ stock solution was added.

Plates streaked by a small volume-Kluyveromyces lactis-strain 7B-, which was previously frozen at $-80^{\circ} \mathrm{C}$ and was saved into glycerol stock solution YPD, was for isolation used (i.e., pure culture techniques). A small amount of $K$. lactis was spread on agar-medium plate and grown at room temperature inside laminar flow hood. After that, a small colony from previous plate was streaked onto a new agar-plate by a sterilized plastic loop (Becton Dickinson and Company) or a metal loop sterilized by using ethanol (PHARMCO-AAPER) and ethanol-flame to get rid of the excess ethanol. In a few days the cells were clustered into many colonies on the whole plate surface.

\subsubsection{Minimal media}

YNB liquid-media solution was made in a $300 \mathrm{~mL}$ side-arm flask $\left(\right.$ BELLCO $\left.^{\circledR}\right)$ which contained $40 \mathrm{~mL}$ of $\mathrm{dH}_{2} \mathrm{O}$ which was autoclaved and finally add $5 \mathrm{~mL}$ of galactose $20 \%$ stock solution for $2 \%$ galactose concentration, and $5 \mathrm{~mL}$ of YNB (10\%) stock solution.

YBC (YNB supplemented with casamino acid) liquid media solution was made in a 300 $\mathrm{mL}$ side-arm flask (BELLCO ${ }^{\circledR}$ ) which contained $40 \mathrm{~mL}$ of $\mathrm{dH}_{2} \mathrm{O}$ and $0.25 \mathrm{~g}$ of casamino acid. This solution was autoclaved and finally to it was add $5 \mathrm{~mL}$ of galactose $(20 \%)$ 
stock solution for making a final $2 \%$ galactose concentration and $5 \mathrm{~mL}$ of YNB $(10 \%)$ stock solution.

\subsubsection{Complex media}

YPGal media solution was made in $300 \mathrm{~mL}$ side-arm flask which contained $45 \mathrm{~mL}$ of $\mathrm{dH}_{2} \mathrm{O}, 0.5 \mathrm{~g}$ of yeast extract and $1 \mathrm{~g}$ of peptone which was autoclaved. Then $5 \mathrm{~mL}$ of galactose $(20 \%)$ stock solution was add for making a $2 \%$ galactose concentration was add.

\subsubsection{Cell culture conditions}

Small-scale cell culture was started by picking a single colony using a sterile inoculating loop (Becton, Dickinson and Company) from an agar-plate (Fisher Scientific Co.) and incubated in 2-3 mL of YPD liquid medium in a $14 \mathrm{~mL}$ polypropylene round-bottom tube (Becton Dickinson and Company) or $5 \mathrm{~mL}$ culture tube with closure (VWR). Then the 14 $\mathrm{mL}$ bottle or $5 \mathrm{~mL}$ culture tube was placed into the shaker table (incubator) at $30^{\circ} \mathrm{C}$ and $250 \mathrm{rpm}$ for overnight growth (or until the cells density reached to 1.0 O.D. @ $600 \mathrm{~nm}$ ). Afterwards, $1 \mathrm{~mL}$ of liquid inoculum culture was mixed with the $50 \mathrm{~mL}$ of sterilized growth medium in a sterilized $300 \mathrm{~mL}$ side-arm flask $\left(B E L L C{ }^{\circledR}\right)$. Inocula should be clean of contamination which would appear under microscope (400x) as small bodies moving among stationary $K$. lactis cells (large bodies). The purity of inoculums and media was check by using a microscope (OLYMPUS BX40 Research Microscopy) at 100x and 400x magnification. The inoculum should have a high density of growth between 0.5-1.0 O.D. (measured using a spectrometer at $600 \mathrm{~nm}$ ) to start flask culture. This high density of the inoculums will help assure that $K$. lactis Cel7B is the dominant cell if any contamination should appear.

In this research, the flask culture was run for between 24-52 hours. During this time, 2 $\mathrm{mL}$ samples were taken every 2 hours starting at time $=0 \mathrm{hr}$ in most experiments except for overnight periods, when sampling was not normally done. By taking $2 \mathrm{~mL}$ from the culturing medium for 10 times for total volume of $20 \mathrm{~mL}$ off $50 \mathrm{~mL}$ lead to increase the head volume on the side-arm flask, however that will not affect the culturing results in a 
$300 \mathrm{~mL}$ flask. These samples were filtered by using $3 \mathrm{~mL}$ syringe $\left(\right.$ monoJECT $^{\mathrm{TM}}$ ) attached to $0.2 \mu$ filter $(0.2 \mu$ paper filter-Whatman or $0.2 \mu$ filter system-VWR) and then transferred into $2 \mathrm{~mL}$ disposable conical sterilized tubes with caps (Freestanding Micro Tube with Cap and Graduations) (VWR). These samples were processed through the procedures described in section 3.3.6 (Small Scale Fermentation of Recombinant K. lactis yeast JSA). The diagram below, Figure 3-1, shows the main steps of analyzing recombinant protein samples by using CMC/DNS assay. 


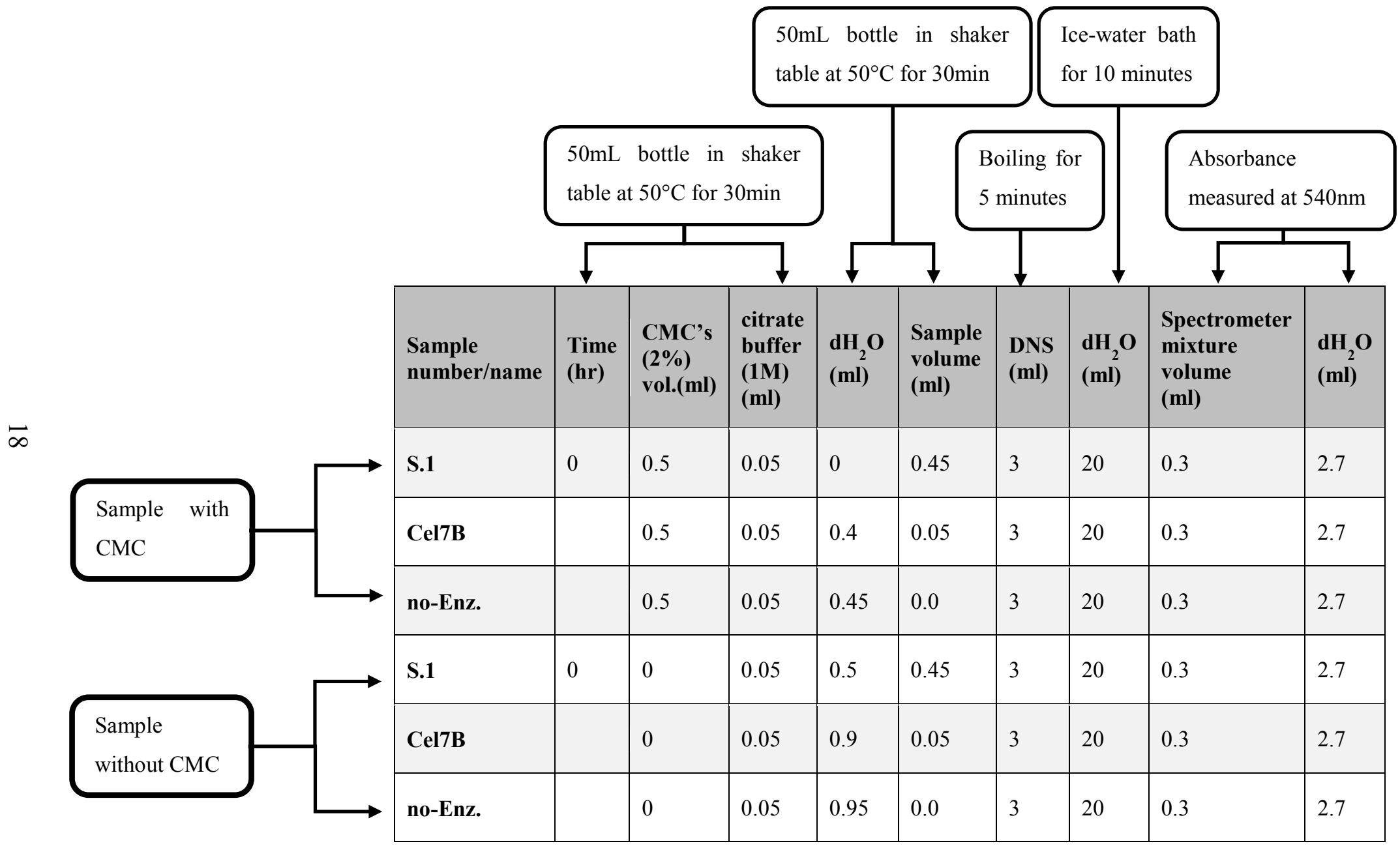

Figure 3-1 The main steps of analyzing recombinant protein samples by using the CMC/DNS assay 


\subsubsection{DNS assay for galactose and Cel7B activity}

The 3,5-dinitrosalicylic acid (DNS) assay reacts with reducing sugars or other reducing compounds to form 3-amino-5-nitrosalicylic acid, which absorbs light at $540 \mathrm{~nm}$. This assay was used in this research project to detect changes in galactose concentration during cell culture and also to detect activity of recombinant Cel7B acting on the substrate CMC. Into a $50 \mathrm{~mL}$ bottle (plastic centrifuge closed capped bottle, VWR) 0.5 $\mathrm{mL}$ of distilled water and $0.05 \mathrm{~mL}$ of citrate buffer ( $1 \mathrm{M}$ in distilled water, $\mathrm{pH}=4.8)$ were added and then the bottle was placed into a shaker table (a Lab-Line ${ }^{\circledR}$ Orbit Environshaker (model $3528-5$ ) at $50^{\circ} \mathrm{C}$ for half an hour with shaking at 250 RPM (BrodeurCampbel 2012).

After wards, the bottle was taken out of the shaker table and to the bottle was added 0.45 $\mathrm{mL}$ of the filtered sample; the sample being either a galactose standard solution or flask cell culture solution containing galactose. The bottle was replaced for another half an hour into the shaker table at the same conditions. The bottle was then taken off the shaker table and $3 \mathrm{~mL}$ of DNS solution was added (Brodeur-Campbel 2012).

The bottle was then immersed in boiling water on a stirred hot plate for 5 minutes. The bottle was then placed immediately into an ice-water bath for 10 minutes. After the bottles cooled to room temperature, $20 \mathrm{~mL}$ of distilled water was added and shaken to mix well. Finally, $4 \mathrm{~mL}$ of this solution was added to a spectrophotometer tube (Fisher Scientific Co.) and absorbance was measured by using a Milton Roy Spectrophotometer (model Spectronic 21D UV) at $540 \mathrm{~nm}$, twice to replicate (Brodeur-Campbel 2012). This DNS procedure was slightly modified to measure Cel7B enzyme activity in the presence of CMC added to flask culture samples. Into a $50 \mathrm{~mL}$ bottle, $0.5 \mathrm{~mL}$ of CMC solution $(2 \% \mathrm{w} / \mathrm{v}$ in distilled water) and $0.05 \mathrm{~mL}$ of citrate buffer $(1 \mathrm{M}$ in distilled water, $\mathrm{pH}=4.8$ ) were added and then the bottle was placed into a shaker table (a Lab-Line ${ }^{\circledR}$ Orbit Environ-shaker (model $3528-5$ )) at $50^{\circ} \mathrm{C}$ for half an hour with shaking at $250 \mathrm{RPM}$. CMC substrate. After half an hour, the bottle was taken out of the shaker table and to the bottle was added $0.45 \mathrm{~mL}$ of the sample flask culture solution containing galactose and 
recombinant Cel7B. The diagram below, Figure 3-2, shows the growth conditions and environments of producing recombinant Cel7B protein.

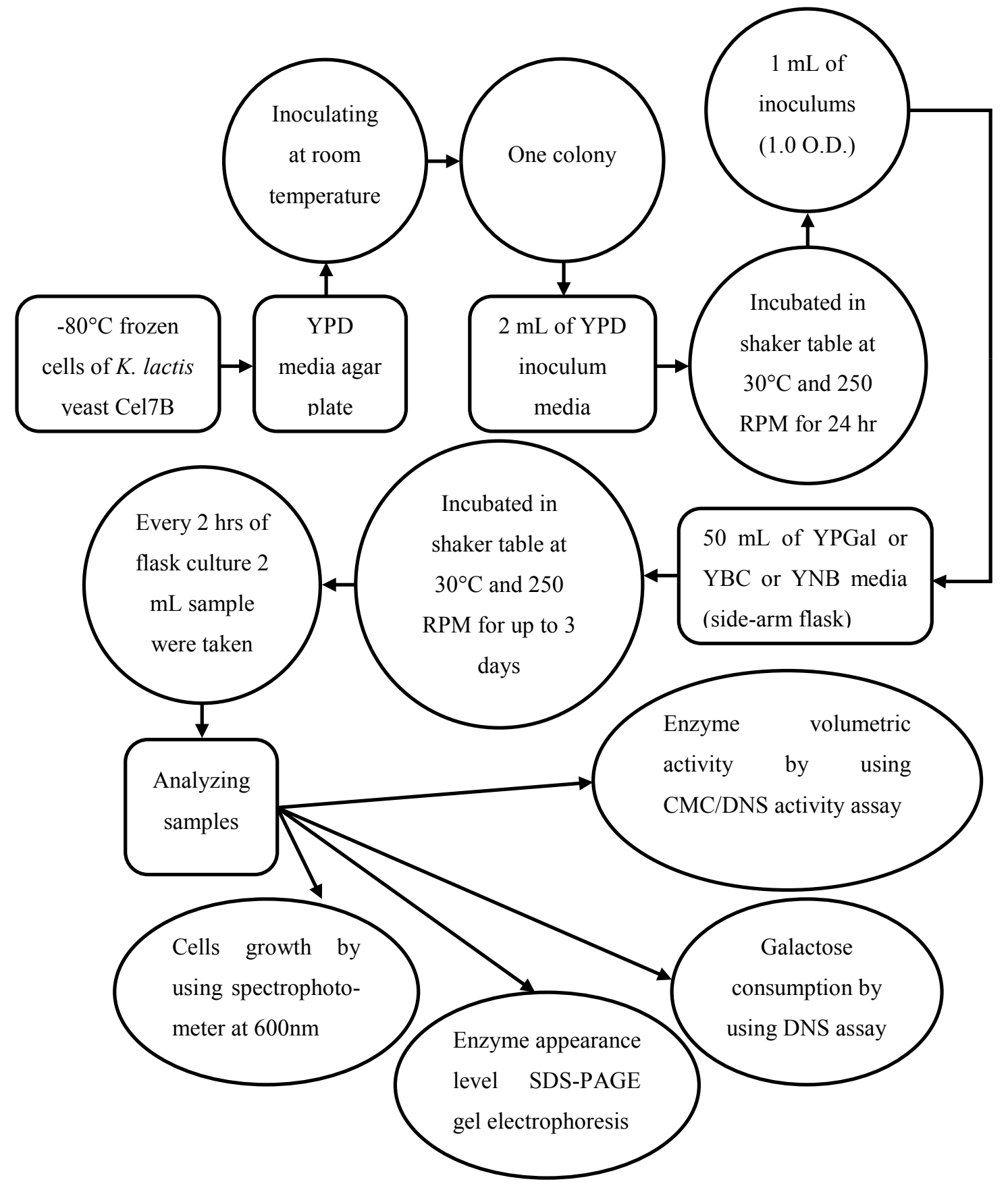

Figure 3-2 The growth conditions and environments of producing recombinant Cel7B protein 


\subsubsection{Galactose standard curve}

The purpose of using this method is to measure responses of known concentrations of galactose to the DNS assay. Standard curves were generated for each experiment in order to determine concentration of galactose versus time during flask culture. The standard curves were also used to evaluate activity of recombinant Cel7B when CMC is the hydrolysis substrate in units of $\mathrm{mg}$ galactose equivalents produced $/ \mathrm{ml} / \mathrm{hr}$. Galactose standard curves were made by using $20 \mathrm{mg} / \mathrm{mL}$ ( $2 \%$ galactose in distilled water) stock solution, which had been diluted by using distilled water to get concentrations which ranged from $0 \mathrm{mg} / \mathrm{mL}$ to $20 \mathrm{mg} / \mathrm{mL}$ of galactose. These standard galactose samples were applied to the DNS assay as described in section 3.3.6. Measured absorbance was paired with known galactose concentrations to create standard curves for each experiment.

Samples from flask culture were analyzed by both using the slope of the trend line equation and $\mathrm{CMC} / \mathrm{DNS}$ absorbance results. The equation of the galactose standard curve leads to finding the value of the galactose equivalent concentrations in all samples in $\mathrm{mg} / \mathrm{mL}$ and enzyme activity in $\mathrm{mg} / \mathrm{mL}^{*} \mathrm{~h}$. Net enzyme activity was determined by taking the difference between the DNS assay response with (sample) and without (control) CMC added to each sample (Brodeur-Campbel 2012).

\subsubsection{Gel electrophoresis method}

The purpose of using this method is to show the presence and molecular weight of the recombinant endoglucanase (Cel7B) in each flask culture sample.

Briefly, the procedure for gel electrophoresis will be presented here, but a complete Job In this research, this electrophoresis method started with prepared gels (Polyacrylamide Gel for Protein Electrophoresis-7.5\% Tris-Glycine Gels, PAGEr ${ }^{\circledR}$ Gold Precast Gels) (Lonza). Then gel was loading into the gel electrophoresis instrument (Power Source 250 V by VWR) and covering with the electrophoresis buffer (Tris-Glycine 5x stock solution) (Brodeur-Campbel 2012).

After that, samples were prepared to load into the gel electrophoresis instrument. Samples mixture solution was made into $0.2 \mathrm{~mL}$ Disposable PCR Tube with Attached Dome Caps 
(VWR), combine equal volumes, $10 \mu \mathrm{L}$ of protein loading dye $\left(\mathrm{AMRESCO}^{\circledR}\right)$ and either the molecular weight marker (ROCKLAND) or recombinant enzyme Cel7B or recombinant enzyme samples of different fermentation media.

Recombinant enzyme samples were concentrated $30-40 \mathrm{x}$ for the complex media protein samples and 30-150 x for the minimum media protein samples. In these experiments, samples for concentration started by using total volume of $1500 \mu \mathrm{L}$ of original protein sample and then it was centrifuged by using a special tube for filtration and ultra filtration (Sartorius Stedim Biotech) for total 1 hour at $12000 \mathrm{rpm}$.

After that, all samples were boiled in a $100^{\circ} \mathrm{C}$ water bath for 3-5 minutes to denature the proteins. After samples boiled, samples had been centrifuged by using a micro-centrifuge (Galaxy 16 Micro-Centrifuge by VWR) for 20 seconds at 12,000 rpm to get the liquid to bottom of tube. Finally, $15 \mu \mathrm{L}$ of the gel mixture samples were load by using (1-200 $\mu \mathrm{L}$ Long Reach Tip by VWR) into the gel electrophoresis lanes.

Silver stain kit: the power supply was turned on at $80 \mathrm{~V}$ for 30 minutes, $0.10 \mathrm{~A}(\mathrm{amp})$ and $20 \mathrm{~W}$ (watt). After 30 minutes, the power supply was turned on at $120 \mathrm{~V}$ for up to 2 hours or until the protein bands reached to bottom of the gel, $0.10 \mathrm{~A}$ (amp) and $20 \mathrm{~W}$ (watt). After 2 hours, the gel electrophoresis was finished and it was ready to wash into ultrapure water two times for 5 minutes. After first washing step, gel was soaking tow times into protein fixing stock solution (30\% ethanol and 10\% acetic acid solution) for 15 minutes. Then, gel was washing two times for 5 minutes by using $10 \%$ ethanol solution, followed by two times, ultrapure water washing for 5 minutes. After the second washing step, gel was sensitizing for 1 minute by Sensitizer Working Solution $(50 \mu \mathrm{L}$ Sensitizer with 25 $\mathrm{mL}$ ultrapure water). Then, gel was washing two times by ultrapure water for 1 minute. After third washing step, gel was staining for 30 minutes by using Stain Working Solution ( $0.5 \mathrm{~mL}$ Enhancer with $25 \mathrm{~mL}$ Stain). After 30 minutes of staining, gel was washing two times for 20 seconds with ultrapure water. After last washing step, gel was developed with Developer Working Solution (0.5 mL Enhancer with $25 \mathrm{~mL}$ Developer) for 2-3 minutes until bands appear. Last but not least, the reaction was stopped by using $5 \%$ acetic acid solution for 10 minutes. Finally, gel was removed out of acetic acid 
solution and a photo was taken by using a digital camera to present the final results of recombinant enzyme locations on the gel. All previous steps of the silver staining were done into shaker table at low shaking level without heat (Thermo SCINTIFIC).

\subsection{Results and Discussions}

\subsubsection{Result of the galactose calibration standard}

Figure 3-1 shows the calibration graph used for the flask culture experiment conducted on June 13, 2012. A galactose calibration standard was run for every new experiment and these calibration standard graphs are in Appendix A for all small-scale culture experiments and in Appendix B for all large-scale culture experiments. In addition to all standard curves for galactose, all measurements for each experiment were tabulated and appear in Appendix A for flask-scale culture and Appendix B for large-scale culture trials (see Table 3-1).

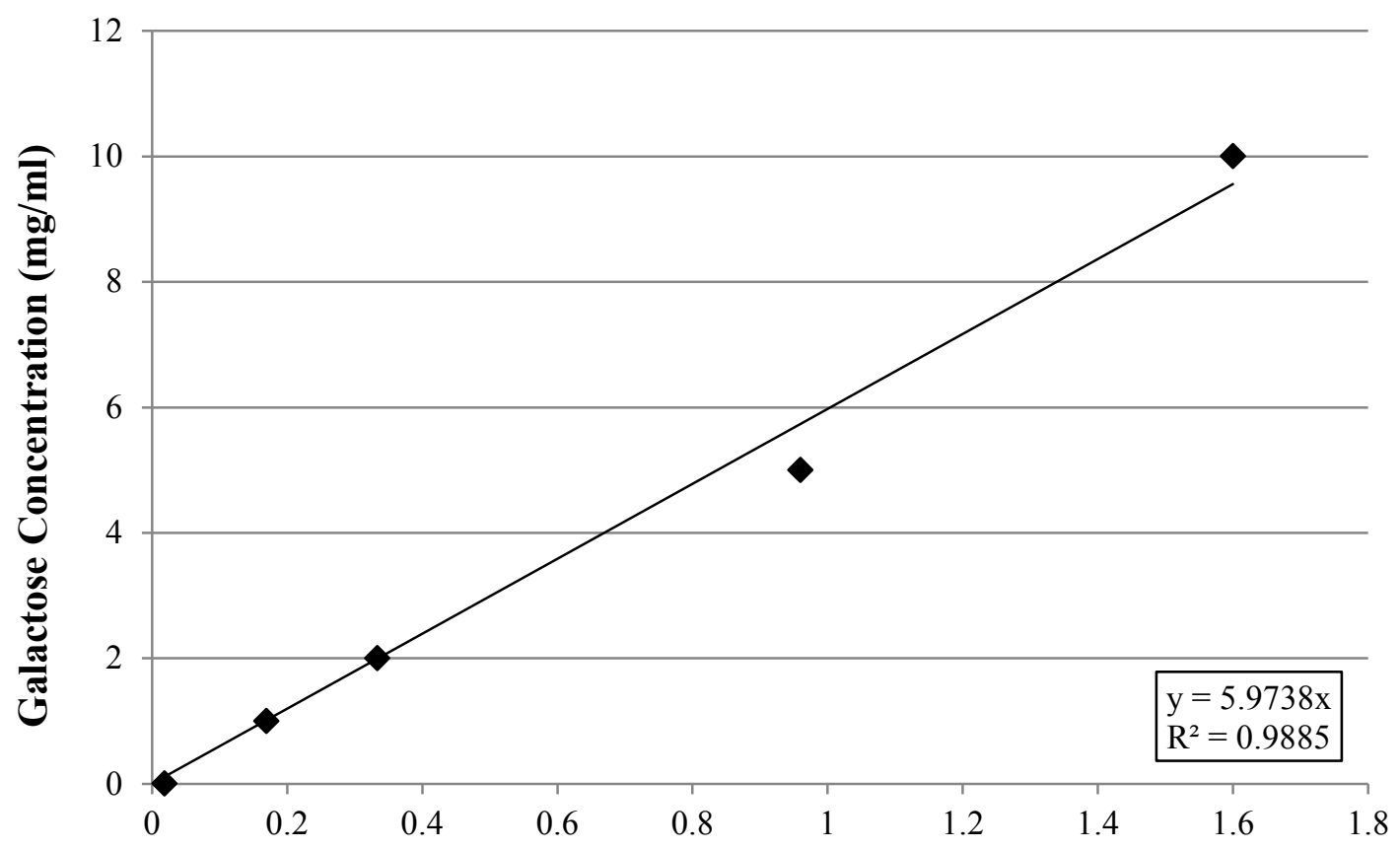

Absorbance 540nm (O.D)

Figure 3-3 Galactose calibration standard using the DNS assay, June 13, 2012 


\subsubsection{Effect of media on $K$. lactis-Cel7B growth density at $2 \%$ of galactose}

Figure 3-4 shows effects of using complex and minimal media on $K$. lactis growth density at $2 \%$ of galactose. $K$. lactis-Cel7B growth density at $2 \%$ galactose shows three different stages. Yeast growth density in YPGal started with slow increase, then increased rapidly between 4-26 hours during the exponential phase of cells culture, and continued increasing slowly to reach density of 1.74 O.D at 46 hours during the stationary phase. $K$. lactis-Cel7B growth density in YNB without casamino acid started almost stable without increasing, then increased fast during between 4-28 hours the exponential phase of fermentation time, and finally continued increasing slowly after 28 hours during the stationary phase. The density of cells growth reached to 1.38 O.D at 46 hours during the stationary phase. K. lactis-Cel7B growth density in YNB with casamino acid was started with slow increase, then was rapidly increasing between 4-24 hours during the exponential phase of cell culturing, and finally was slowly increasing to reach density of 1.7 O.D at 52 hours during the stationary phase. Growth rate of $K$. lactis-Cel7B was positively affected by using YPGal complex media and YNB minimal medium with casamino acid because these media have amino acid components (peptone and casamino acid) that provide a good environment to culture $K$. lactis-Cel7B yeast, this component is missing in the YNB minimal medium without casamino acid. 


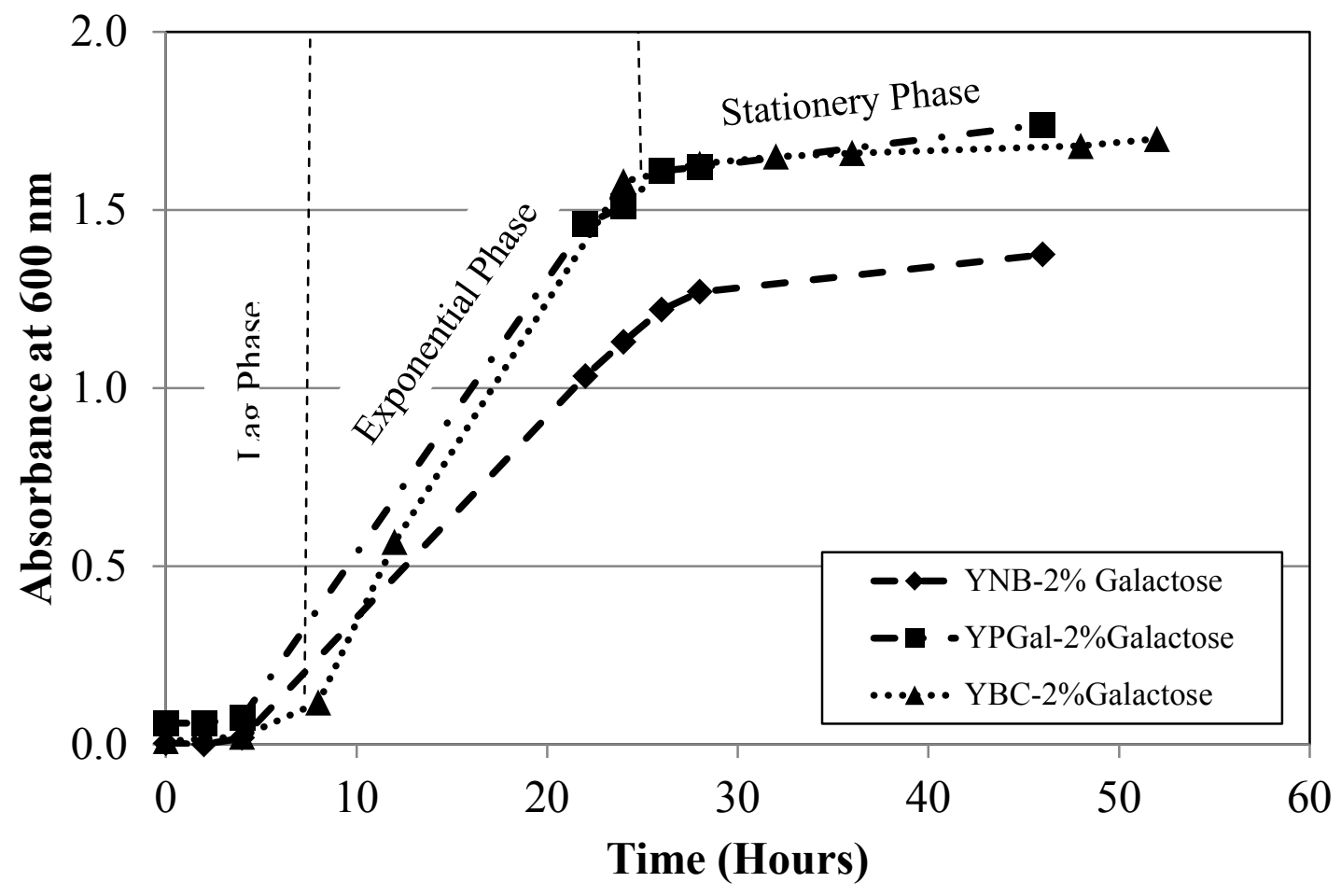

Figure 3-4 Growth density of $K$. lactis-Cel7B yeast on three different media in flask culture: YPGal, YNB, and YBC with concentration of galactose $(2 \%)$

\subsubsection{Effect of initial galactose concentration on growth density of $K$. lactis-Cel7B in different media}

Figure 3-5 shows effects of initial galactose concentration on growth density of K. lactisCel7B in complex medium YPGal. There was a difference between the growth density of $K$. lactis-Cel7B yeast with $1 \%$ and $2 \%$ initial concentrations of galactose in the rich medium YPGal. The growth density of $K$. lactis-Cel7B in YPGal with concentration 2\% of galactose started increasing rapidly after 4 hours during the exponential phase of cells culture time and then started increasing slowly again after 26 hours during the stationary phase to reached density of 1.74 O.D. It took 13 hours during the exponential phase to increased fast with initial concentration 1\% of galactose, and again after 28 hours during the stationary phase of cells culture was slowly increasing to reach a density of 1.64 O.D. 
Growth optical density of $K$. lactis-Cel7B increased with increasing initial concentration of galactose. Also, there was a reduced "lag" phase with $2 \%$ initial galactose concentration compared to $1 \%$.

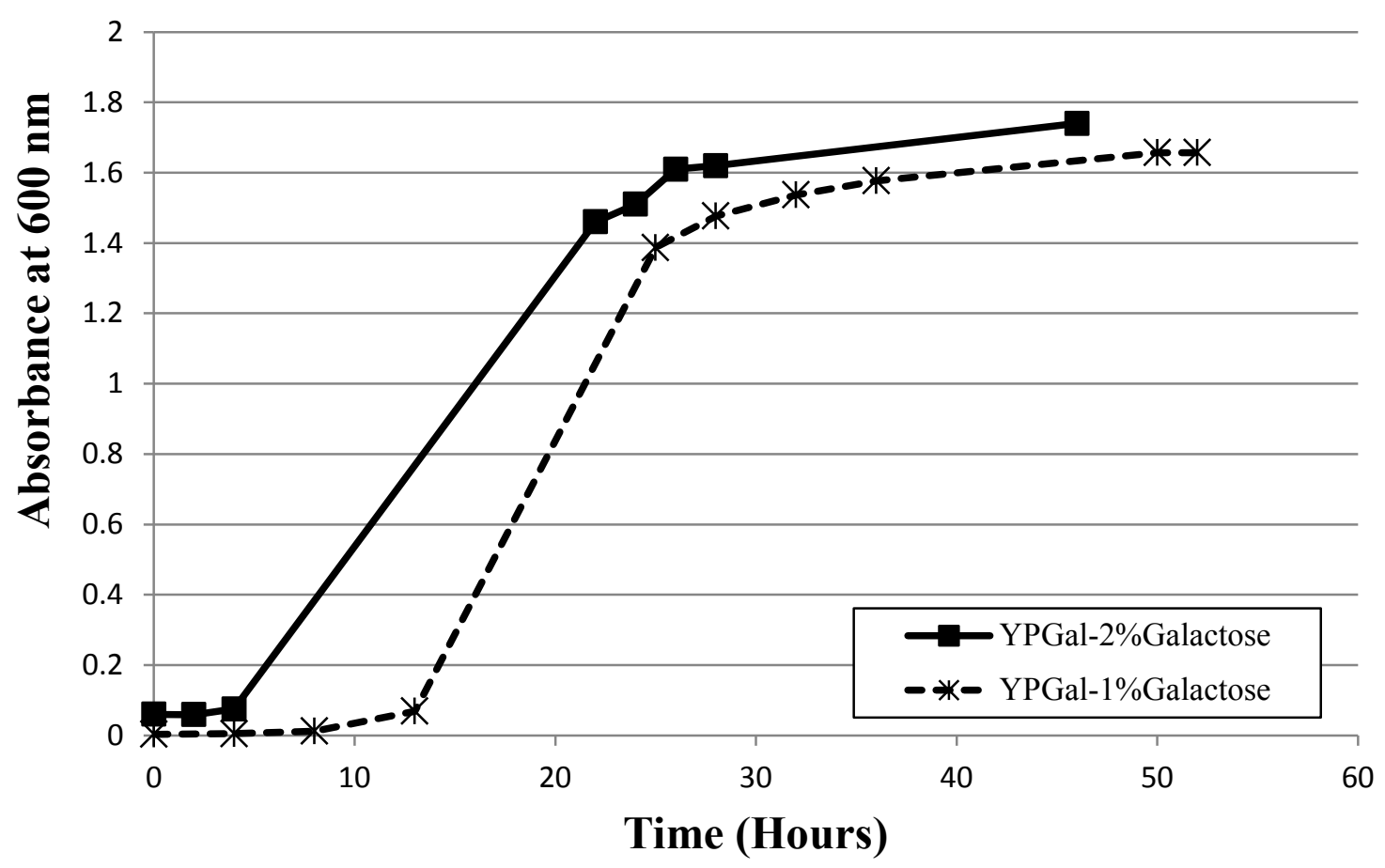

Figure 3-5 Growth of $K$. lactis-Cel7B yeast in flask culture of YPGal media with two different concentrations of galactose $(1 \% \& 2 \%)$

Figure 3-6 shows effects of initial galactose concentration on growth density of $K$. lactisCel7B in minimal medium with casamino acid, YBC. There was a slight difference between the growth density of $\mathrm{K}$. lactis-Cel7B with $1 \%$ and $2 \%$ initial concentrations of galactose in YBC. The growth density of $K$. lactis-Cel7B in YBC with concentration 2\% of galactose started increasing rapidly after 4 hours during the exponential phase of cells culture time and then started increasing slowly again after 24 hours during the stationary phase to reached density of 1.7 O.D. While it took 8 hours during the exponential phase to begin rapid cell growth with initial concentration $1 \%$ of galactose, and again after 25 hours during the stationary phase of cells culture was slowly increasing to reach a density 
of 1.67 O.D. The initial galactose concentration in minimal medium with casamino acid affected growth density of $K$. lactis-Cel7B in positive way, while growth density of yeast increased with increasing the initial concentration of galactose.

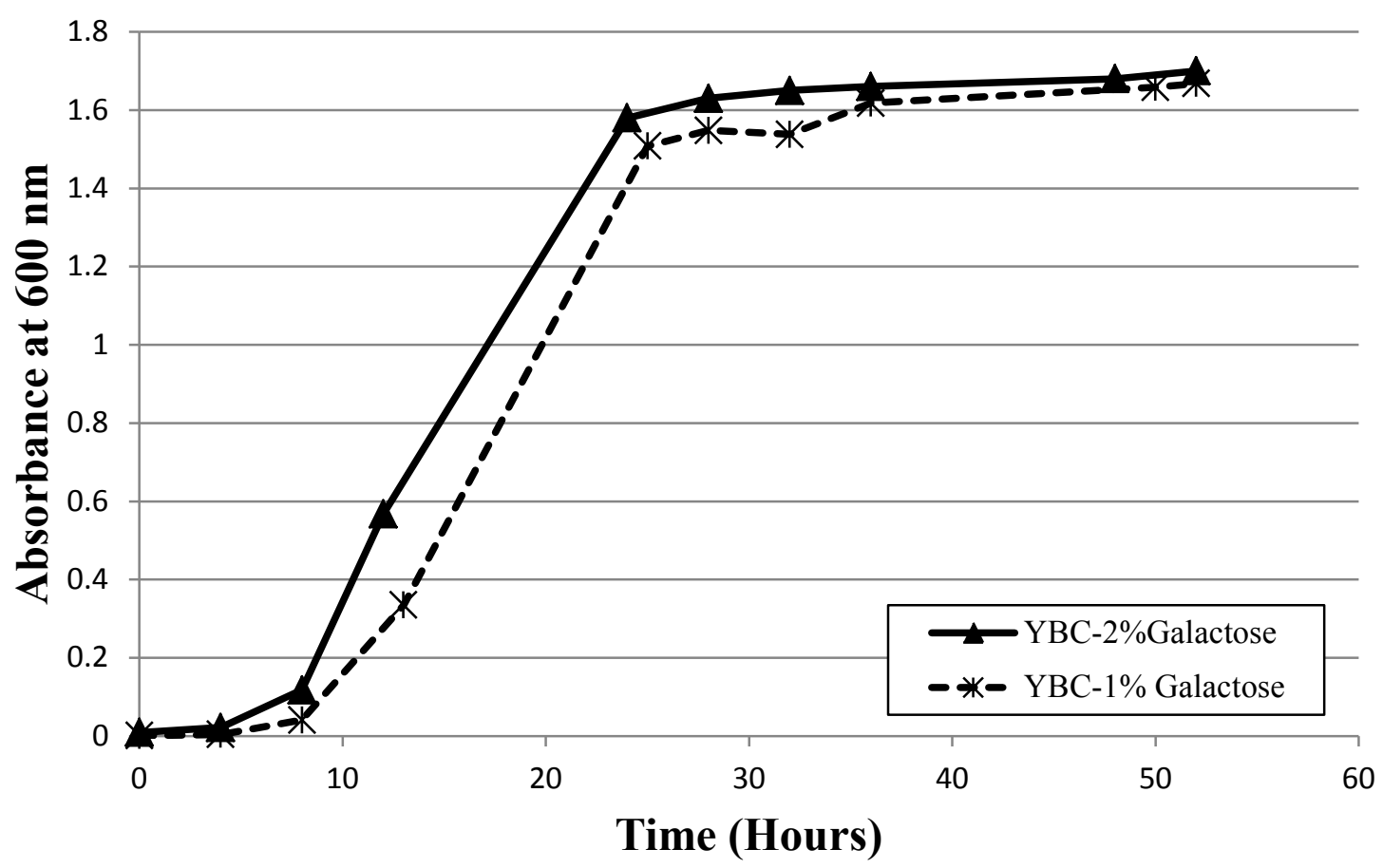

Figure 3-6 Growth density of $K$. lactis-Cel7B yeast in flask culture of YBC media with $1 \%$ and $2 \%$ initial concentration of galactose

\subsubsection{Effect of 1\% galactose concentration on growth density of $K$. lactis-Cel7B in YPGal and YBC}

Figure 3-7 shows effect of 1\% initial concentration of galactose on growth density of $K$. lactis-Cel7B in complex medium YPGal and supplemented minimal medium YBC. The growth density of $K$. lactis-Cel7B in YBC medium with $1 \%$ initial concentration of galactose started rapidly after 8 hours during the exponential phase of cells culture, and after 25 hours during the stationary phase of cells culture was slowly increasing to reach a density of 1.67 O.D. Growth density took 13 hours during the exponential phase to 
increase rapidly in YPGal, and after 28 hours during the stationary phase of cells culture was slowly increasing to reach a density of 1.67O.D. Minimal medium with casamino acid exhibited a slight increase in cells growth density of K. lactis-Cel7B compared to complex medium YPGal with $1 \%$ initial concentration of galactose.

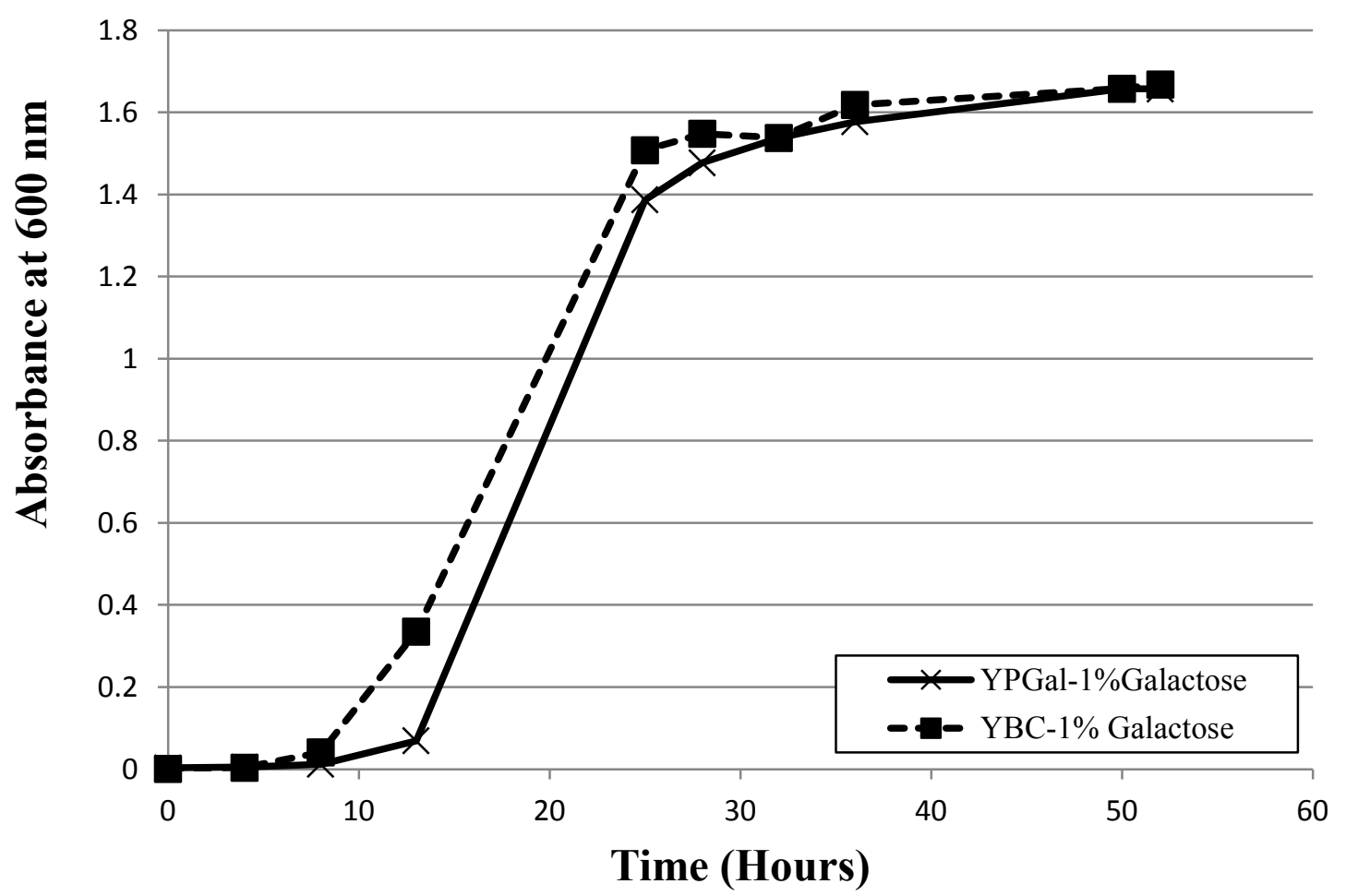

Figure 3-7 Comparison between cells growth density of $\mathrm{K}$. lactis-Cel7B yeast in different media (YPGal and YBC) with initial $1 \%$ concentration of galactose

Figure 3-8 shows effect of 2\% initial concentration of galactose on growth density of $K$. lactis-Cel7B in complex medium YPGal and supplemented minimal medium YBC. The growth density of $K$. lactis-Cel7B in YBC started increasing rapidly after 8 hours during the exponential phase of cell culture and then transitioned to increasing more slowly again after 24 hours during the stationary phase to reached density of 1.7 O.D. The growth density of $K$. lactis-Cel7B in YPGal started increasing rapidly after 4 hours during the exponential phase of cells culture time and then more slowly after 26 hours 
during the stationary phase to reached density of 1.74 O.D. Complex medium YPGal had the effect to slightly increase growth density of $K$. lactis-Cel7B more than minimal medium with casamino acid YBC with $2 \%$ initial concentration of galactose.

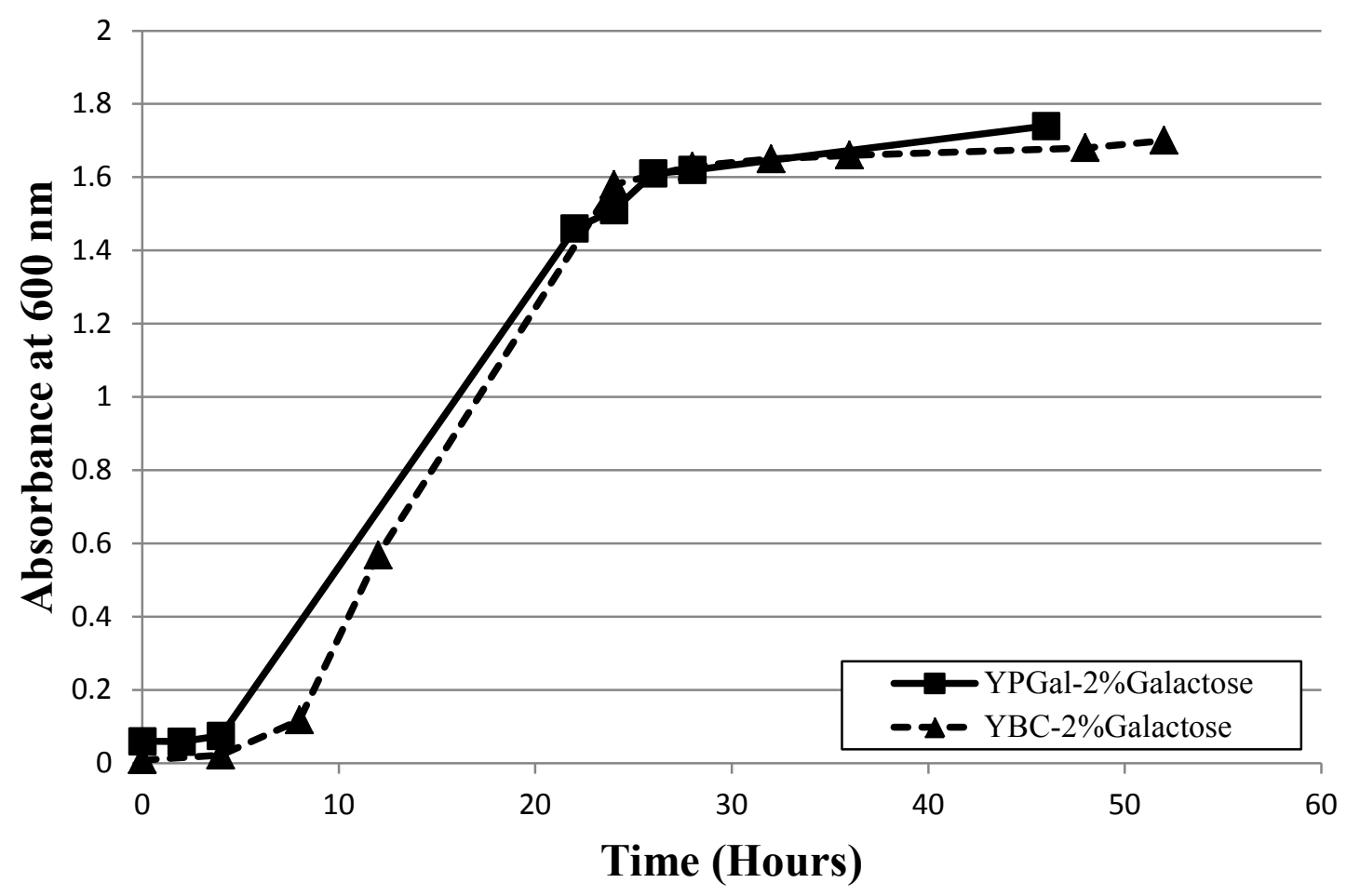

Figure 3-8 Comparison between cells growth density of $K$. lactis-Cel7B in different media (YPGal and YBC) with $2 \%$ initial concentration of galactose

\subsubsection{Effect of culture media on biosynthesis of recombinant enzyme Cel7B}

Figure 3-9 below shows effect of culture media on appearance of extracellular recombinant enzyme Cel7B. Recombinant Cel7B appeared in culture media samples for YPGal, YBC, and YNB medium. Bands for endoglucanase enzyme at 67,000 Da was stronger into YPGal medium than for the YBC medium. It shows thin bands for the YNB medium, there was a small production of Cel7B enzyme into minimum medium without casamino acid. Figure below shows time effects into recombinant enzyme production in 
YPGal, YBC and YNB media. For all media, production of enzyme was higher in the second day of culturing. All of them has a strong band into the second day lane in SDSPAGE gel than the first day lane.

Compared to molecular weight marker, most bands showed up with stronger binding at 67,000 Da while some samples gave a lighter band at 55,000 Da. The wild-type of Cel7B enzyme from $T$. reesei usually binds at 52,000 Daltons. Each band of the molecular weight marker shows different component; binds at 14, 000 Da for Cytochrome C, binds at 18,000 Da for Myoglobin, binds at 30,000 Da for Carbonic Anhydrase, binds at 45,000 Da for Ovalbumin, binds at 67,000 Da for Bovine Albumin, binds at 97,000 Da for Phosphorylase B, and binds at 120,000 Da for $\beta$ - Galactosidase.

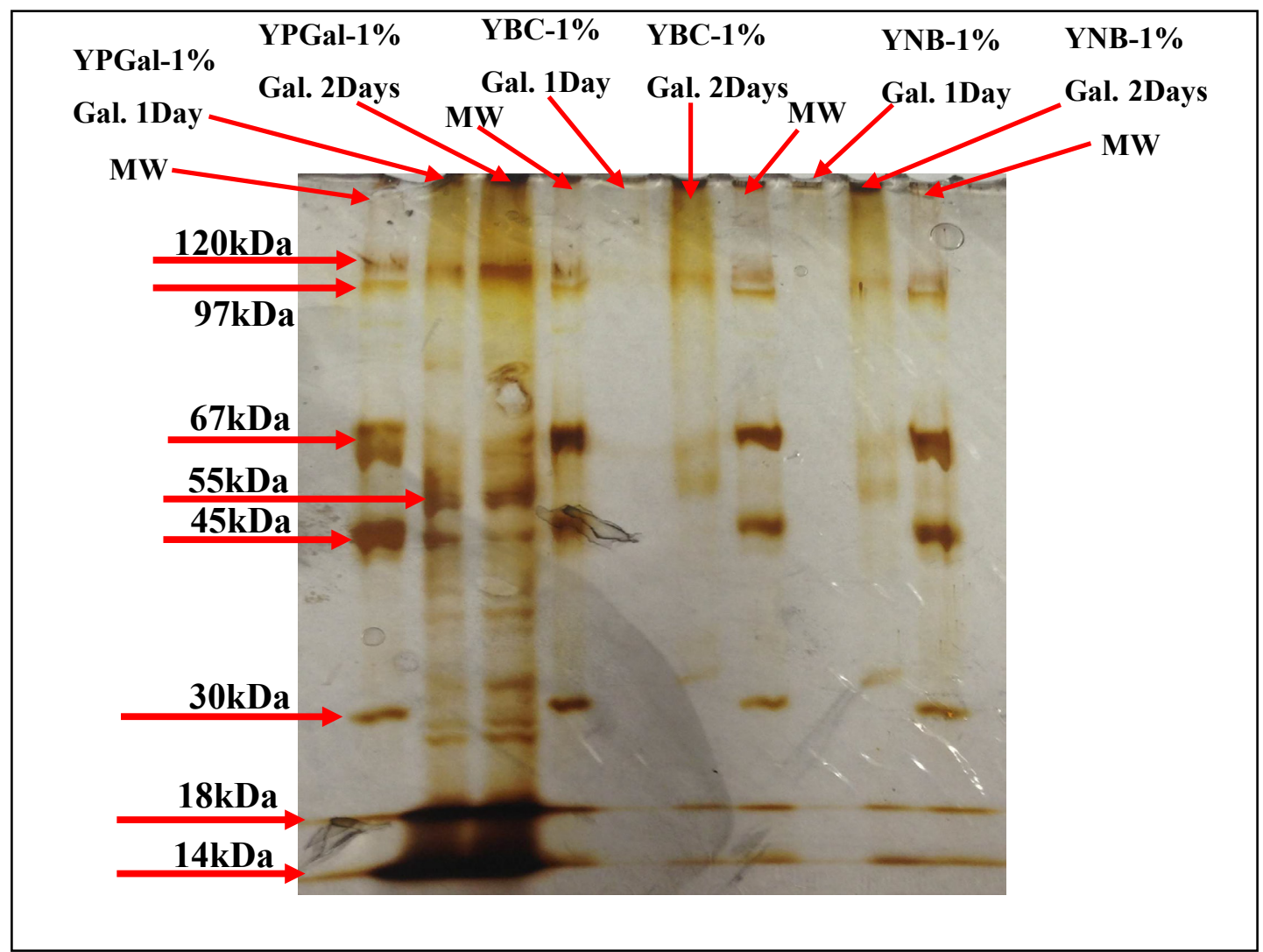

Figure 3-9 Gel electrophoresis of recombinant enzyme Cel7B produced in different media and with $1 \%$ initial galactose concentrations: complex medium YPGal and minimal medium YNB without casamino acids and with (YBC) 


\subsubsection{Effect of initial concentration of galactose on recombinant enzyme Cel7B volumetric activity during flask culture in complex medium YPGal}

Figure 3-10 below shows changes in $K$. lactis-Cel7B results during flask culture in complex medium YPGal at 1\% initial galactose concentration. There were three data sets to show the change in these results over time: cell growth density, galactose consumption, and the recombinant enzyme volumetric activity. Initial concentration of galactose was $8 \mathrm{mg} / \mathrm{mL}$ during the lag phase of cells culture, and then concentration decreased rapidly during the exponential phase of cells culture, and finally during the stationery phase galactose concentration remained at $0 \mathrm{mg} / \mathrm{mL}$.

There were two phases of recombinant enzyme volumetric activity over time. Recombinant enzyme volumetric activity was $0\left(\mathrm{mg} / \mathrm{mL}^{*} \mathrm{~h}\right)$ during the lag phase of cell culture, then it started increasing rapidly during both exponential and stationary phases of flask culture to reach $0.5\left(\mathrm{mg} / \mathrm{mL}^{*} \mathrm{~h}\right)$. Volumetric activity of recombinant Cel7B appeared to coincide with cell growth, there in this experiment activity appeared to be growth associated. Volumetric activity measures enzyme action on CMC after correcting for presence of any remaining galactose in culture medium. Also, there was some scatter on the data shown in Figure 3-10 due to random errors in the DNS assay, which may have come about from human mistakes in dispensing reagents or timing of samples processed in the DNS procedure (boiling step for example). Also, from the research conducted for this project it was observed that the freshness of the DNS reagent affects results from one experiment to another. This is the main reason for processing galactose calibration standards for each new flask culture experiment (Brodeur-Campbel 2012). 


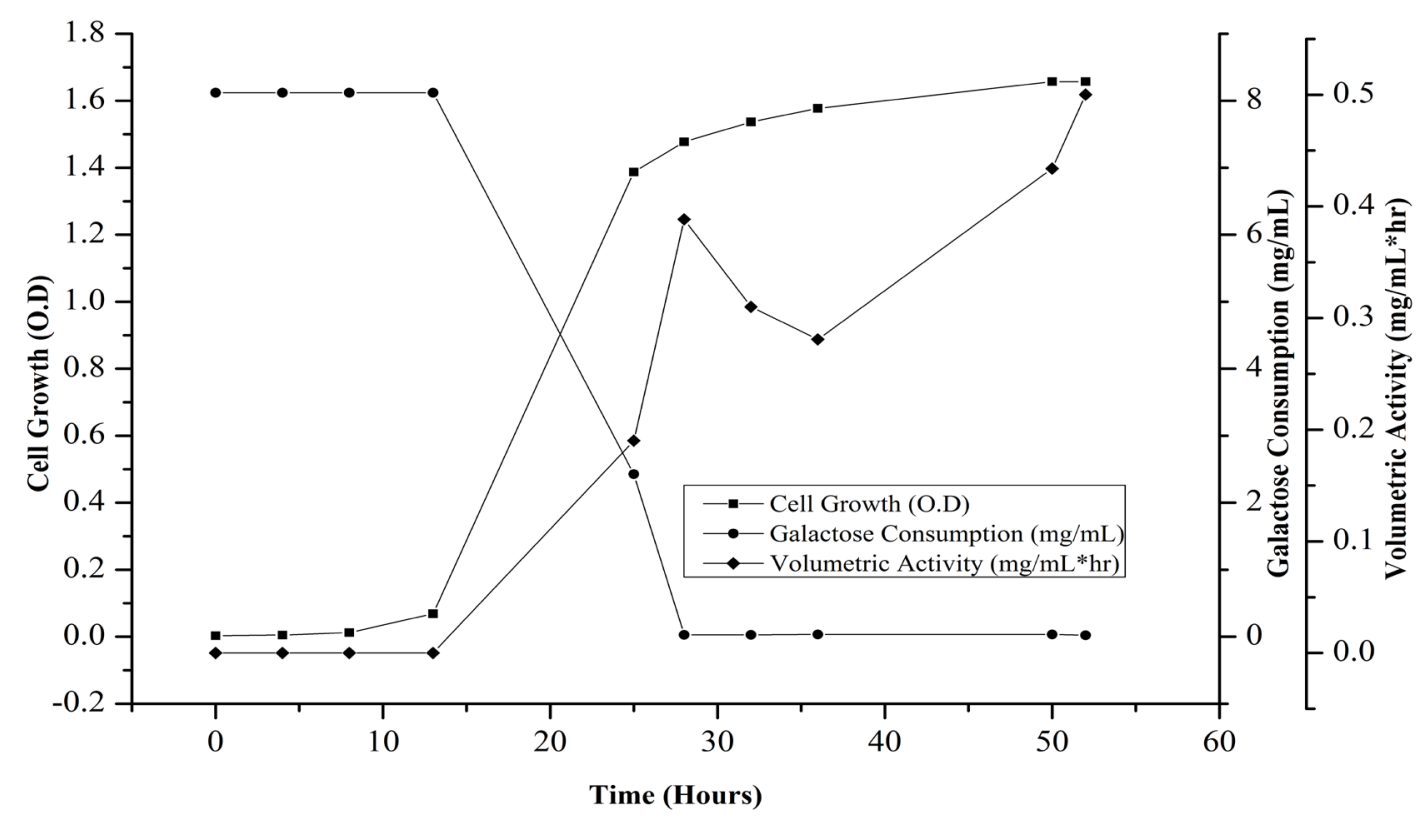

Figure 3-10 Complex medium YPGal-1\% galactose samples, cell growth, galactose consumption, and Cel7B volumetric activity, March 28, 2012

Figure 3-11 below shows change in galactose concentration during flask culture in complex media YPGal at $2 \%$ initial galactose concentration. There were three phases to the change in galactose concentration over time. Initial concentration of galactose was 12 $\mathrm{mg} / \mathrm{mL}$ during the lag phase of cell culture, and then concentration decreased rapidly during the exponential phase, and finally during the stationary phase galactose concentration remained at $1.6 \mathrm{mg} / \mathrm{mL}$. Unfortunately, volumetric enzyme activity was not measured for this experiment at $2 \%$ galactose concentration. 


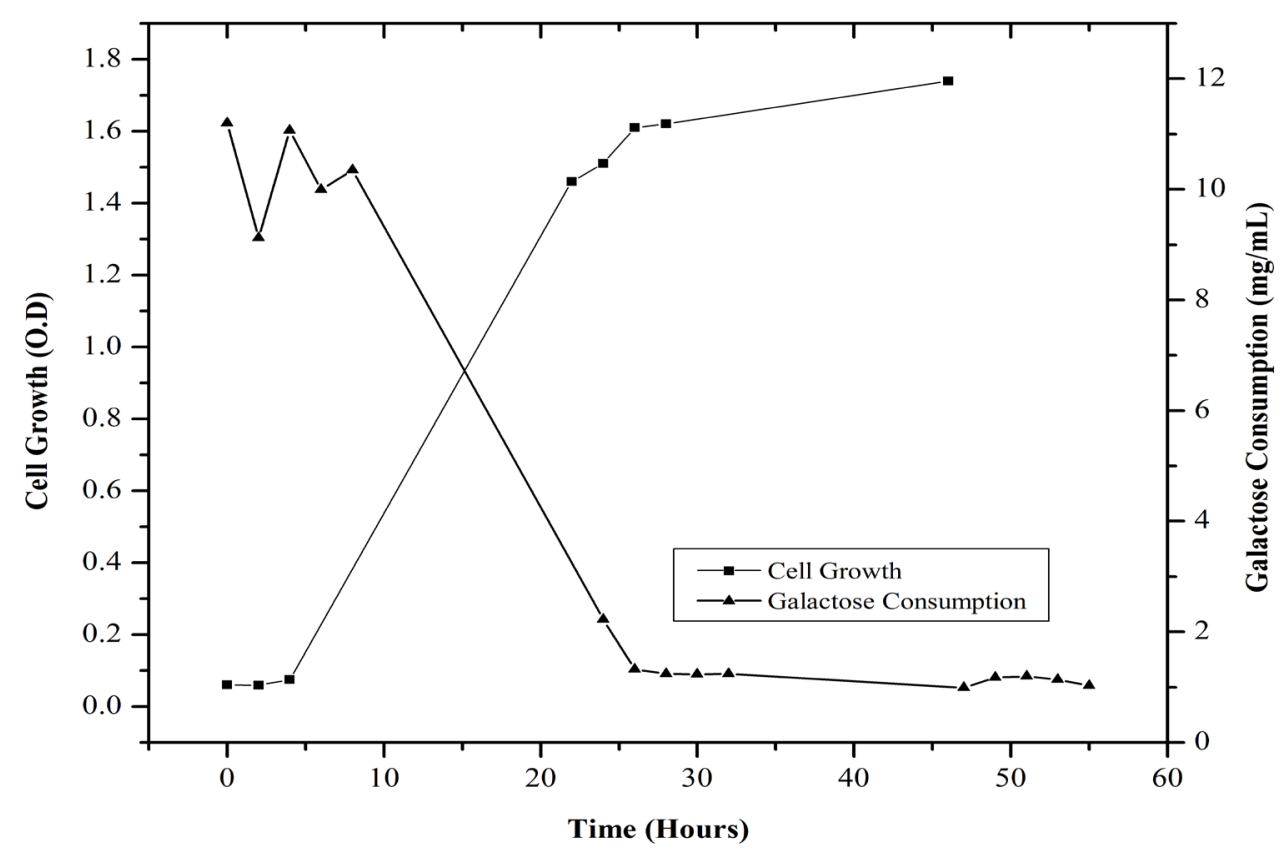

Figure 3-11 Complex medium YPGal-2\% Galactose, cell growth, galactose consumption, and Cel7B volumetric activity, November 4, 2011

Comparisons between change in galactose concentration during flask culture in complex media YPGal at 1\% initial galactose concentration (Figure 3-10) and change in galactose concentration during flask culture in complex media YPGal at 2\% initial galactose concentration (Figure 3-11) show both utilized all galactose within 30 hours of cells culture.

\subsubsection{Effect of initial concentration of galactose on recombinant enzyme Cel7B activity during flask culture in minimal medium YBC}

Figure 3-12 below shows change in galactose concentration over time starting at $1 \%$ initial galactose concentration in minimal medium with casamino acid YBC. As also shown in Figure 3-10, there were three phases of changes in galactose concentration over time. Initial concentration of galactose was steady during the lag phase of cells culture at $8 \mathrm{mg} / \mathrm{mL}$, then during the exponential phase of cells culture (overnight period) galactose 
concentration dropped to near $0 \mathrm{mg} / \mathrm{mL}$, and during the stationary phase galactose concentration remained at about $0 \mathrm{mg} / \mathrm{mL}$.

Figure 3-12 below shows change in recombinant Cel7B volumetric activity during cells growth on YBC with 1\% initial concentration of galactose. There were two phases of recombinant enzyme activity over time. Recombinant enzyme activity was near 0 $\left(\mathrm{mg} / \mathrm{mL}^{*} \mathrm{~h}\right)$ during the lag phase and exponential phase of cells culture, then it started increasing during the stationary phase of the cell culture to reach a maximum volumetric activity of $0.16\left(\mathrm{mg} / \mathrm{mL}^{*} \mathrm{~h}\right)$. However, compared to the data in Figure 3-10, recombinant Cel7B volumetric activity was not as closely associated with cell growth.

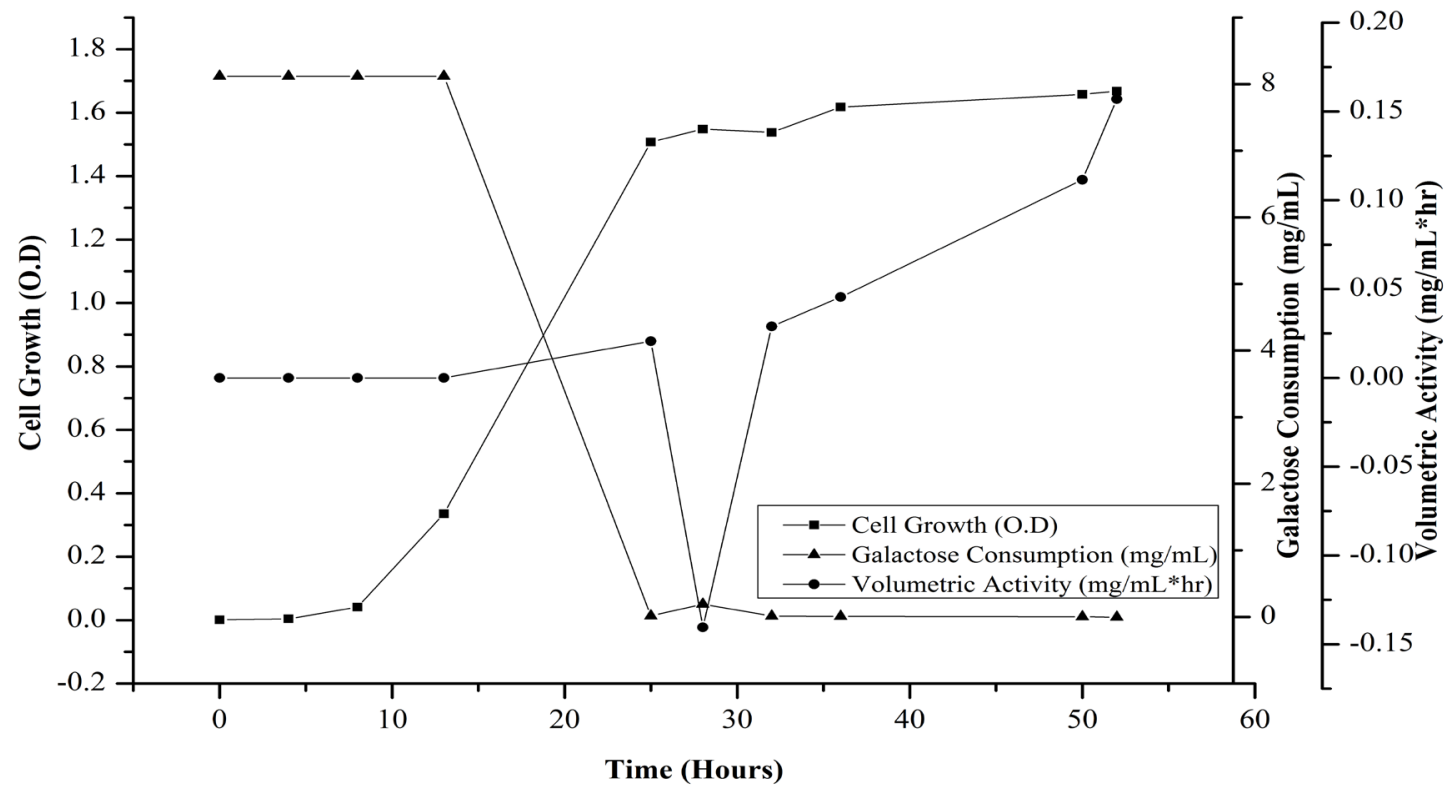

Figure 3-12 Minimal medium with casamino acid YBC-1\%, cell growth, galactose consumption, and Cel7B volumetric activity, March 28, 2012

Figure 3-13 below shows change in galactose concentration over time starting at 2\% initial galactose concentration in minimal medium with casamino acid YBC. As also shown in Figure 3-12, there were three phases of changes in galactose concentration over 
time. Initial concentration of galactose was steady during the lag phase of cells culture at $16-18 \mathrm{mg} / \mathrm{mL}$, and then during the exponential phase of cells culture (overnight period) galactose concentration dropped to near $0 \mathrm{mg} / \mathrm{mL}$, and during the stationary phase of cells growth galactose concentration remained at about $0 \mathrm{mg} / \mathrm{mL}$.

Figure 3-13 below shows change in recombinant Cel7B volumetric activity during growth on YBC with 2\% initial concentration of galactose. There were three phases of recombinant enzyme activity over time in this experiment. Recombinant volumetric enzyme activity was between -0.5 and $-2.0\left(\mathrm{mg} / \mathrm{mL}^{*} \mathrm{~h}\right)$ during the lag phase of cells culture. These negative activity values indicate the confounding effects of high background concentration of galactose on measurement of recombinant enzyme activity using the DNS assay. A galactose concentration decreased to near zero during exponential growth, activity increased to near zero. Finally, during the stationary phase volumetric enzyme activity was increasing rapidly again to reach approximately 0.8 $\left(\mathrm{mg} / \mathrm{mL}^{*} \mathrm{~h}\right)$. As shown also in Figure 3-12, recombinant Cel7B volumetric activity is not closely associated with cell growth but increases much more pronouncedly during stationary phase of cell growth. 


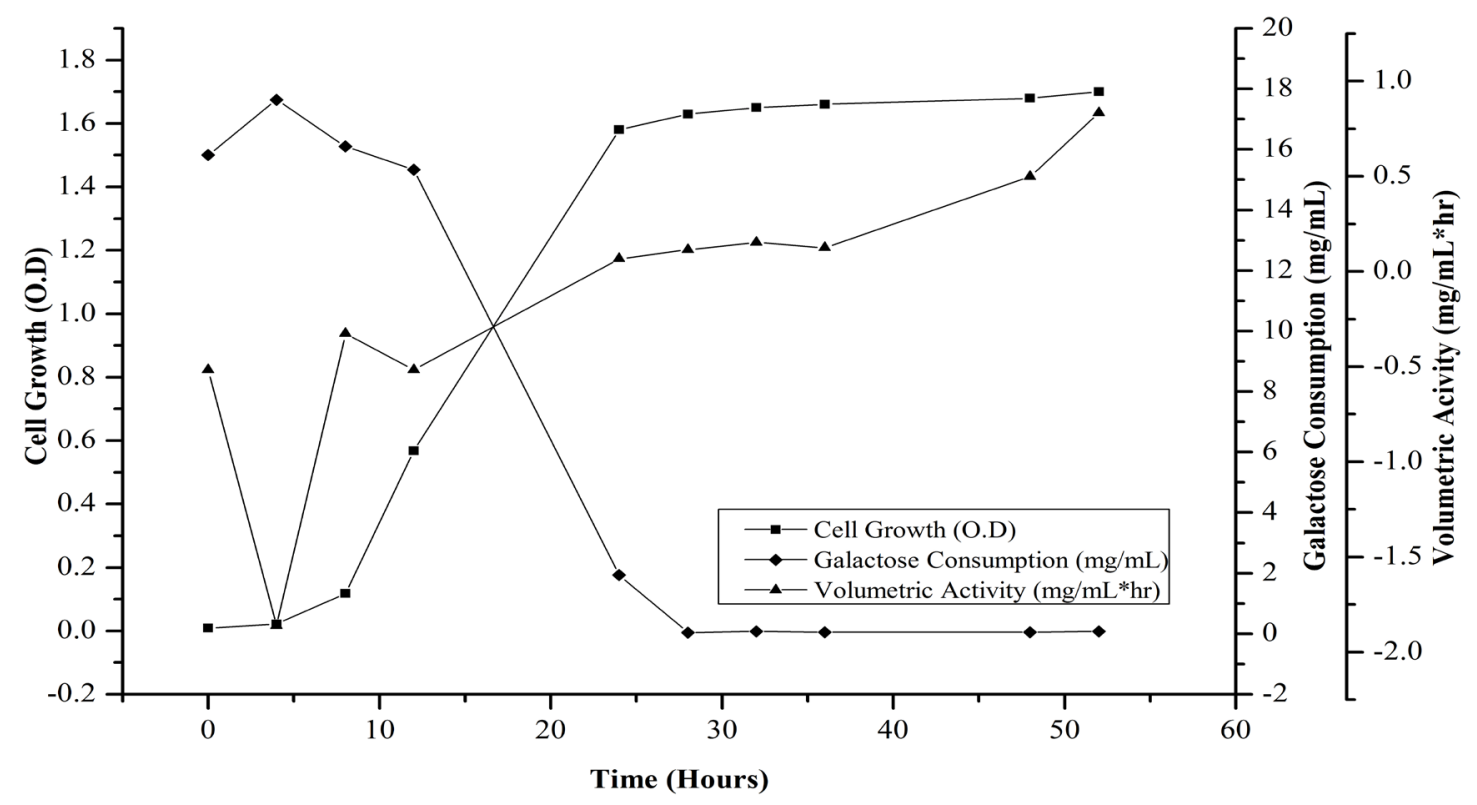

Figure 3-13 Minimal medium with casamino acid YBC-2\%, cell growth, galactose consumption, and Cel7B volumetric activity, March 6, 2012

In Figure 3-12 (1\% galactose) it is seen that all of the sugar was consumed within 24 hours, whereas Figure 3-13 (2\% galactose) some galactose remained at 24 hours. $K$. lactis appeared to require more time to grow and consume all of the sugars in the $2 \%$ galactose media compared to the $1 \%$ media. . The consumption rate of galactose $\left(\mu_{\text {net }}\right)$ is same with any concentration above $1 \%$ when $\mathrm{k}_{\mathrm{m}}<<1$, then $\mu_{\max }=\mu_{\text {net. }}$ K. lactis consumed galactose at same rate into different media with different concentration of galactose, but the different will be the time of consumption all galactose. Such as the comparison between YPGal media cultures with two different concentration of galactose $1 \%$ and $2 \%$. Galactose into $2 \%$ galactose medium takes longer time than $1 \%$ galactose.

The effect of initial galactose concentration on volumetric activity of recombinant Cel7B is clearly shown by comparing results from Figures 3-12 and 3-13. Enzyme volumetric activity on YBC-2\% galactose reached to $0.8\left(\mathrm{mg} / \mathrm{mL}^{*} \mathrm{~h}\right)$ while enzyme activity on YBC- 
$1 \%$ galactose reached to $0.16\left(\mathrm{mg} / \mathrm{mL}^{*} \mathrm{~h}\right)$. Based on these experiments, increasing initial concentration of galactose in YBC minimal media had the effect to increase recombinant enzyme activity. 


\section{Chapter 4: Bioreactor Culture of Recombinant Cel7B Production}

\subsection{Research Objectives}

The main objectives of using the large scale bioreactor are to:

- Measure effects of using large scale "bioreactor" culture on K. lactis-Cel7B yeast growth and recombinant enzyme production and activity and compare to flaskscale culture results

- Evaluate effects of using YPGal complex media with 1\% galactose concentration on $K$. lactis-Cel7B yeast growth and recombinant enzyme production and activity

\subsection{Source of yeast and laboratory equipment}

The laboratory equipment used in this chapter is identical to section 3.2, except for the bioreactor and media transfer pump. The following additional pieces of laboratory equipment were used in this research; the pump was a MINIPULS 3 from GILSON ${ }^{\circledR}$, the air filter was $0.2 \mu \mathrm{m}$-Sterilizing Grade Filter from AERVENT ${ }^{\mathrm{TM}}$ and the bioreactor was a BIOFLO 3000, Batch/Continuous Bioreactor from New Brunswick Scientific.

\subsection{Materials and methods}

\subsubsection{K. lactis strain 7B}

K. lactis-Cel7B was used in this chapter is same as that yeast was used in section 3.3.1.

\subsubsection{Experiment design}

The experiments listed in Table 4-1 were designed to address the research objectives set forth in section 4.1. The information in Table 4.1 is organized by date of experiment, type of media, concentration of galactose, and purpose of experiment. In each experiment there was a purpose and there were some targeted measurements such as cell growth of K. lactis-Cel7B, galactose concentration, and enzyme activity of cell culture samples over time. Laboratory methods for the cell culture experiments in Table 4.1 are presented below and the results of these experiments are provided in sections to follow. 
Table 4-1 Experiments Conducted in Large-Scale Culture of $K$. lactis Cel7B

\begin{tabular}{|l|l|l|l|l|}
\hline Date & $\begin{array}{l}\text { Type of } \\
\text { media }\end{array}$ & $\begin{array}{l}\text { Galactose } \\
\text { concentration }\end{array}$ & $\begin{array}{l}\text { Culturing } \\
\text { time }\end{array}$ & \multicolumn{1}{c|}{ Purpose } \\
\hline $\begin{array}{l}\text { May } \\
23, \\
2012\end{array}$ & $\begin{array}{l}\text { Complex } \\
\text { media } \\
\text { YPGal. }\end{array}$ & $\begin{array}{l}1 \%(\mathrm{w} / \mathrm{v})-10 \\
\mathrm{mg} / \mathrm{mL}\end{array}$ & 25 hours & $\begin{array}{l}\text { Measure K. lactis growth, galactose concentration, } \\
\text { and recombinant Cel7B enzyme activity in complex } \\
\text { media YPGal. with 1\% (w/v) galactose concentration } \\
\text { Results are presented in figures }(4-1,4-2,4-3) \text { and } \\
\text { tables (B-2, B-3) }\end{array}$ \\
\hline $\begin{array}{l}\text { June } \\
13, \\
2012\end{array}$ & $\begin{array}{l}\text { Complex } \\
\text { media } \\
\text { YPGal. }\end{array}$ & $\begin{array}{l}1 \%(\mathrm{w} / \mathrm{v})-10 \\
\mathrm{mg} / \mathrm{mL}\end{array}$ & 16 hours & $\begin{array}{l}\text { Measure K. lactis growth, galactose concentration, } \\
\text { and recombinant Cel7B enzyme activity in complex } \\
\text { media YPGal. with 1\% (w/v) galactose concentration } \\
\text { Results are presented in figures (4-4, 4-5, 4-6) and } \\
\text { tables (B-5, B-6) }\end{array}$ \\
\hline
\end{tabular}

\subsubsection{Types of agar and culture media}

Agar and culture media were used in this chapter is identical to that in sections 3.3.4.1 and 3.3.4.3.

\subsubsection{Inocula media "overnight growth media"}

Inoculums growth media, in this study research, is rich media YPD: yeast extract $(1 \mathrm{~g})$, peptone $(2 \mathrm{~g})$, and glucose $(1 \mathrm{~g})$ was mixed into $100 \mathrm{~mL}$ of distilled water in a $250-\mathrm{mL}$ side arm flask. Usually, a filter-sterilized glucose concentrated solution (200 g/L) was added to the media solution after autoclaving because glucose, like galactose, gets degraded at high temperature. For bioreactor scale experiments, inoculum was incubated for one and one half day because the cells needed a longer time into to reach 1.0 O.D. compared to smaller inoculums

\subsubsection{Complex liquid YPGal media}

It was found that the media boiled over when the flask was filled near the tip and covered by aluminum foil, resulting in contamination and loss of media. Therefore, it was deemed necessary to design an improved container for autoclaving media. The end result was a 4liter flask with two metal tubes, one short and one long, embedded in a rubber plug (see Appendix C, Figure C-2). The last third of the long tube was bent to allow media to be pumped from the bottom of the flask using a peristaltic pump into the pre-sterilized 10liter bioreactor. It was also determined that the flask should be no more than half full of 
media, in order to prevent boiling-over. All media was autoclaved without galactose (which was filter-sterilized instead), because galactose chains break when exposed to high temperatures.

\subsubsection{Stock solutions}

Stock solutions were used in this chapter are same as section 3.3.3

\subsection{Cell culture conditions}

Large-scale cell culture was started by picking a single colony using a disposable inoculating loop from an agar-plate and incubated in $3 \mathrm{~mL}$ of YPD liquid media in a 14 $\mathrm{mL}$ polypropylene round-bottom tube with closure. Then the $14 \mathrm{~mL}$ bottle was placed into the shaker table (incubator) at $30^{\circ} \mathrm{C}$ and $250 \mathrm{RMP}$ for 3-5 hours of growth. After wards, $3 \mathrm{~mL}$ liquid inoculums culture was mixed with the $50 \mathrm{~mL}$ of sterilized inoculums culture in a sterilized $300 \mathrm{~mL}$ side-arm flask. Then the $300 \mathrm{~mL}$ side-arm flask was placed into the shaker table (incubator) at $30^{\circ} \mathrm{C}$ and $250 \mathrm{rpm}$ for overnight growth (or until the cells density reached to 1.0 O.D). Inoculums should be clean of contamination, and so the purity of inoculums and media was check by using a microscope at 100x and 400x magnification. The inoculums should have a high density of growth between 0.5-1.0 O.D. (measured using a spectrometer at $600 \mathrm{~nm}$ ) to start the bioreactor culture. This high density of the pure $K$. lactis Cel7B inoculums will lead to a successful fermentation with no contamination.

In this research, the batch bioreactor culture was run for between 16-30 hours. During this time, $10 \mathrm{~mL}$ samples were taken every 2 hours starting at time $=0 \mathrm{hr}$ in most experiments except for overnight periods, when sampling was not normally done. Before taking the sample, approximately $5 \mathrm{ml}$ of liquid was recovered from the sample port, thereby flushing out the contents of the sample drop tube. Then about $5 \mathrm{ml}$ of new sample was taken. These samples were filtered by using $5 \mathrm{~mL}$ syringe $\left(\right.$ monoJECT $^{\mathrm{TM}}$ ) attached to $0.2 \mu$ filter and then transferred into $14 \mathrm{~mL}$ sterilized polypropylene round-bottom tubes (Becton Dickinson). These samples were processed through the procedures described in 
section 4.10 Appendix C contains a detailed bioreactor preparation and operation procedures which were followed for each experiment.

\subsection{Bioreactor}

The methods presented here were used to measure effect of bioreactor-scale batch culture on recombinant enzyme production and activity over time in complex media with $1 \%$ (10 $\mathrm{mg} / \mathrm{mL}$ ) initial concentration of galactose. In this research, a BioFlo 3000 was used (Batch/continuous-Bioreactor, New Brunswick Scientific). Experiments were run in with two different volume of growth media; 3 liters and 5 liters. Purity of K. lactis Cel7B was checked for every sample taken under a microscope at 100x and 400x.

\subsection{Cleaning bioreactor and sterilization}

Cleaning of the bioreactor was conducted with different steps after each experiment: 1) each part of the bioreactor was bleached (3\% bleach) in order to sterilize K. lactis-Cel7B prior to disposing of cell culture solution down the drain, 2) each component of the bioreactor was washed with a warm soap solution, 3) each component was rinsed with distilled water, 4) each component was air-dried, and then all parts were connected to each other and apply grease to o-rings between glass and metal parts to prevent leaks, 5) all slots/holes on bioreactor were plugged with glass wool, and then cover with aluminum foil, and all aluminum foil was a fixed to the metal of the bioreactor by using autoclave adhesive tape to prevent contamination of bioreactor. After this cleaning procedure, the bioreactor was autoclaved empty (with $100-\mathrm{mL}$ distilled water) and every item that is connected to the bioreactor during a cell culture run such as glass sampling vial, sample valve unit, and solution tubes. This autoclave procedure was done two times one night before bioreactor was used in the next day.

\section{7 $\quad$ Starting up bioreactor}

There are many steps that must be done before starting the fermentation procedures: 1) checking gases availability and connecting to the bioreactor, 2) connecting water ports and thermocoule ports into the bioreactor, 3) turning on water source to the bioreactor, and confirm that water comes out of the bioreactor, 4) controlling temperature at $30{ }^{\circ} \mathrm{C}$, 
5) setting up base $(6 \mathrm{~N} \mathrm{NaOH})$ and acid $(1 \mathrm{~N} \mathrm{HCl})$ solutions and connecting them to bioreactor, 6) starting to pump heat sterilized growth media into the bioreactor, 7) testing the function of $\mathrm{pH}$ probe and $\mathrm{DO}$ probe, 8) setting up computer that connected to bioreactor and choosing the main variables such as $\mathrm{pH}$, and agitation; that is important to measure and control, to improve growth yeast and increase producing of enzyme in media. The detailed laboratory procedure for Bioflow 3000 operation for these experiments is found in the Job Safety Assessment (JSA) folder in room 205 and titled "Bioflow 3000 K. lactis Cel7B".

\subsection{Pumping up media into bioreactor}

Sterilized complex medium with an initial $1 \%$ galactose concentration was pumped by using the medium transfer apparatus (large flask (4-L) with metal tubes attached to rubber cap) (Appendix C, figure C-2) pumper (MINIPULS 3-GILSON ${ }^{\circledR}$ ), and sterilized flexible tubes used in the pumper. Afterwards, inoculum medium $(50 \mathrm{~mL})$ was transferred by the same way using the medium transfer apparatus and then was pumped to the bioreactor (Appendix C figure C-3).

\subsection{Purity of growth media and inoculums}

Usually and especially for the bioreactor runs the purity of media and inoculum medium were checked by placing a small sample under a microscope at 400 magnification. These samples included inoculum medium, growth medium, and every two hours for the bioreactor medium. Checking purity of media is really important to avoid any contaminations that could reduce $K$. lactis Cel7B yeast growth and interfere with recombinant protein "endoglucanase" production.

\subsection{DNS assay for galactose concentration and Cel7B activity}

This section is identical to section 3.3.6

\subsection{Galactose standard curve}

This section is identical to section 3.3.7

\subsection{Results and discussion of bioreactor experiments}




\subsubsection{Recombinant Cel7B activity and galactose concentration in complex media YPGal-1\% Galactose, May23, 2012}

Figure 4-1 shows effect of bioreactor culture on growth of $K$. lactis-Cel7B yeast in complex medium YPGal with 1\% initial concentration of galactose. The growth density of $K$. lactis-Cel7B yeast in YPGal medium with 1\% initial concentration of galactose was started rapidly during the exponential phase of cells culture time, and during the stationary phase of cells culture was slowly increasing to reach a density of 8.32 O.D. A dilution of 10:1 was used on samples to determine these high O.D. levels.

Figure 4-1 below shows change in galactose concentration during bioreactor culture in complex medium YPGal at 1\% initial galactose concentration in bioreactor run on May 23,2012 . There were three phases to the change in galactose concentration over time. Initial concentration of galactose was about $7 \mathrm{mg} / \mathrm{mL}$ during the lag phase of cell culture, and then concentration decreased rapidly during the exponential phase, and finally during the stationary phase galactose concentration remained at a low level of $0.7 \mathrm{mg} / \mathrm{mL}$. This low level of galactose is interpreted to be zero $\mathrm{mg} / \mathrm{mL}$ as there appears to be a small positive bias in the DNS assay for this experiment,

The effect of bioreactor culture compared to flask culture on galactose concentration is clearly shown by comparing results from Figures 3-10 and 4-1. In both experiments the initial concentration of galactose was around $8 \mathrm{mg} / \mathrm{mL}$, but during flask culture yeast utilized all galactose in 28 hours of cells culture, while during bioreactor culture yeast utilized all galactose in 18 hours. This result means galactose utilizing rate of yeast was increased during bioreactor culture compared to flask culture. This occurred presumably because of more optimal growth conditions that existed in the automated and controlled bioreactor.

Figure 4-1 shows recombinant endoglucanase volumetric activity in complex medium YPGal with an initial concentration of 1\% galactose for bioreactor run on May 23, 2012. There were three phases of recombinant enzyme volumetric activity over time. Recombinant enzyme volumetric activity was very high at the start, $1.5 \mathrm{mg} / \mathrm{ml}$ / h during 
the lag phase of cells culturing to reach $2.3 \mathrm{mg} / \mathrm{mL}^{*} \mathrm{hr}$, and then was started decreasing rapidly during the exponential phase to reach $0 \mathrm{mg} / \mathrm{mL}^{*} \mathrm{~h}$, and final step was again increasing rapidly during both exponential and stationary phases to reach a maximum of $1.63 \mathrm{mg} / \mathrm{mL}^{*} \mathrm{~h}$.

The reason for high variability of volumetric enzyme activity within the first 6 hours is suspected to be due to high background of galactose, which is believed to interfere with the DNS assay. Later in the fermentation when background of galactose is low, the effect of enzyme action on CMC is more certain with less variability. We believe that $\mathrm{CMC} / \mathrm{DNS}$ method is more accurate to measure low enzyme activity when there is low concentration of galactose in the background.

The effect of bioreactor culture on volumetric activity of recombinant Cel7B is clearly shown by comparing results from Figures 3-10 and 4-1 (see table 4-2 below). Recombinant enzyme volumetric activity was affected positively during bioreactor culture and more than during flask culture. Enzyme volumetric activity in complex medium YPGal with concentration of 1\% galactose during bioreactor culture was higher by $1.1 \mathrm{mg} / \mathrm{mL}^{*} \mathrm{~h}$ than enzyme volumetric activity of endoglucanase in YPGal-1\% galactose during flask culture. It is also evident that enzyme volumetric activity begins to increase earlier in bioreactor culture (approximately $10 \mathrm{hrs}$.) compared to small-flask culture (approximately 20 hrs.). Based on these experiments, there is also evidence that recombinant enzyme production starts to increase in both bioreactor and small-flask culture after galactose is consumed in the medium and after relatively high cell concentration is achieved in the medium. 
Table 4- 2 Comparing results from Figures 3-10 and 4-1

\begin{tabular}{|l|l|l|}
\hline Key & Figure 3-10 & Figure 4-1 \\
\hline Cell growth (O.D) & $\begin{array}{l}\text { Reached } 1.7 \text { at } 52 \mathrm{hr} \text { of } \\
\text { culturing (no dilution) }\end{array}$ & Reached 8.32 with dilution \\
\hline $\begin{array}{l}\text { Galactose Consumption } \\
(\mathrm{mg} / \mathrm{mL})\end{array}$ & $\begin{array}{l}\text { All galactose was consumed } \\
\text { into } 28 \mathrm{hr}\end{array}$ & $\begin{array}{l}\text { All galactose was consumed } \\
\text { into } 18 \mathrm{hr}\end{array}$ \\
\hline $\begin{array}{l}\text { Volumetric Activity } \\
(\mathrm{mg} / \mathrm{mL} * \mathrm{hr})\end{array}$ & Reached 0.5 into $52 \mathrm{hr}$ & Reached 1.63 into $30 \mathrm{hr}$ \\
\hline
\end{tabular}

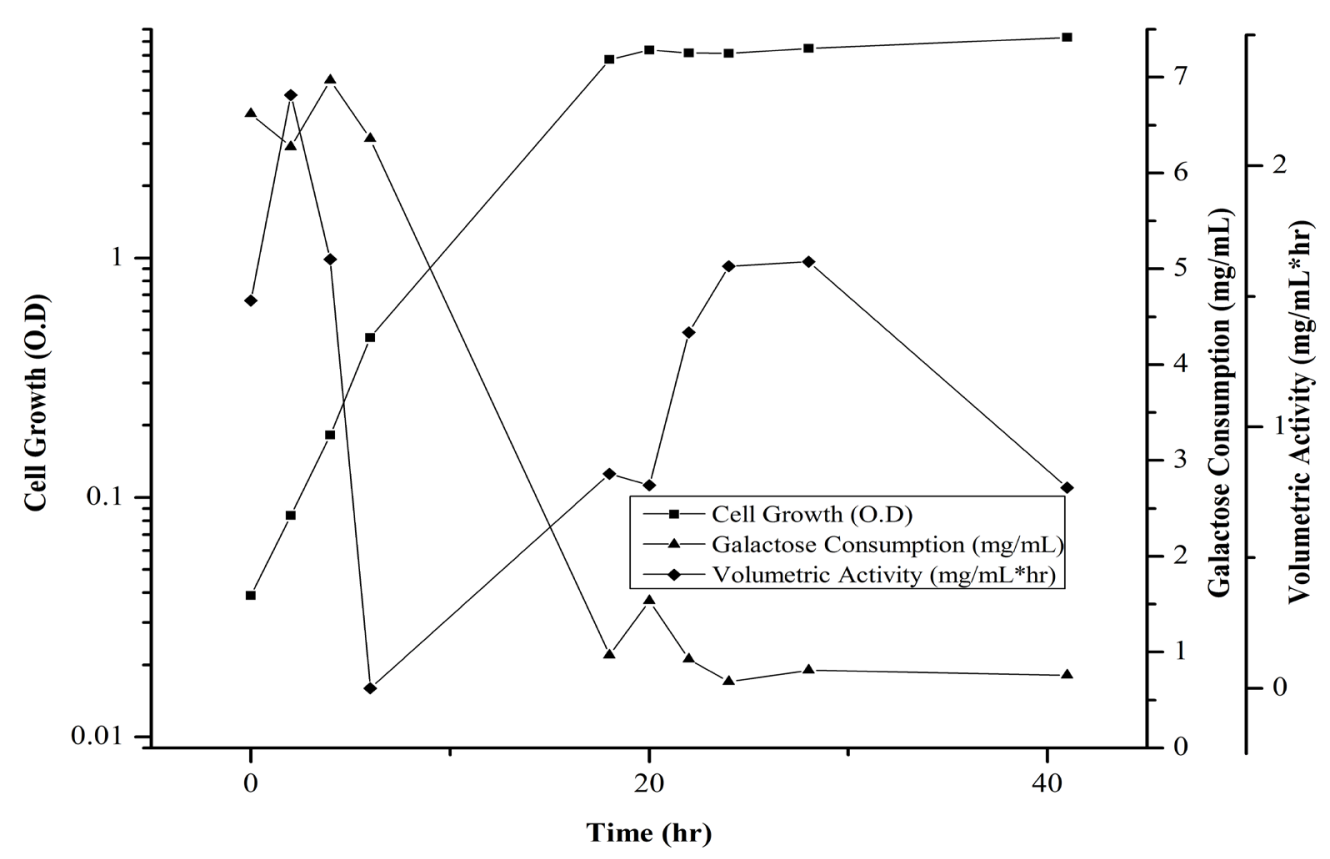

Figure 4-1 K. lactis-Cel7B yeast growth, galactose consumption, and volumetric activity into complex medium YPGal-1\% Galactose samples "Large Scale", May 23, 2012

Figure 4-2 below shows the log growth rate of the $K$. lactis-Cel7B yeast on complex medium YPGal with $1 \%$ galactose concentration. The growth rate was increasing rapidly 
during the lag phase of the culturing time. Then growth rate jumped to constant rate during the stationary phase after 20 hours of culturing.

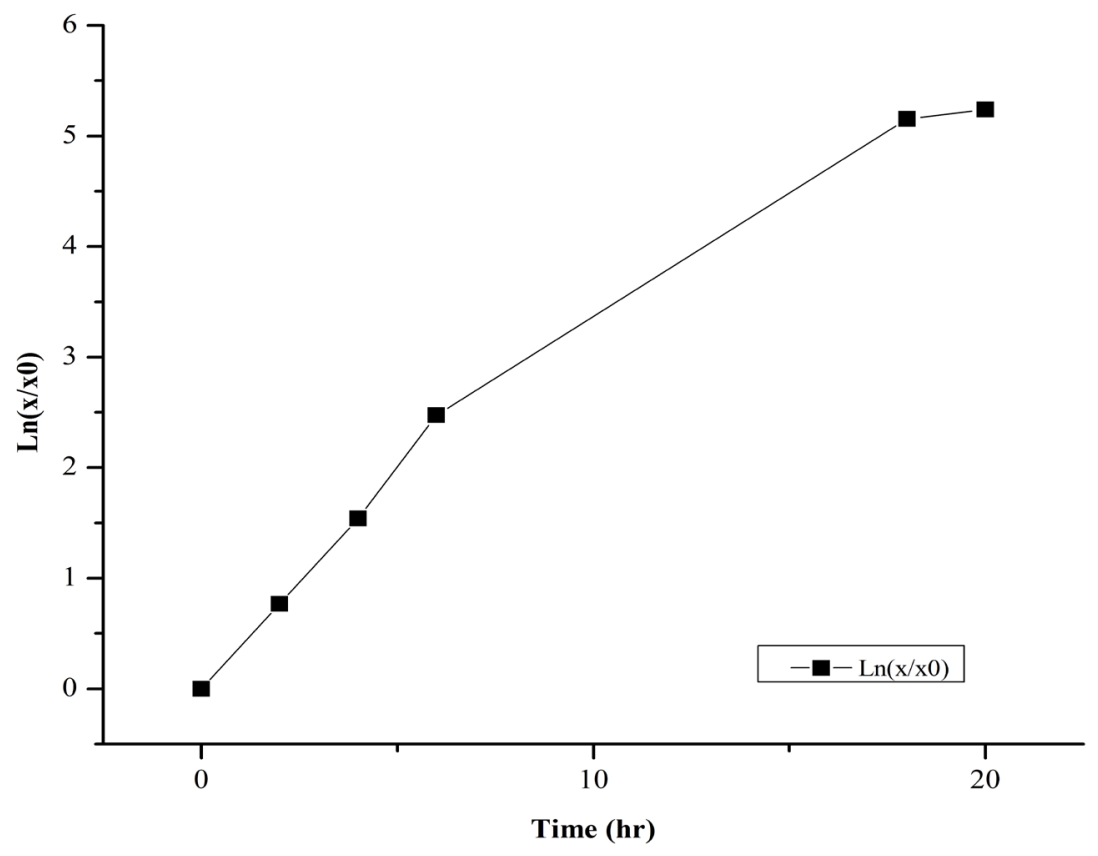

Figure 4-2 K. lactis-Cel7B log growth curve on complex medium YPGal-1\% Galactose "Bioreactor Scale", May 23, 2012

\subsubsection{Recombinant Cel7B activity and galactose concentration in complex medium YPGal-1\% Galactose, June13, 2012}

Figure 4-3 shows effect of bioreactor culture on growth rate of K. lactis-Cel7B in complex medium YPGal with 1\% initial concentration of galactose. This experiment can be considered a replicate of the May 23, 2012 experiment. The growth of K. lactis-Cel7B started rapidly during the exponential phase of cells culture time, and during the stationary phase of cells culture was slowly increasing to reach a density of 7.96 O.D. This high level of O.D. was similar to the maximum from the May 23 experiment. 
Figure 4-3 below shows change in galactose concentration during bioreactor culture in complex medium YPGal at 1\% initial galactose concentration. There were three phases to the change in galactose concentration over time. Initial concentration of galactose was 8 $\mathrm{mg} / \mathrm{mL}$ during the lag phase of cells culture, and then concentration decreased rapidly during the exponential phase, and finally during the stationary phase galactose concentration remained at $0 \mathrm{mg} / \mathrm{mL}$. This consumption of galactose is similar to that observed in the May 23 experiment.

The effect of bioreactor culture on galactose concentration is clearly shown by comparing results from Figures 3-10 and 4-3. In both the initial concentration of galactose was started at $8 \mathrm{mg} / \mathrm{mL}$, but during flask culture yeast utilized all galactose in 28 hours of cells culture, while during bioreactor culture yeast utilized all galactose in 16 hours. This result means the galactose utilizing rate of yeast was increased during bioreactor culture compared to flask culture.

Figure 4-3 shows recombinant endoglucanase volumetric activity for bioreactor run on June 13, 2012. There were two phases of recombinant enzyme activity over time. Recombinant enzyme volumetric activity was at less than $0 \mathrm{mg} / \mathrm{ml}^{*} \mathrm{~h}$ during the lag phase of cells culture and with high variability, and then started increasing rapidly during exponential and stationary phase of cells culturing to reach $0.93 \mathrm{mg} / \mathrm{mL}^{*} \mathrm{~h}$.

As explained before, the reason for high variability of volumetric enzyme activity during the lag phase is suspected to be due to high background concentration of galactose coupled with low enzyme action on CMC. Later in the fermentation when background of galactose is low, the effect of enzyme action on CMC is more certain with less variability. From this research, CMC/DNS method is more accurate to measure low enzyme activity with low concentration of galactose in the background.

The effect of bioreactor culture on volumetric activity of recombinant Cel7B is clearly shown by comparing results from Figures 3-10 and 4-3. Recombinant enzyme volumetric activity was affected positively during bioreactor culture and was higher than during flask culture. Enzyme volumetric activity in complex medium YPGal with concentration of 1\% galactose during bioreactor culture was higher by $0.4 \mathrm{mg} / \mathrm{mL}^{*} \mathrm{~h}$ than enzyme activity of 
endoglucanase in YPGal-1\% galactose during flask culture. It is also evident that enzyme volumetric activity begins to increase earlier in bioreactor culture (approximately $10 \mathrm{hrs}$.) compared to small-flask culture (approximately $20 \mathrm{hrs}$.). Based on these experiments, it is also interesting that recombinant enzyme production starts to increase in both bioreactor and small-flask culture after most of the galactose is consumed in the medium and after relatively high cell concentration is achieved in the medium. The volumetric activity shown in Figure 4-3 has less variability than Figure 4-1 during all growth phases.

There was not any literature that could be found to explain the wide variability of volumetric activity data at the lag phase. Many things may have effects on CMC/DNS method such as; the stock solution of CMC, the stock solution of DNS, and the stock solution of citrate buffer. It is preferred to prepare these soultions every time new enzyme samples are analyzed, to get more accurate results from the CMC/DNS method.

Table 4- 3 Comparing results from Figures 3-10 and 4-3

\begin{tabular}{|l|l|l|}
\hline Key & Figure 3-10 & Figure 4-3 \\
\hline Cell growth (O.D) & Reached 1.7 without dilution & Reached 7.96 with dilution \\
\hline $\begin{array}{l}\text { Galactose Consumption } \\
(\mathrm{mg} / \mathrm{mL})\end{array}$ & $\begin{array}{l}\text { All galactose was consumed } \\
\text { into } 28 \mathrm{hr}\end{array}$ & $\begin{array}{l}\text { All galactose was consumed } \\
\text { into } 16 \mathrm{hr}\end{array}$ \\
\hline $\begin{array}{l}\text { Volumetric Activity } \\
\left(\mathrm{mg} / \mathrm{mL}^{*} \mathrm{hr}\right)\end{array}$ & Reached 0.5 into $52 \mathrm{hr}$ & Reached 0.93 into $30 \mathrm{hr}$ \\
\hline
\end{tabular}




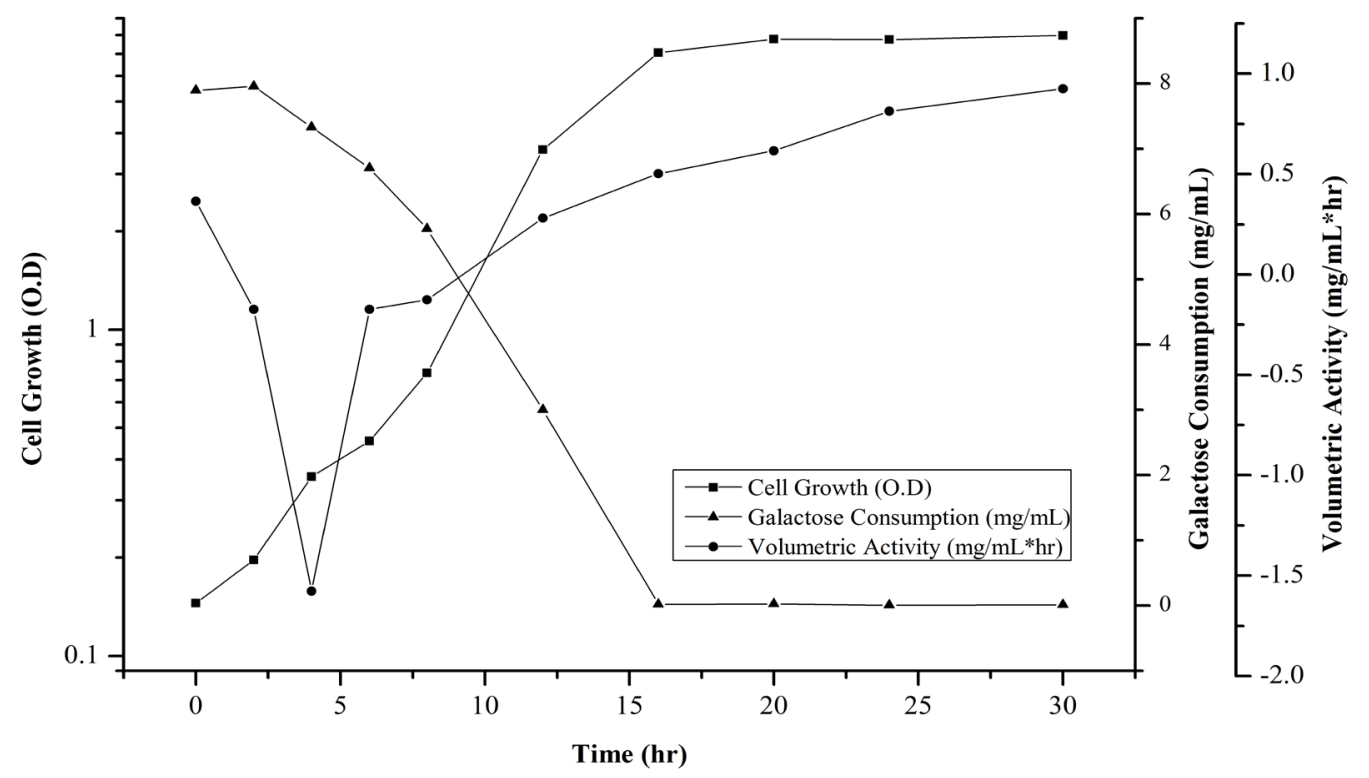

Figure 4-3 K. lactis- Cel7B yeast growth, galactose consumption, and volumetric activity into YPGal-1\% Galactose samples "Bioreactor Scale", June 13, 2012

Figure 4-4 below shows the log growth rate of the $K$. lactis-Cel7B on complex medium YPGal with $1 \%$ galactose concentration, it is same as Figure 4-2. The growth rate was increasing rapidly by 2 hours during the lag phase of the culturing time. Then growth rate increased fast by 4 to reach a constant rate during the stationary phase after 16 hours of culturing. 


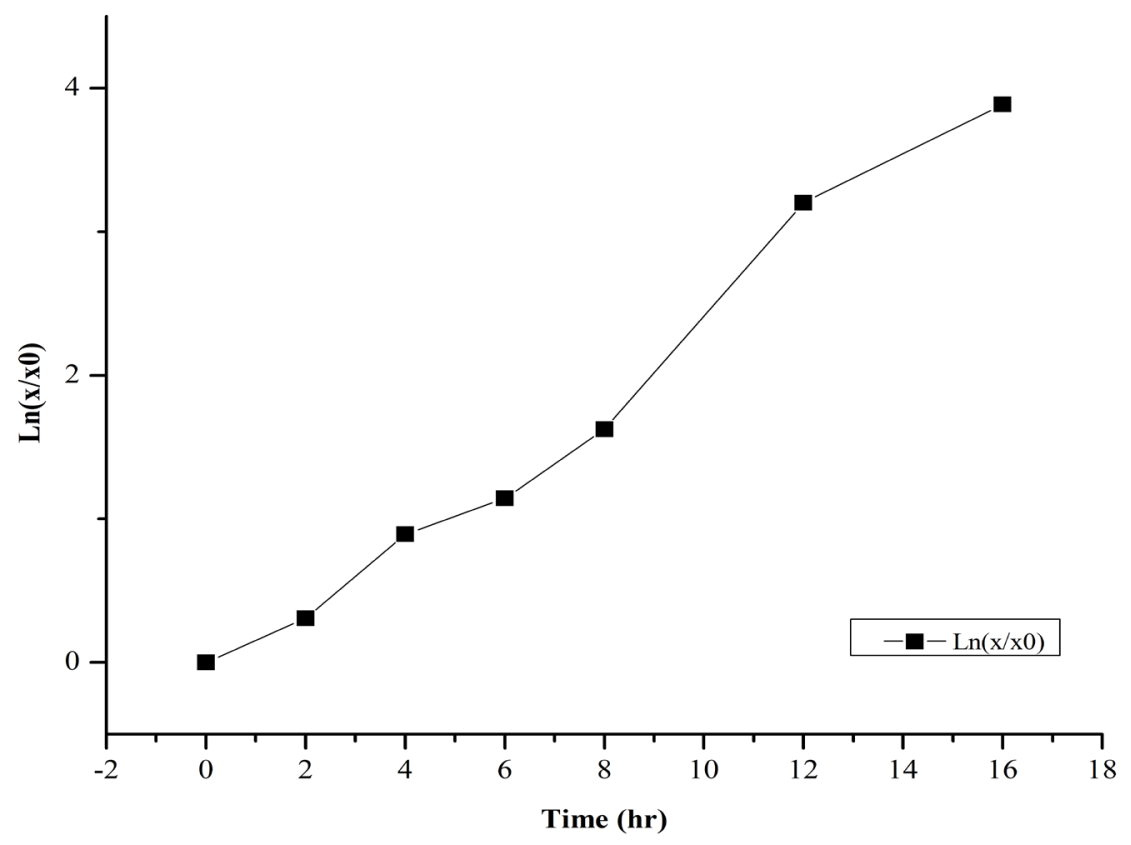

Figure 4-4 K. lactis- Cel7B log growth curve on YPGal-1\% Galactose "Bioreactor Scale", June 13, 2012

Complex medium with an initial 1\% concentration of galactose in May 23, 2012 (Figure 4-1) exhibited a slight increase in growth of $K$. lactis-Cel7B compared to complex media YPGal with 1\% initial concentration of galactose in June 13, 2012 (Figure 4-3). The small difference in ultimate cell density is evidence that good replication of cell growth results was achieved in these two bioreactor trails.

The effect of bioreactor culture is clearly shown by comparing results from Figures 4-1 and 4-3. In both the initial concentration of galactose was started around $8 \mathrm{mg} / \mathrm{mL}$, but in May 23, 2012 during bioreactor culture yeast utilized all galactose in 18 hours of cells culture, while in June 13, 2012 during bioreactor culture yeast utilized all galactose in 16 hours. The small difference in the time required for galactose consumption is more evidence of good reproducibility of bioreactor experiment and results. 
The effect of bioreactor culture on volumetric activity of recombinant Cel7B is clearly shown by comparing results from Figures 4-1 and 4-3. Recombinant enzyme volumetric activity was affected positively in May 23, 2012 during bioreactor culture more than in June 13, 2012 during bioreactor culture. Enzyme volumetric activity in complex medium YPGal with concentration of 1\% galactose in May 23, 2012 during bioreactor culture was higher by $0.7 \mathrm{mg} / \mathrm{mL}^{*} \mathrm{~h}$ than enzyme activity of endoglucanase in YPGal-1\% galactose in June 13, 2012 during bioreactor culture. In both experiments May 23 and June 13, 2012 is also evident that enzyme volumetric activity begins to increase earlier in bioreactor culture (approximately $10 \mathrm{hrs}$.) compared to small-flask culture (approximately $20 \mathrm{hrs}$.).

The growth data from the two bioreactor experiments are shown in Figure 4-5, representing averages of the two experiments and standard deviation error bars for the first four data points, which all occur during exponential phase. The slope of the best fit through these data points is the maximum specific growth rate constant, or in the terminology of biochemical engineering textbooks, $\mu_{n e t}$, the net specific growth rate greater than the death rate. Doubling time of cell growth mass can be calculated from these equations (Shuler and Kargi 2002).

$$
\begin{gathered}
\ln \left(\frac{x}{x_{0}}\right)=\mu_{\text {net }} t \\
\mu_{\text {net }}=\mu_{\max }=\text { slope } \\
\tau_{d}=\frac{\ln (2)}{\mu_{\text {net }}}=\frac{0.693}{\mu_{\text {net }}}
\end{gathered}
$$

From Figure $4-5$, the $\mu_{\text {net }}=0.264 / \mathrm{hr}$, and then the final value of the doubling time of cell growth is $\tau_{\mathrm{d}}=2.63$ hours. 


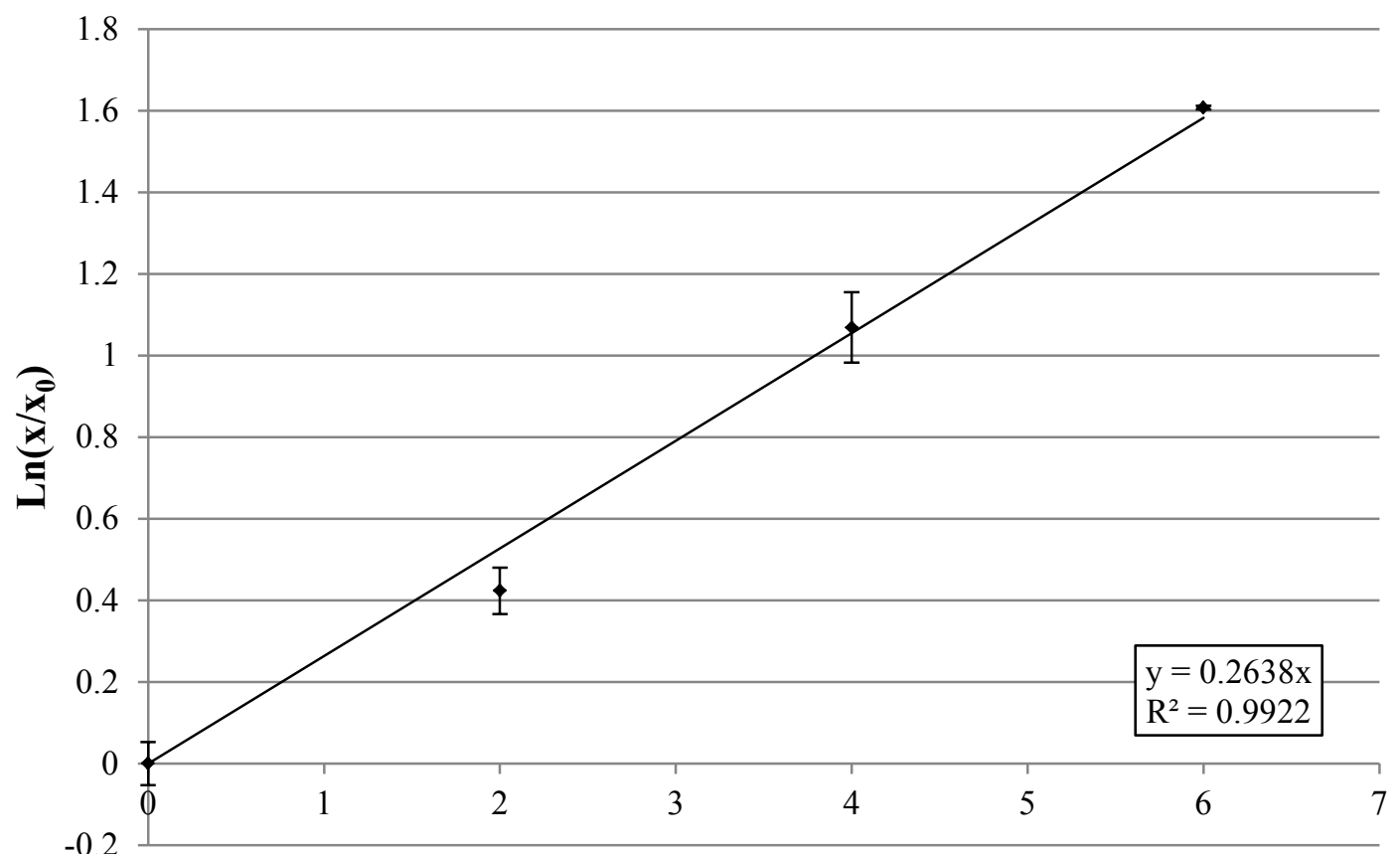

Time (hr)

Figure 4-5 K. lactis- Cel7B average growth data on YPGal-1\% Galactose samples "Bioreactor Scale", June 13 and May 23, 2012

\subsection{Convert unit of volumetric activity of recombinant enzyme Cel7B of $K$. lactis from $\mathrm{mg} / \mathrm{mL} / \mathrm{hr}$ to $\mu \mathrm{M} / \mathrm{min}$ :}

Volumetric activity of the Cel7B recombinant enzyme of K. lactis was measured in units of $\mathrm{mg} /\left(\mathrm{mL}^{*} \mathrm{hr}\right)$ in all previous sections. By using the calculation method below will allow volumetric activity in units of $\mu \mathrm{M} / \mathrm{min}$. This is necessary to compare the measurements of volumetric activity in this thesis to one literature source.

Volumetric Activity $\frac{m g}{m L * h r} *$ Time $\frac{h r}{60 \mathrm{~min}} *$ Volume $\frac{1000 \mathrm{~mL}}{L} *$ Weight $\frac{g}{1000 \mathrm{mg}}$

* MW $\frac{\text { mol }}{180.2 \mathrm{~g}}=$ Volumetric Activity $\left(\frac{\mu M}{\min }\right.$ or $\left.\frac{\mu m o l}{L * \min }\right)$ 
The volumetric activity for experiment of May 23 was $150.76 \mu \mathrm{M} / \mathrm{min}$ and for experiment of June 13 was $86.02 \mu \mathrm{M} / \mathrm{min}$. These results are shown into the figure below and are compared to a literature result of recombinant Cel7B activity by using a different yeast (Pichia Pastoris).

The comparison in Figure 4-6 showed higher activity for the recombinant enzyme produced by using Pichia Pastoris (Generoso et al. 2012), which was $340 \mu \mathrm{M} / \mathrm{min}$, than the activity of recombinant enzyme Cel7B of $K$. lactis, which was between 86.02$150.76 \mu \mathrm{M} / \mathrm{min}$ in this research project. That means the volumetric activity of recombinant enzyme of $K$. lactis is comparable to one literature result at $2 \% \mathrm{CMC}$, but was lower by about one half.

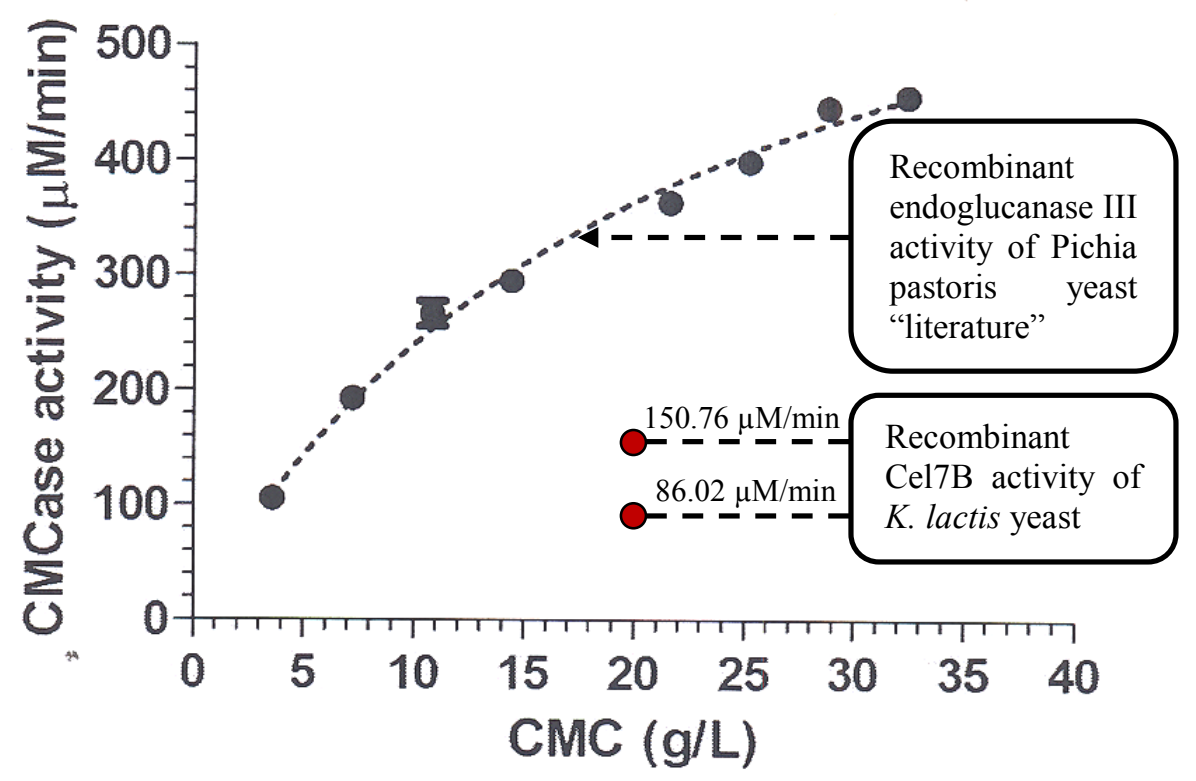

Figure 4-6 Comparison Endoglucanase Volumetric Activity of $\boldsymbol{K}$. lactis-Cel7B Yeast versus Pichia Pastoris Yeast (Generoso et al. 2012) 


\section{Chapter 5: Conclusions}

This research investigated the effects of culture media (minimal versus complex media), flask-scale versus bioreactor-scale culture, and concentration of carbon and energy source ( $2 \%$ or $1 \%$ galactose) on production of recombinant Cel7B enzyme by K. lactis-Cel7B yeast. There were two analytical tools to achieve the goals of this research: 1) CMC/DNS assay to measure effect of different methods on recombinant enzyme activity, and galactose concentration, and 2) Gel electrophoresis to show effects of different culture media on presence of recombinant enzyme and on the size of recombinant enzyme.

In Chapter 3, most of the research results were presented on flask-scale culture of $K$. lactis Cel7B. Gel electrophoresis experiments showed that the minimal media without amino acid addition (YNB) produce a small amount of endoglucanase enzyme, but in other complex media and minimal media with casamino acid addition, the enzyme band appeared at $67,000 \mathrm{Da}$, which is slightly higher in molecular weight than native Cel7B obtained from a commercial formulation $(52,000 \mathrm{Da})$. These flask-scale results also showed that there is a difference between complex media YPGal and minimal media with casamino acid $\mathrm{YBC}$ on $K$. lactis growth. K. lactis Cel7B yeast grows faster in complex media YPGal and YBC than in minimal media YNB at 2\% galactose. Also, cells grew to higher level and at a faster rate in $2 \%$ galactose compared to $1 \%$ galactose for both YPGal and YBC media. Because the consumption rate $\mu_{\text {net }}$ of galactose same at both concentrations, then $K$. lactis-Cel7B yeast consumed galactose with same rate, which it takes longer time to consumed the higher concentration such as medium with $2 \%$ galactose. When K. lactis Cel7B yeast growth was compared at the same level of galactose for YPGal and YBC media, nearly the same growth rate and growth level (O.D.) were obtained. In experiments where recombinant Cel7B net activity was measured at $1 \%$ galactose initial concentration in YPGal and YBC media, higher enzyme activity was detected for the complex media YPGal. Higher activity of recombinant Cel7B was detected for flask culture in $2 \%$ galactose compared to $1 \%$ galactose for YBC media. 
Chapter 4 results show the effect bioreactor-scale culture of $K$ lactis-Cel7B yeast in YPGal media with $1 \%$ galactose. Two experiments were conducted under these culture conditions at $30^{\circ} \mathrm{C}, \mathrm{pH} 7.0$, dissolved oxygen of $50 \%$ of saturation, and $250 \mathrm{rpm}$ agitation (variable depending on DO control). K lactis-Cel7B yeast growth curves were quite reproducible with maximum O.D. of between 7 and 8 (when factoring dilution of 10:1). Galactose was consumed rapidly during the first 15 hours of bioreactor culture and recombinant Cel7B started to appear in the culture at 10-15 hours and increased thereafter up to a maximum of between 0.9 and $1.6 \mathrm{mg} / \mathrm{mL} / \mathrm{hr}$ in these experiments. These bioreactor enzyme volumetric activity results are much higher than comparable experiments conducted with flask-scale culture $(0.5 \mathrm{mg} / \mathrm{mL} / \mathrm{hr})$. However, there was more variability in the recombinant Cel7B activity assay (CMC/DNS assay) in the bioreactor experiments compared to the flask-culture results. The reasons for variability in activity assay are thought to be due to high background of galactose, experimenter error, and "freshness" of the DNS reagent, and not associated with scale of $K$ lactisCel7B yeast culture.

This research can be summarized in the following main conclusions.

Complex media produced more recombinant enzyme than minimal media.

$>$ Medium with higher percentage of carbon and energy source produced more of Cel7B enzyme.

$>$ K. lactis-Cel7B enzyme produced in this study research bind at higher bind level the wild-type of Cel7B enzyme

$>$ Bioreactor culturing produced high production of recombinant enzyme than flask culturing.

$>$ Bioreactor production of the Cel7B enzyme was lower than the literature result by using different tube of yeast, but was comparable. 


\section{References}

Brodeur-Campbel M. 2012. BIOCHEMICAL CONVERSIONS OF LIGNOCELLULOSIC BIOMASS FOR SUSTAINABLE FUEL-ETHANOL PRODUCTION IN THE UPPER MIDWEST [DISSERTATION].

Dickson RC, Riley MI. 1989. The lactose-galactose regulon of Kluyveromyces lactis. Biotechnology (Reading, Mass.) 13:19-40.

Eijsink VGH, Vaaje-Kolstad G, Vårum KM, Horn SJ. 2008. Towards new enzymes for biofuels: lessons from chitinase research. Trends in Biotechnology 26(5):228-235.

Generoso WC, Malago-Jr W, Pereira N, Jr., Henrique-Silva F. 2012. Recombinant expression and characterization of an endoglucanase III (cel12a) from Trichoderma harzianum (Hypocreaceae) in the yeast Pichia pastoris. Genet Mol Res 11(2):1544-57.

Hockney RC. 1994. Recent developments in heterologous protein production in Escherichia coli. Trends in Biotechnology 12(11):456-463.

Hsieh H, Da Silva N. 1998. Partial-pKD1 plasmids provide enhanced structural stability for heterologous protein production in Kluyveromyces lactis. Applied Microbiology and Biotechnology 49(4):411-416.

Hsieh HB, Da Silva NA. 2000. Development of a LAC4 promoter-based gratuitous induction system in Kluyveromyces lactis. Biotechnology and Bioengineering 67(4):408-416.

King BC, Donnelly MK, Bergstrom GC, Walker LP, Gibson DM. 2009. An optimized microplate assay system for quantitative evaluation of plant cell wall-degrading enzyme activity of fungal culture extracts. Biotechnology and Bioengineering 102(4):1033-1044.

Lynd LR, Weimer PJ, van Zyl WH, Pretorius IS. 2002. Microbial Cellulose Utilization: Fundamentals and Biotechnology. Microbiology and Molecular Biology Reviews 66(3):506-577. 
Makrides SC. 1996. Strategies for achieving high-level expression of genes in Escherichia coli. Microbiological Reviews 60(3):512-38.

McFarland KC, Ding H, Teter S, Vlasenko E, Xu F, Cherry J. 2007. Development of Improved Cellulase Mixtures in a Single Production Organism. Industrial Application of Enzymes on Carbohydrate-Based Material. American Chemical Society. p. 19-31.

Mosier N, Wyman C, Dale B, Elander R, Lee YY, Holtzapple M, Ladisch M. 2005. Features of promising technologies for pretreatment of lignocellulosic biomass. Bioresour Technol 96(6):673-86.

Read JD, Colussi PA, Ganatra MB, Taron CH. 2007. Acetamide selection of Kluyveromyces lactis cells transformed with an integrative vector leads to highfrequency formation of multicopy strains. Applied and environmental microbiology 73(16):5088-5096.

Sambrook J, Reussell DW. 2001. Molecular Cloning A Laboratory Manual COLD SPRING HARBOR LABORATORY PRESS, New York.

Sherman F, Fink GR, Hicks JB. 1986. Laboratory course manual for methods in yeast genetics.

Shonnard DR, Brodeur-Campbell MJ, Martin-Garcia AR, Kalnes TN. 2012. Chemical Engineering for Bioenergy Plants Concepts and Strategies. In: Kole C, Chandrshekhar J, P., Shonnard DR, editors. Handbook of bioenergy crop plants.

Shuler ML, Kargi F. 2002. Bioprocess engineering. Prentice Hall New York.

Swinkels B, Ooyen AJ, Bonekamp F. 1993. The yeastKluyveromyces lactis as an efficient host for heterologous gene expression. Antonie van Leeuwenhoek 64(2):187-201.

Torres W, Pansare SS, Goodwin JG. 2007. Hot Gas Removal of Tars, Ammonia, and Hydrogen Sulfide from Biomass Gasification Gas. Catalysis Reviews 49(4):407456.

van der Vlugt-Bergmans CJB, van Ooyen AJJ. 1999. Expression cloning in Kluyveromyces lactis. Biotechnology Techniques 13(1):87-92. 
Van Ooyen AJJ, Dekker P, Huang M, Olsthoorn MMA, Jacobs DI, Colussi PA, Taron CH. 2006. Heterologous protein production in the yeast Kluyveromyces lactis. FEMS Yeast Research 6(3):381-392.

Veldboom LR, Lee M. 1996. Genetic Mapping of Qunatitative Trait Loci in Maize in Stress and Nonstress Environments: II. Plant Height and Flowering. Crop Sci. 36(5):1320-1327.

Wray LV, Witte MM, Dickson RC, Riley MI. 1987. Characterization of a positive regulatory gene, LAC9, that controls induction of the lactose-galactose regulon of Kluyveromyces lactis: structural and functional relationships to GAL4 of Saccharomyces cerevisiae. Molecular and Cellular Biology 7(3):1111-1121.

Wyman CE, Dale BE, Elander RT, Holtzapple M, Ladisch MR, Lee YY. 2005a. Coordinated development of leading biomass pretreatment technologies. Bioresource Technology 96(18):1959-1966.

Wyman CE, Dale BE, Elander RT, Holtzapple M, Ladisch MR, Lee YY. 2005 b. Comparative sugar recovery data from laboratory scale application of leading pretreatment technologies to corn stover. Bioresource Technology 96(18):20262032. 


\section{Appendix A: Small Scale "Shake Flask" Experiments}

The experiments follow a sequential order

Experiment: YPGal-2\% Galactose "Shake Flask-Small Scale"

Date: November (1-4), 2011

\section{Purpose of the experiment:}

Measure $K$. lactis samples for galactose concentration in complex media YPGal. with 2\% $(\mathrm{w} / \mathrm{v})$ galactose concentration

Table A-1 Measurement of Galactose Concentration by using DNS assay into Galactose standard samples (November 8, 2011)

\begin{tabular}{|l|l|l|l|l|l|l|l|l|l|l|}
\hline $\begin{array}{l}2 \% \text { Galactose } \\
\begin{array}{l}\text { Concentration } \\
(\mathrm{mg} / \mathrm{ml})\end{array}\end{array}$ & $\begin{array}{l}2 \% \\
\text { Galactose } \\
\text { volume } \\
(\mathrm{ml})\end{array}$ & $\begin{array}{l}\mathrm{dH2O} \\
\text { volume } \\
(\mathrm{ml})\end{array}$ & $\begin{array}{l}\text { Dilution\#1 } \\
\text { concentration } \\
(\mathrm{mg} / \mathrm{ml})\end{array}$ & $\begin{array}{l}\text { Sample } \\
\text { volume } \\
(\mathrm{ml})\end{array}$ & $\begin{array}{l}\text { citrate } \\
\text { buffer } \\
\text { volume } \\
(\mathrm{ml})\end{array}$ & $\begin{array}{l}\mathrm{dH2O} \\
\text { volume } \\
(\mathrm{ml})\end{array}$ & $\begin{array}{l}\text { DNS } \\
\text { volume } \\
(\mathrm{ml})\end{array}$ & $\begin{array}{l}\text { Spectrometer } \\
\text { volume (ml) }\end{array}$ & $\begin{array}{l}\text { dH2O } \\
\text { volume } \\
(\mathrm{ml})\end{array}$ & $\begin{array}{l}\text { A @ } \\
540 \mathrm{~nm} \\
(\mathrm{O} . \mathrm{D})\end{array}$ \\
\hline 20 & 1 & 0 & 20 & 0.75 & 0.075 & 0.675 & 3 & 0.2 & 3 & 1.75 \\
\hline 20 & 1 & 0.5 & 13.33 & 0.75 & 0.075 & 0.675 & 3 & 0.2 & 3 & 1.46 \\
\hline 20 & 1 & 1 & 10 & 0.75 & 0.075 & 0.675 & 3 & 0.2 & 3 & 0.81 \\
\hline 20 & 1 & 2 & 6.66 & 0.75 & 0.075 & 0.675 & 3 & 0.2 & 3 & 0.81 \\
\hline 20 & 1 & 4 & 4 & 0.75 & 0.075 & 0.675 & 3 & 0.2 & 3 & 0.38 \\
\hline 20 & 1 & 6 & 2.85 & 0.75 & 0.075 & 0.675 & 3 & 0.2 & 3 & 0.42 \\
\hline 20 & 1 & 9 & 2 & 0.75 & 0.075 & 0.675 & 3 & 0.2 & 3 & 0.31 \\
\hline 20 & 1 & 19 & 1 & 0.75 & 0.075 & 0.675 & 3 & 0.2 & 3 & 0.16 \\
\hline 20 & 1 & 29 & 0.66 & 0.75 & 0.075 & 0.675 & 3 & 0.2 & 3 & 0.07 \\
\hline 20 & 1 & 39 & 0.5 & 0.75 & 0.075 & 0.675 & 3 & 0.2 & 3 & 0.07 \\
\hline 20 & 1 & 49 & 0.4 & 0.75 & 0.075 & 0.675 & 3 & 0.2 & 3 & 0.06 \\
\hline
\end{tabular}




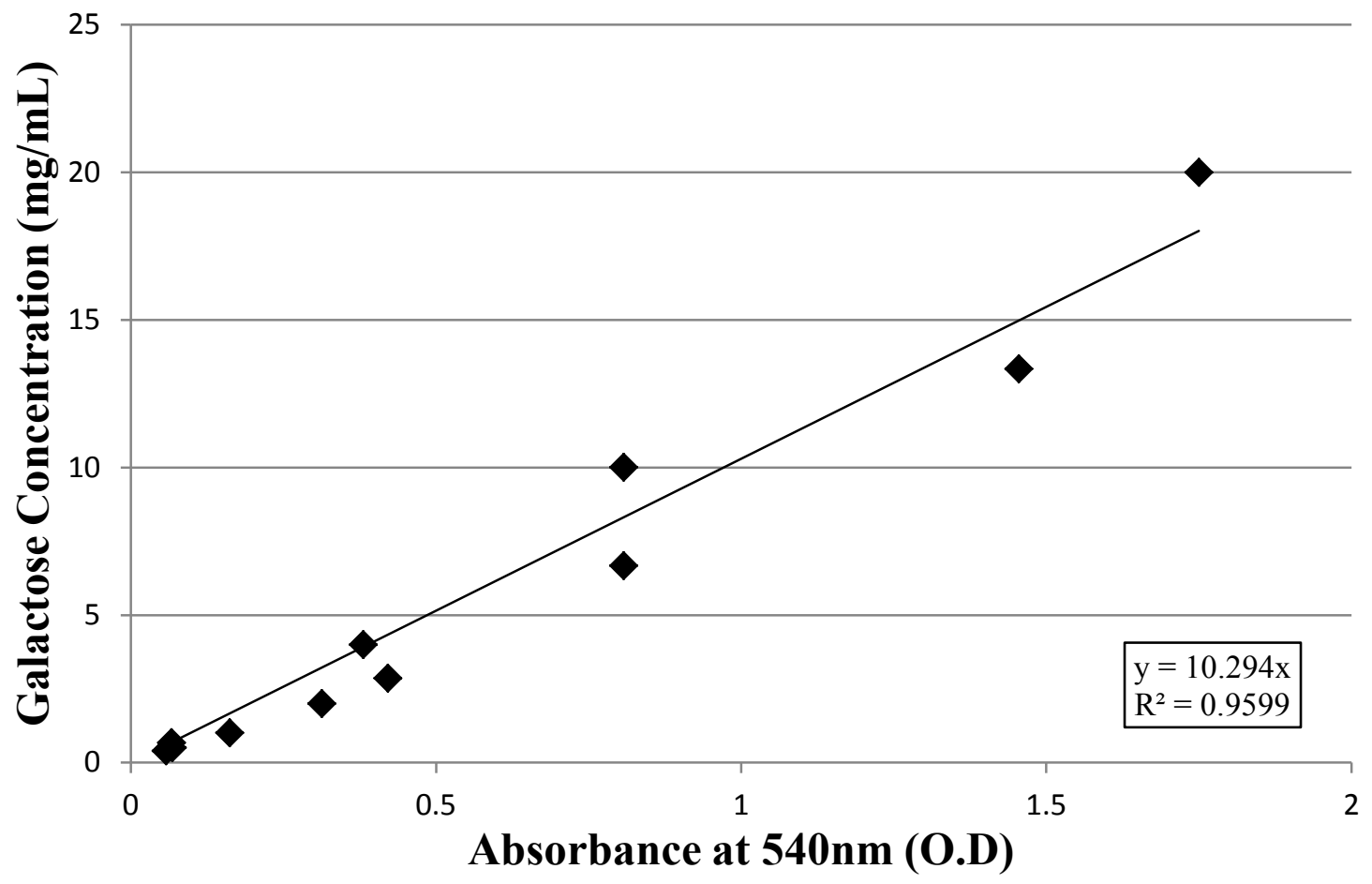

Figure A-1 Galactose Standard Curve-2\%, November 8, 2011 
Table A-2 Measurement of Galactose Concentration into YPGal-2\% Galactose samples by using DNS tool (November 4, 2011)

\begin{tabular}{|l|l|l|l|l|}
\hline Sample \# & Time (hours) & A@540nm (O.D) & Final A540nm(O.D) & $\begin{array}{l}\text { Galactose concentration } \\
(\mathrm{mg} / \mathrm{ml})\end{array}$ \\
\hline 1 & 0 & 1.148 & 1.088 & 11.194 \\
\hline 2 & 2 & 0.946 & 0.886 & 9.120 \\
\hline 3 & 4 & 1.135 & 1.075 & 11.066 \\
\hline 4 & 6 & 1.031 & 0.971 & 9.995 \\
\hline 5 & 8 & 1.065 & 1.005 & 10.345 \\
\hline 6 & 24 & 0.276 & 0.216 & 2.224 \\
\hline 7 & 26 & 0.189 & 0.129 & 1.323 \\
\hline 8 & 28 & 0.181 & 0.121 & 1.240 \\
\hline 9 & 30 & 0.180 & 0.120 & 1.235 \\
\hline 10 & 32 & 0.181 & 0.121 & 1.240 \\
\hline 11 & 47 & 0.157 & 0.097 & 0.993 \\
\hline 12 & 49 & 0.174 & 0.114 & 1.174 \\
\hline 13 & 51 & 0.176 & 0.116 & 1.194 \\
\hline 14 & 53 & 0.171 & 0.111 & 1.137 \\
\hline 15 & 55 & 0.160 & 0.100 & 1.029 \\
\hline 16 & $7 \mathrm{~B}$ & 0 & 0.035 & 0.360 \\
\hline 17 & No-Enz. & 0 & 0.000 & 0 \\
\hline
\end{tabular}


Experiment: YNB-2\% Galactose "Shake Flask-Small Scale"

Date: December 12, 2011

\section{Purpose:}

Measure $K$. lactis growth, and galactose concentration in minimal media YNB with 2\% $(w / v)$ galactose concentration

Table A-3 Measurement of Galactose Concentration by using DNS assay into Galactose standard samples (December 12, 2011)

\begin{tabular}{|l|l|l|l|l|l|l|l|l|l|l|}
\hline $\begin{array}{l}\text { YNB-2\% } \\
\text { Galactose } \\
\text { conc. } \\
(\mathrm{mg} / \mathrm{ml})\end{array}$ & $\begin{array}{l}2 \% \\
\text { Gala. } \\
\text { vol. } \\
(\mathrm{ml})\end{array}$ & $\begin{array}{l}\mathrm{dH}_{2} \mathrm{O} \\
\text { vol. } \\
(\mathrm{ml})\end{array}$ & $\begin{array}{l}\text { Dilu.\#1 } \\
\text { Conc. } \\
(\mathrm{mg} / \mathrm{ml})\end{array}$ & $\begin{array}{l}\text { Sample } \\
\text { volume } \\
(\mathrm{ml})\end{array}$ & $\begin{array}{l}\text { citrate } \\
\text { buffer } \\
\text { vol. } \\
(\mathrm{ml})\end{array}$ & $\begin{array}{l}\mathrm{dH}_{2} \mathrm{O} \\
\text { volume } \\
(\mathrm{ml})\end{array}$ & $\begin{array}{l}\text { DNS } \\
\text { Vol. } \\
(\mathrm{ml})\end{array}$ & $\begin{array}{l}\text { Spectrometer } \\
\text { Volume } \\
(\mathrm{ml})\end{array}$ & $\begin{array}{l}\mathrm{dH}_{2} \mathrm{O} \\
\text { vol. } \\
(\mathrm{ml})\end{array}$ & $\begin{array}{l}\mathrm{A} @ \\
540 \mathrm{~nm} \\
(\mathrm{O} . \mathrm{D})\end{array}$ \\
\hline 20 & 0 & 1 & 0 & 0.75 & 0.075 & 0.675 & 3 & 0.2 & 3 & 0.011 \\
\hline 20 & 1 & 0 & 20 & 0.75 & 0.075 & 0.675 & 3 & 0.2 & 3 & \\
\hline 20 & 1 & 0.5 & 13.33 & 0.75 & 0.075 & 0.675 & 3 & 0.2 & 3 & 0.893 \\
\hline 20 & 1 & 1 & 10 & 0.75 & 0.075 & 0.675 & 3 & 0.2 & 3 & 0.675 \\
\hline 20 & 1 & 2 & 6.66 & 0.75 & 0.075 & 0.675 & 3 & 0.2 & 3 & 0.536 \\
\hline 20 & 1 & 4 & 4 & 0.75 & 0.075 & 0.675 & 3 & 0.2 & 3 & 0.459 \\
\hline 20 & 1 & 6 & 2.85 & 0.75 & 0.075 & 0.675 & 3 & 0.2 & 3 & 0.298 \\
\hline 20 & 1 & 9 & 2 & 0.75 & 0.075 & 0.675 & 3 & 0.2 & 3 & 0.237 \\
\hline 20 & 1 & 19 & 1 & 0.75 & 0.075 & 0.675 & 3 & 0.2 & 3 & 0.158 \\
\hline 20 & 1 & 29 & 0.66 & 0.75 & 0.075 & 0.675 & 3 & 0.2 & 3 & 0.08 \\
\hline 20 & 1 & 39 & 0.5 & 0.75 & 0.075 & 0.675 & 3 & 0.2 & 3 & 0.047 \\
\hline 20 & 1 & 49 & 0.4 & 0.75 & 0.075 & 0.675 & 3 & 0.2 & 3 & 0.026 \\
\hline
\end{tabular}




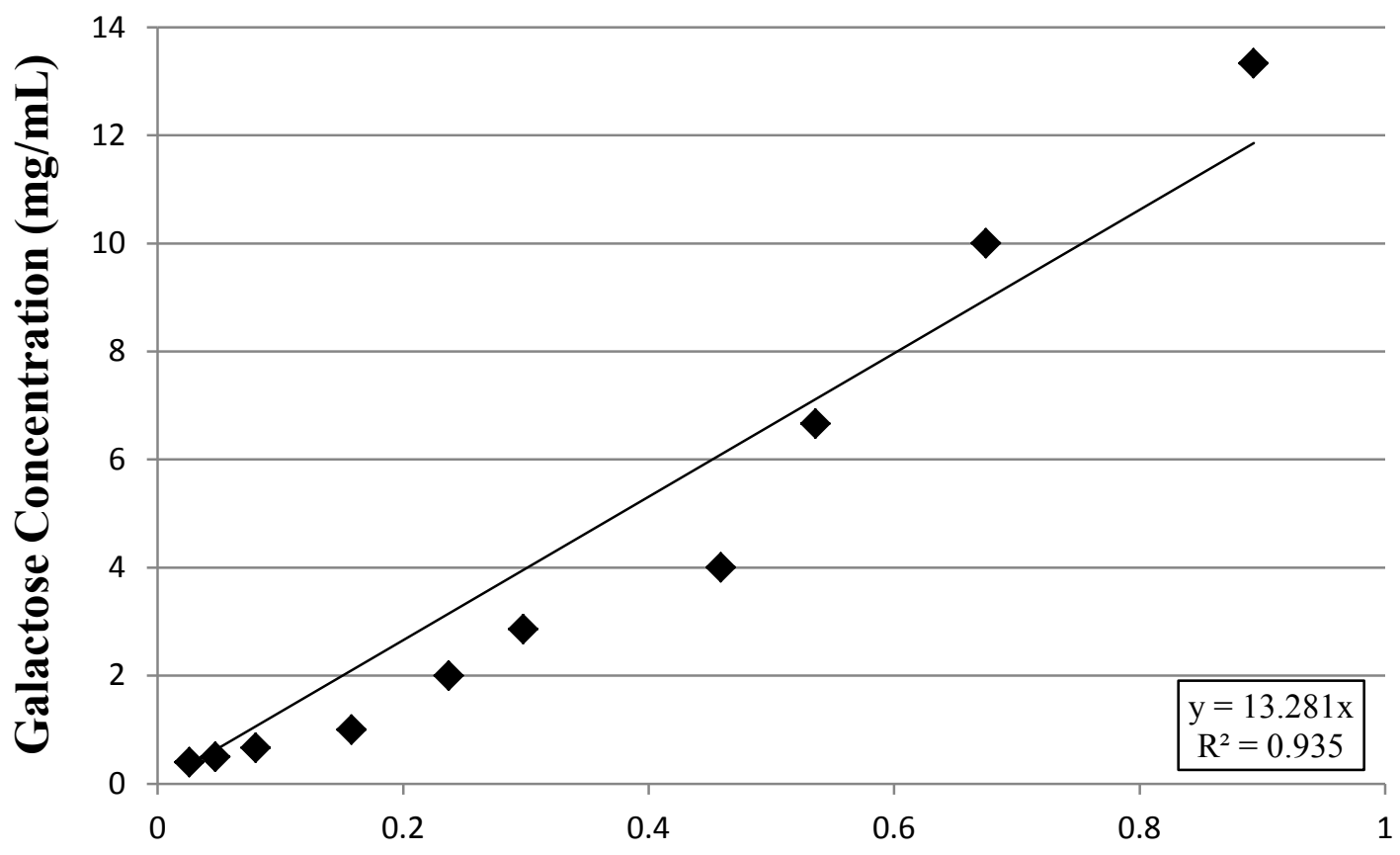

Absorbance 540nm (O.D)

Figure A-2 Galactose Standard Curve into experiment of growing yeast Cel7B intoYNB-2\% Galactose, December 12, 2011

Table A-4 Measurement of yeast growth density into YNB-2\% Galactose by using spectrometer (absorbance) at $600 \mathrm{~nm}$ (December 12, 2011)

\begin{tabular}{|l|l|l|}
\hline simple's number & simple's time(h) & Simple absorbance@600nm \\
\hline just YNB-2\%Gal & 0 & -0.003 \\
\hline 1 & 0 & 0.016 \\
\hline 2 & 2 & 0.016 \\
\hline 3 & 4 & 0.029 \\
\hline 4 & 21 & 1.14 \\
\hline 5 & 23 & 1.185 \\
\hline 6 & 25 & 1.198 \\
\hline 7 & 27 & 1.263 \\
\hline 8 & 29 & 1.295 \\
\hline 9 & 44 & 1.368 \\
\hline 10 & 46 & 1.385 \\
\hline 11 & 48 & 1.405 \\
\hline 12 & 50 & 1.415 \\
\hline 13 & 52 & 1.41 \\
\hline
\end{tabular}




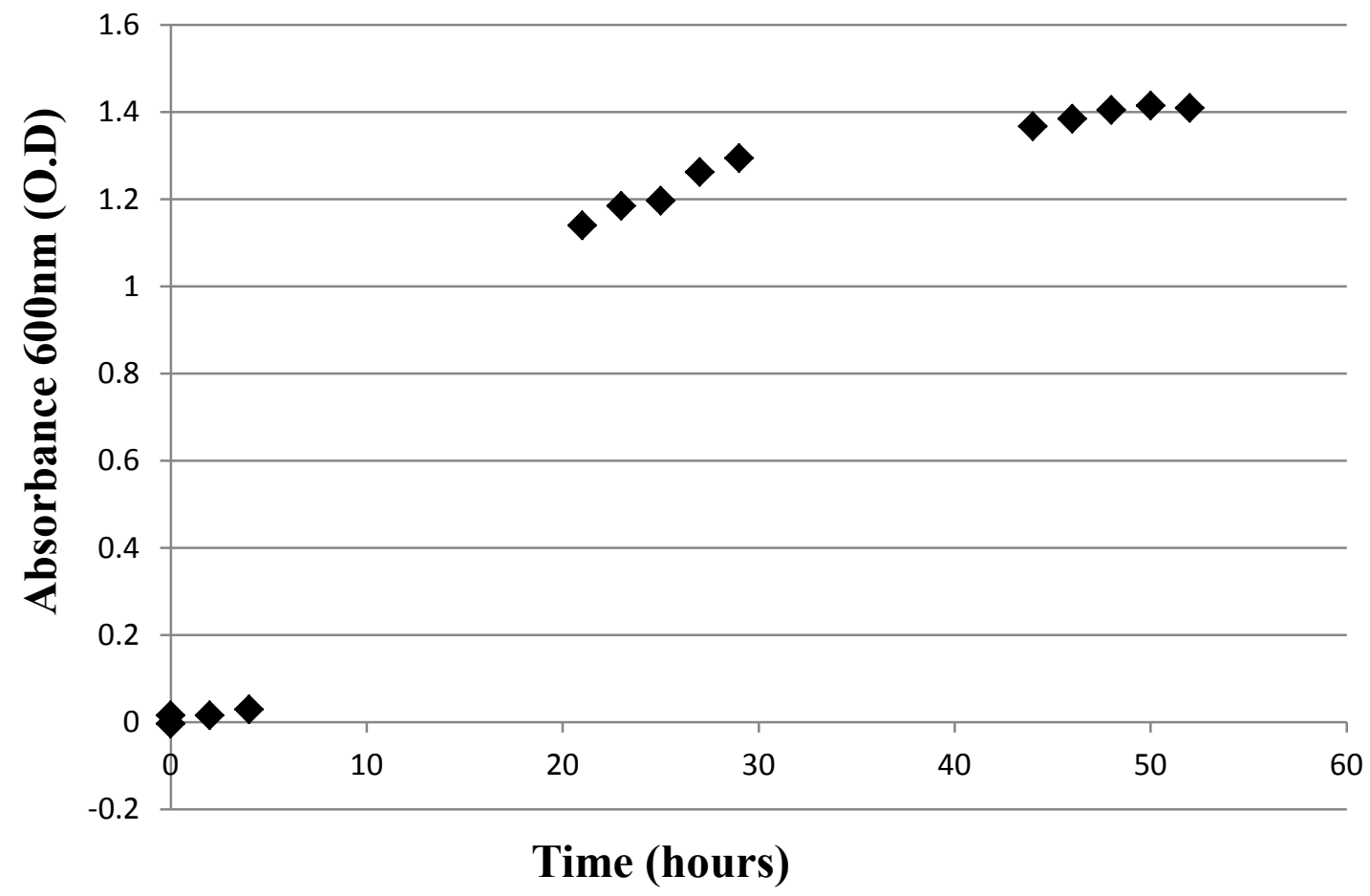

Figure A-3 K. lactis-Cel7B yeast growth density into YNB-2\% Galactose "Shake Flask-Small Scale", December 12, 2011 
Table A-5 Measurement of Galactose Concentration into YNB-2\% Galactose samples by using CMC/DNS tool (December 12, 2011)

\begin{tabular}{|l|l|l|l|l|l|l|l|l|ll|l|}
\hline $\mathrm{S} \#$ & $\begin{array}{l}\text { Time } \\
(\mathrm{H})\end{array}$ & $\begin{array}{l}\text { S. vol. } \\
(\mathrm{ml})\end{array}$ & $\begin{array}{l}\text { citrate } \\
\text { buffer } \\
(\mathrm{ml})\end{array}$ & $\begin{array}{l}\mathrm{dH}_{2} \mathrm{O} \\
(\mathrm{ml})\end{array}$ & $\begin{array}{l}\mathrm{DNS} \\
(\mathrm{ml})\end{array}$ & $\begin{array}{l}\text { Spectrometer } \\
\text { mix volume } \\
(\mathrm{ml})\end{array}$ & $\begin{array}{l}\text { (H) } \\
(\mathrm{ml})\end{array}$ & $\begin{array}{l}\text { A@540 } \\
(\mathrm{O} . \mathrm{D})\end{array}$ & $\begin{array}{l}\text { Net } \\
\text { @540nm } \\
(\mathrm{O} . \mathrm{D})\end{array}$ & $\begin{array}{l}\text { Gal. } \\
\text { Conc. } \\
(\mathrm{mg} / \mathrm{ml})\end{array}$ \\
\hline $\mathrm{dH} 2 \mathrm{O}$ & & 0.75 & 0.075 & 0.675 & 3 & 0.2 & 3 & 0.02 & 0 & 0 \\
\hline 1 & 0 & 0.75 & 0.075 & 0.675 & 3 & 0.2 & 3 & 1.33 & 1.31 & 17.43 \\
\hline 2 & 2 & 0.75 & 0.075 & 0.675 & 3 & 0.2 & 3 & 1.30 & 1.28 & 16.99 \\
\hline 3 & 4 & 0.75 & 0.075 & 0.675 & 3 & 0.2 & 3 & 1.33 & 1.31 & 17.43 \\
\hline 4 & 21 & 0.75 & 0.075 & 0.675 & 3 & 0.2 & 3 & 1.20 & 1.18 & 15.70 \\
\hline 5 & 23 & 0.75 & 0.075 & 0.675 & 3 & 0.2 & 3 & 1.18 & 1.16 & 15.43 \\
\hline 6 & 25 & 0.75 & 0.075 & 0.675 & 3 & 0.2 & 3 & 1.12 & 1.10 & 14.64 \\
\hline 7 & 27 & 0.75 & 0.075 & 0.675 & 3 & 0.2 & 3 & 1.11 & 1.09 & 14.54 \\
\hline 8 & 29 & 0.75 & 0.075 & 0.675 & 3 & 0.2 & 3 & 1.10 & 1.08 & 14.40 \\
\hline 9 & 44 & 0.75 & 0.075 & 0.675 & 3 & 0.2 & 3 & 0.46 & 0.44 & 5.89 \\
\hline 10 & 46 & 0.75 & 0.075 & 0.675 & 3 & 0.2 & 3 & 0.55 & 0.53 & 7.07 \\
\hline 11 & 48 & 0.75 & 0.075 & 0.675 & 3 & 0.2 & 3 & 0.47 & 0.44 & 5.96 \\
\hline 12 & 50 & 0.75 & 0.075 & 0.675 & 3 & 0.2 & 3 & 0.35 & 0.33 & 4.47 \\
\hline 13 & 52 & 0.75 & 0.075 & 0.675 & 3 & 0.2 & 3 & 0.32 & 0.30 & 4.01 \\
\hline
\end{tabular}




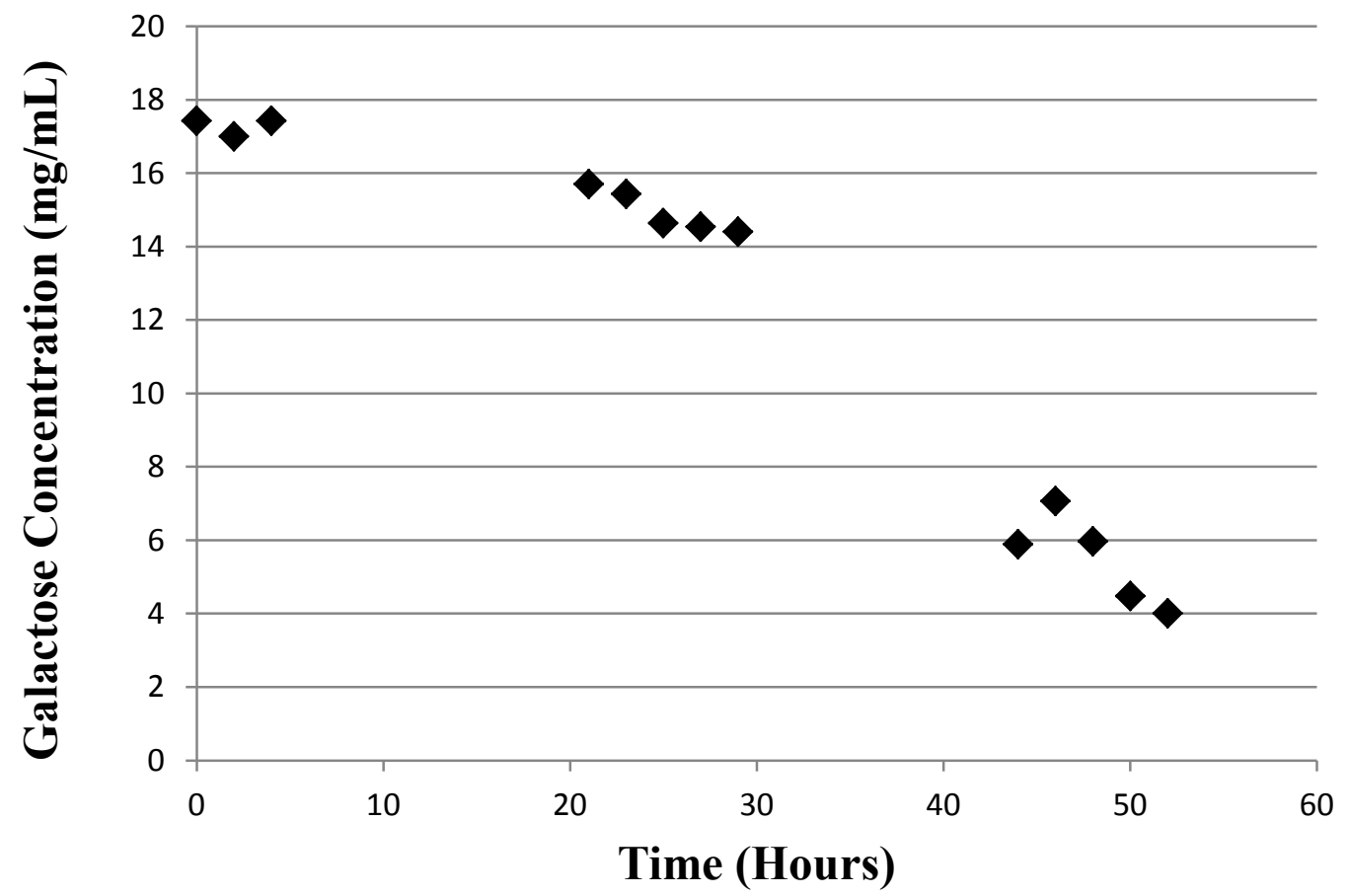

Figure A-4 Galactose Concentration into YNB-2\% Galactose "Shake Flask-Small Scale", December 12, 2011 
Experiment: YPGal-2\% Galactose and YNB-2\% Galactose "Shake Flask-Small Scale"

Date: January 9, 2012

Table A- 6 Experiments Conducted in Small-Scale Culture of K. lactis Cel7B

\begin{tabular}{|c|l|l|l|l|}
\hline Date & $\begin{array}{l}\text { Type of } \\
\text { media }\end{array}$ & $\begin{array}{l}\text { Galactose } \\
\text { concentration }\end{array}$ & $\begin{array}{l}\text { Culturing } \\
\text { time }\end{array}$ & \multicolumn{1}{c|}{ Purpose } \\
\hline $\begin{array}{l}\text { Jan 9, } \\
2012\end{array}$ & $\begin{array}{l}\text { Complex } \\
\text { media } \\
\text { YPGal. }\end{array}$ & $\begin{array}{l}2 \%(\mathrm{w} / \mathrm{v})-20 \\
\mathrm{mg} / \mathrm{mL}\end{array}$ & 26 hours & $\begin{array}{l}\text { Measure } K \text {. lactis growth in complex media YPGal with } 2 \%(\mathrm{w} / \mathrm{v}) \\
\text { galactose concentration }\end{array}$ \\
\hline $\begin{array}{l}\text { Jan } 9, \\
2012\end{array}$ & $\begin{array}{l}\text { Minimal } \\
\text { media } \\
\text { YNB }\end{array}$ & $\begin{array}{l}2 \%(\mathrm{w} / \mathrm{v})-20 \\
\mathrm{mg} / \mathrm{mL}\end{array}$ & 52 hours & $\begin{array}{l}\text { Measure } \text { K. lactis growth in minimal media YNB with } 2 \%(\mathrm{w} / \mathrm{v}) \\
\text { galactose concentration }\end{array}$ \\
\hline
\end{tabular}

Table A-7 Measurement of yeast growth density into YNB-2\% Galactose and YPGal.-2\% Galactose by using spectrometer (absorbance) at $600 \mathrm{~nm}$ (January 9 , 2012)

\begin{tabular}{|l|l|l|l|}
\hline \multicolumn{2}{|c|}{ YNB-2\% Galactose } & \multicolumn{2}{c|}{ YPGal-2\%Galactose } \\
\hline Time(h) & Absorbance@600nm & Time(h) & Absorbance @600 nm \\
\hline 0 & 0.003 & 0 & 0.06 \\
\hline 2 & 0 & 2 & 0.059 \\
\hline 4 & 0.018 & 4 & 0.075 \\
\hline 22 & 1.034 & 22 & 1.46 \\
\hline 24 & 1.13 & 24 & 1.51 \\
\hline 26 & 1.22 & 26 & 1.61 \\
\hline 28 & 1.27 & 28 & 1.62 \\
\hline 46 & 1.375 & 46 & 1.74 \\
\hline
\end{tabular}




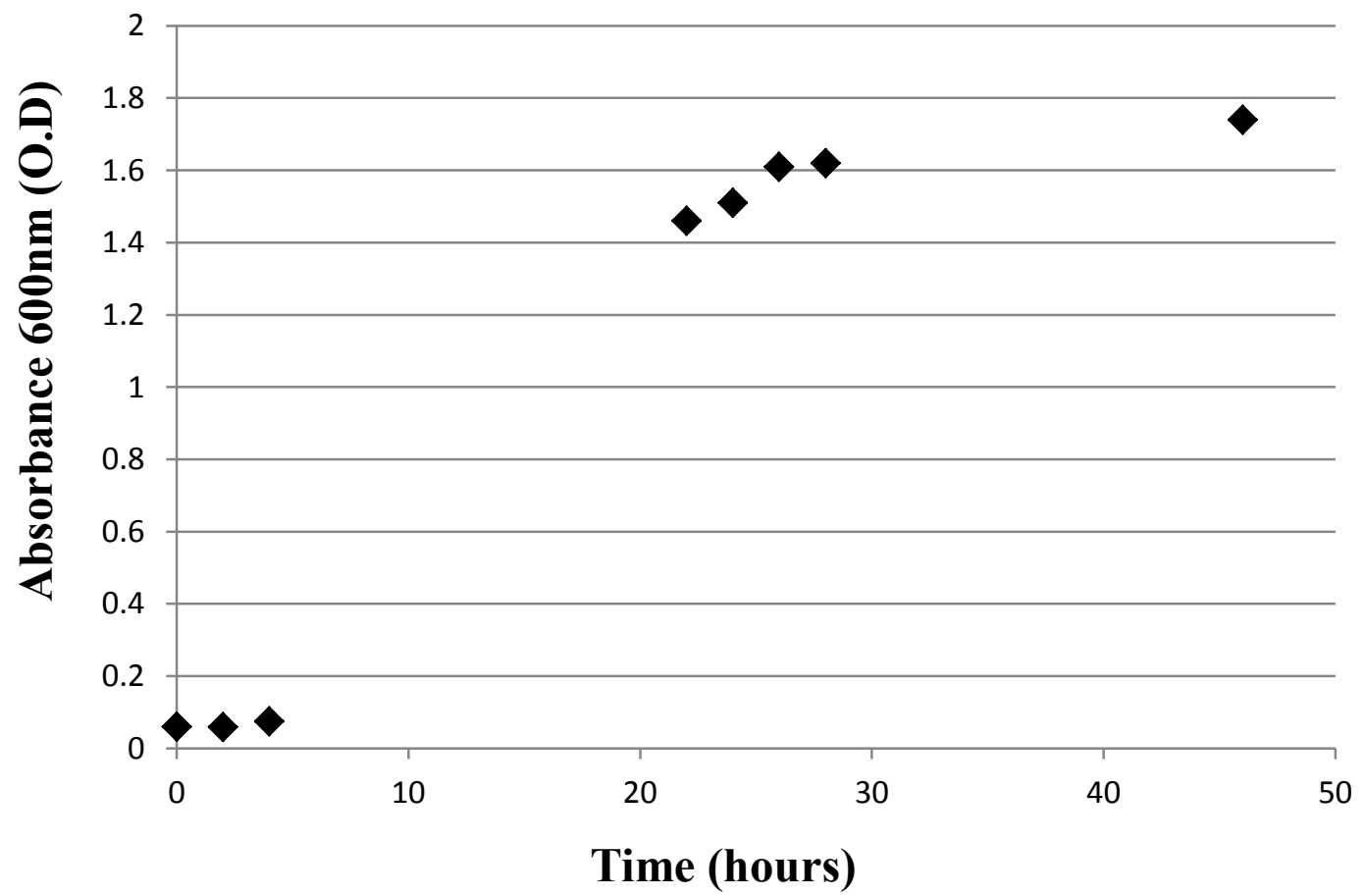

Figure A-5 K. lactis-Cel7B yeast growth density into YPGal.-2\% Galactose "Shake Flask-Small Scale", January 9, 2012 


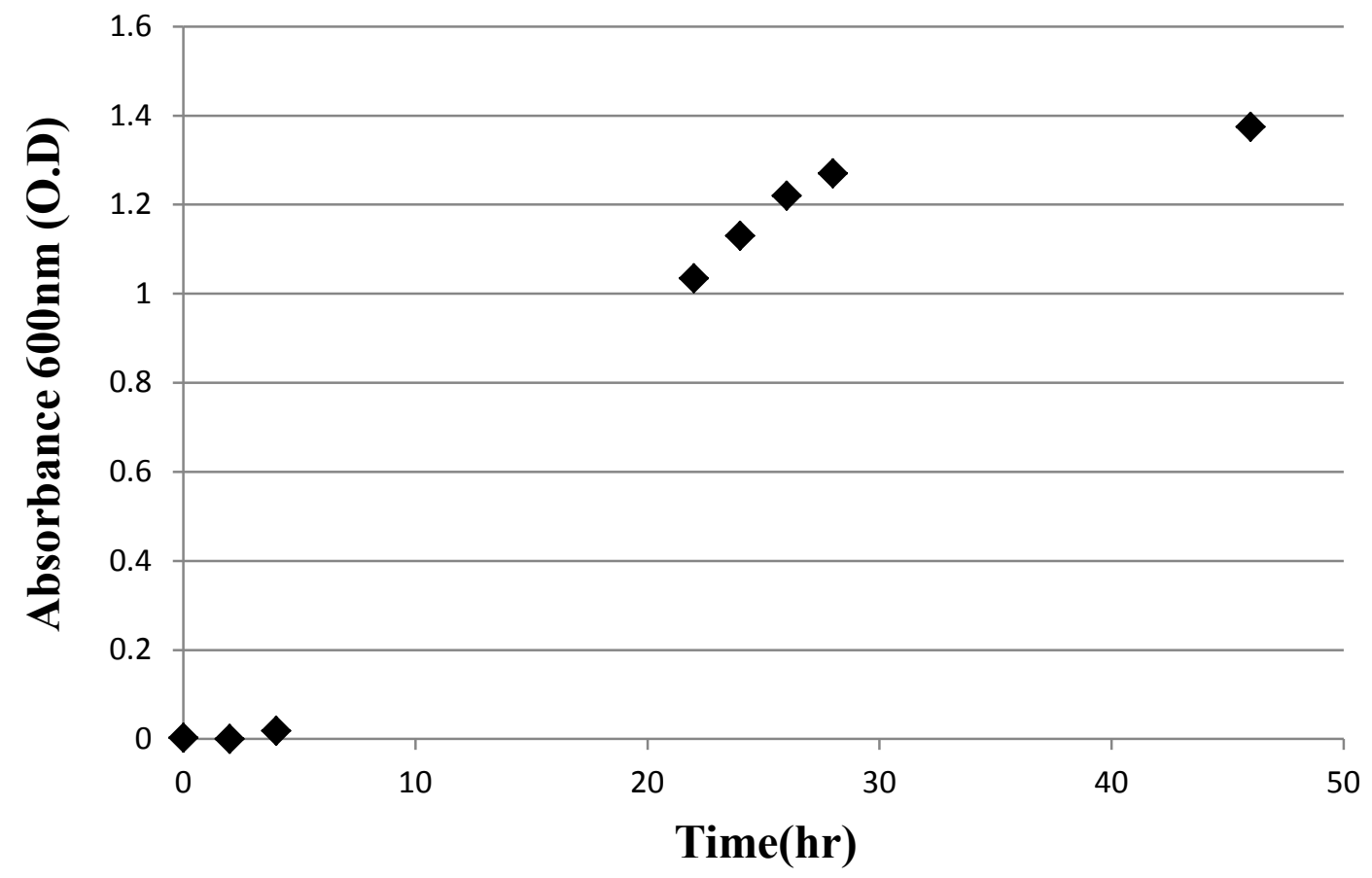

Figure A-6 K. lactis-Cel7B yeast growth density into YNB-2\% Galactose "Shake Flask-Small Scale", January 9, 2012 
Experiment: YBC-2\% Galactose "Shake Flask-Small Scale"

Date: Tuesday, March 6, 2012

\section{Purpose:}

Measure $K$. lactis growth, galactose concentration, and recombinant Cel7B enzyme activity in minimal media YBC with $2 \%(\mathrm{w} / \mathrm{v})$ galactose concentration

Table A-8 Measurement of yeast growth density into YBC-2\% Galactose by using spectrometer (absorbance) at $600 \mathrm{~nm}$ (March 6, 2012)

\begin{tabular}{|l|l|}
\hline \multicolumn{2}{|c|}{ YBC-2\%Galactose } \\
\hline Time(h) & absorbance @600nm \\
\hline 0 & 0.009 \\
\hline 4 & 0.022 \\
\hline 8 & 0.118 \\
\hline 12 & 0.568 \\
\hline 24 & 1.58 \\
\hline 28 & 1.63 \\
\hline 32 & 1.65 \\
\hline 36 & 1.66 \\
\hline 48 & 1.68 \\
\hline 52 & 1.7 \\
\hline
\end{tabular}




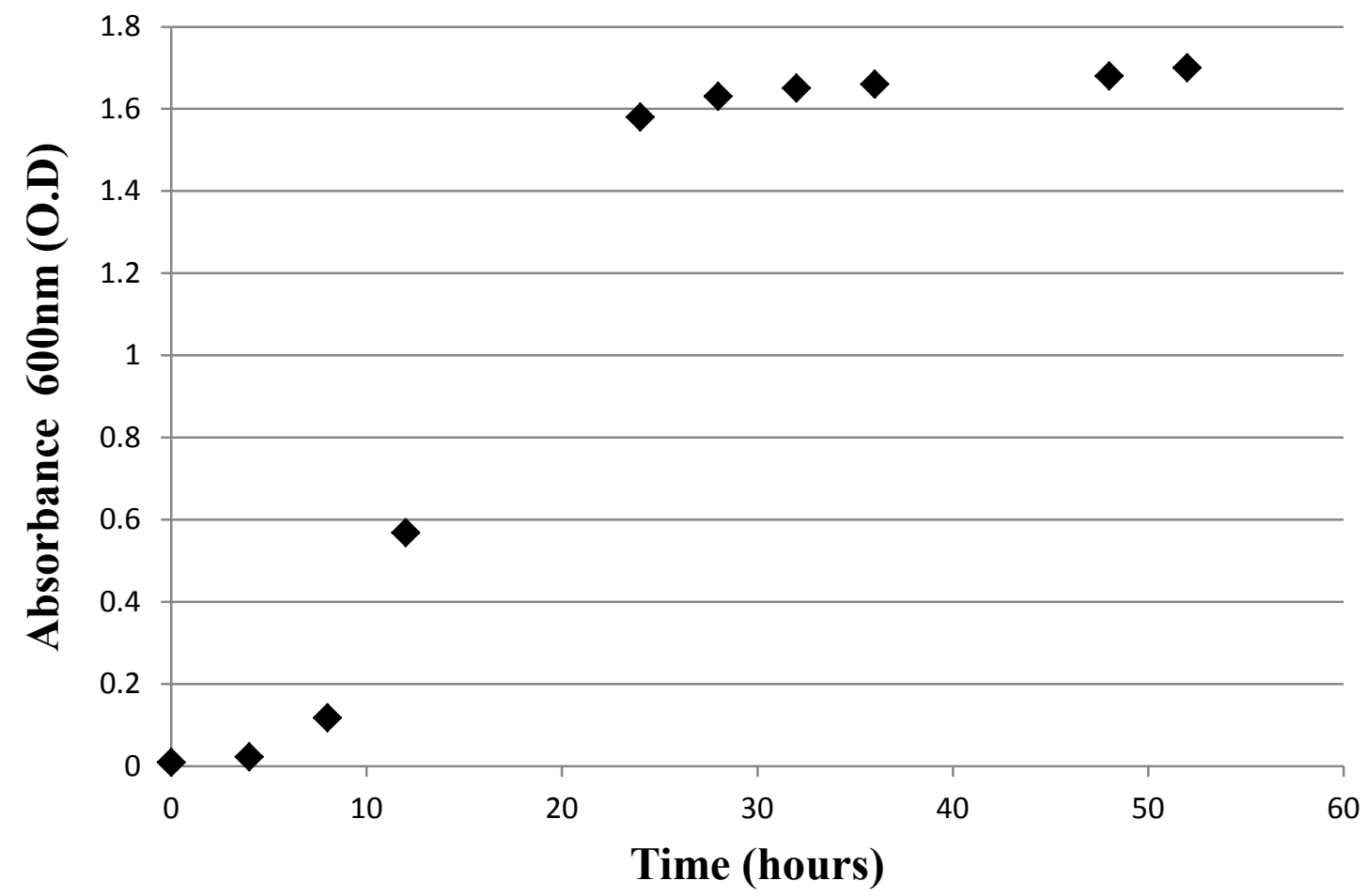

Figure A-7 K. lactis-Cl7B yeast growth density into YBC-2\% Galactose "Shake Flask-Small Scale", March 6, 2012

Table A-9 Measurement of Galactose Concentration by using CMC/DNS assay into Galactose standard samples (March 6, 2012)

\begin{tabular}{|l|l|l|l|}
\hline Sample number & Sample name & Galactose conc. $(\mathrm{mg} / \mathrm{ml})$ & Absorbance @ $595 \mathrm{~nm}$ \\
\hline 1 & GS $20 \mathrm{mg} / \mathrm{ml}$ & 20 & 1.9 \\
\hline 2 & GS $10 \mathrm{mg} / \mathrm{m}$ & 10 & 1.213 \\
\hline 3 & GS $5 \mathrm{mg} / \mathrm{ml}$ & 5 & 0.705 \\
\hline 4 & GS $2 \mathrm{mg} / \mathrm{ml}$ & 2 & 0.272 \\
\hline 5 & GS $1 \mathrm{mg} / \mathrm{ml}$ & 1 & 0.109 \\
\hline 6 & GS $0 \mathrm{mg} / \mathrm{ml}$ & 0 & 0 \\
\hline
\end{tabular}




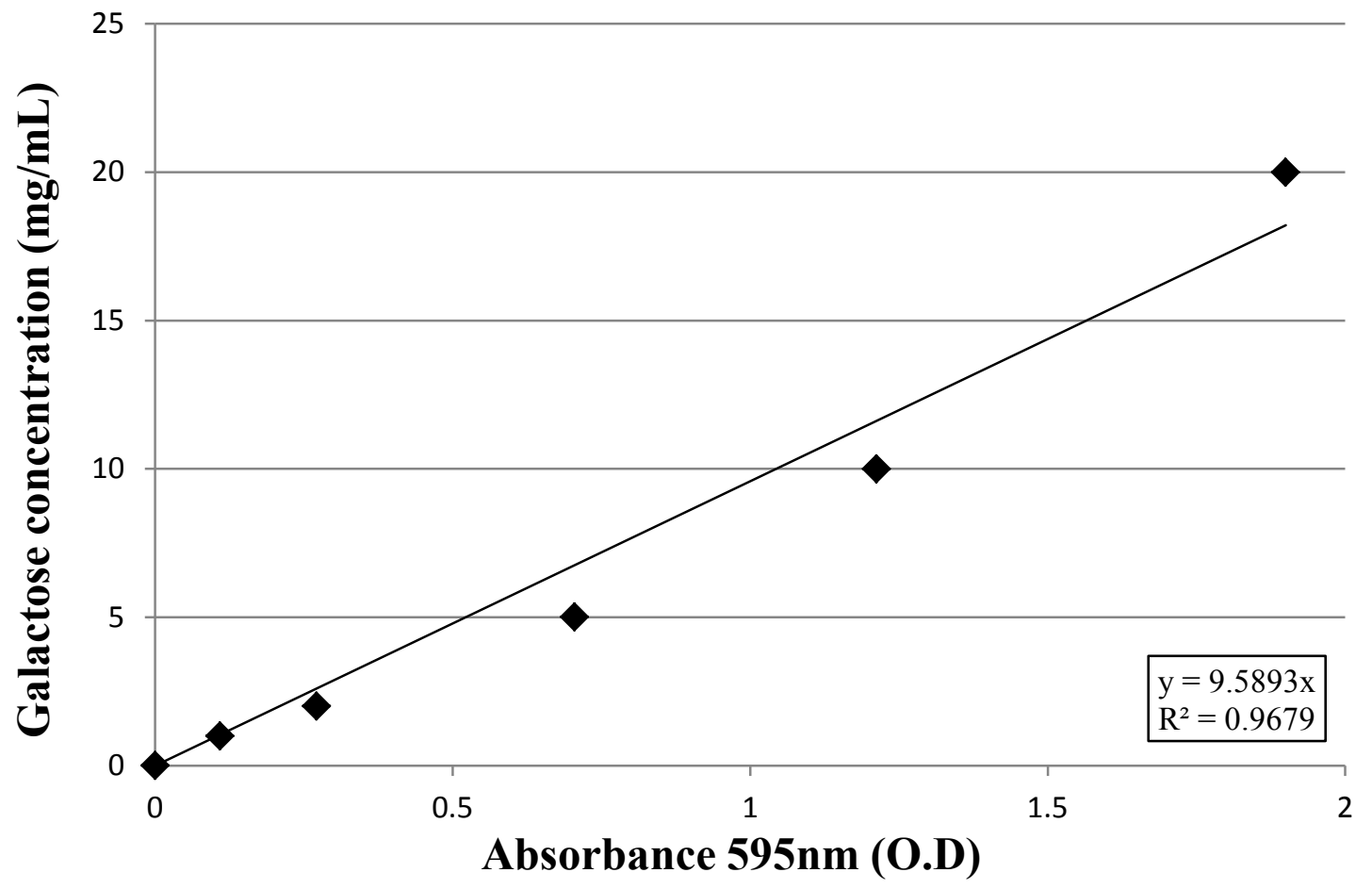

Figure A-8 Galactose Standard Curve into experiment of growing yeast Cel7B intoYBC-2\% Galactose, March 6, 2012

\section{Some definitions:}

- Net Absorbance (O.D):

Absorbance of enzyme sample with $\mathrm{CMC}$ - Absorbance of enzyme sample without CMC

- Net Galactose Concentration (mg/mL):

Net Absorbance of enzyme sample * Slope of Galactose Standard Curve

- Galactose Consumption (mg/mL):

Absorbance of enzyme sample without CMC * Slope of Galactose Standard Curve

- Volumetric Activity (mg/mL*hr):

Net Galactose Concentration (mg/mL) /1 (hr) 
Table A-10 Measurement of Galactose Concentration and Net Activity of Enzyme into YBC-2\% Galactose samples by using CMC/DNS tool (March 6, 2012)

\begin{tabular}{|c|c|c|c|c|c|c|c|}
\hline Sample & Time (hours) & A595nm & $\begin{array}{l}\text { Final } \\
\text { A595nm }\end{array}$ & $\begin{array}{l}\text { Net } \\
\text { A595nm }\end{array}$ & $\begin{array}{l}\text { Net Galactose } \\
\text { conc. }(\mathrm{mg} / \mathrm{ml})\end{array}$ & $\begin{array}{l}\text { Galactose } \\
\text { Consumption } \\
(\mathrm{mg} / \mathrm{ml})\end{array}$ & $\begin{array}{l}\text { Volumetric } \\
\text { activity of } \\
\text { Enzyme } \\
\left(\mathrm{mg} / \mathrm{ml}^{*} \mathrm{~h}\right)\end{array}$ \\
\hline YBC & 0 & 1.6 & 1.595 & -0.054 & -0.517 & & -0.517 \\
\hline YBC & 4 & 1.65 & 1.645 & -0.194 & -1.860 & & -1.860 \\
\hline YBC & 8 & 1.65 & 1.645 & -0.034 & -0.326 & & -0.326 \\
\hline YBC & 12 & 1.55 & 1.545 & -0.054 & -0.517 & & -0.517 \\
\hline YBC & 24 & 0.215 & 0.21 & 0.007 & 0.067 & & 0.067 \\
\hline YBC & 28 & 0.021 & 0.016 & 0.012 & 0.115 & & 0.115 \\
\hline YBC & 32 & 0.029 & 0.024 & 0.016 & 0.153 & & 0.153 \\
\hline YBC & 36 & 0.023 & 0.018 & 0.013 & 0.124 & & 0.124 \\
\hline YBC & 48 & 0.063 & 0.058 & 0.052 & 0.498 & & 0.498 \\
\hline YBC & 52 & 0.1 & 0.095 & 0.087 & 0.834 & & 0.834 \\
\hline $7 \mathrm{~B}$ & 0 & 0.231 & 0.226 & 0.211 & 2.023 & & 2.023 \\
\hline no-Enz. & 0 & 0.005 & 0 & 0 & 0 & & 0 \\
\hline YBC & 0 & 1.65 & 1.649 & & & 15.812 & \\
\hline YBC & 4 & 1.84 & 1.839 & & & 17.634 & \\
\hline YBC & 8 & 1.68 & 1.679 & & & 16.100 & \\
\hline YBC & 12 & 1.6 & 1.599 & & & 15.333 & \\
\hline YBC & 24 & 0.204 & 0.203 & & & 1.946 & \\
\hline YBC & 28 & 0.005 & 0.004 & & & 0.038 & \\
\hline YBC & 32 & 0.009 & 0.008 & & & 0.076 & \\
\hline YBC & 36 & 0.006 & 0.005 & & & 0.047 & \\
\hline YBC & 48 & 0.007 & 0.006 & & & 0.057 & \\
\hline YBC & 52 & 0.009 & 0.008 & & & 0.076 & \\
\hline $7 \mathrm{~B}$ & 0 & 0.016 & 0.015 & & & 0.143 & \\
\hline no-Enz. & 0 & 0.001 & 0 & & & 0 & \\
\hline
\end{tabular}


Experiment: YPGal-1\% Galactose and YBC-1\% Galactose "Shake Flask-Small Scale" Date: March 28, 2012

Table A-11 Experiments Conducted in Small-Scale Culture of K. lactis Cel7B

\begin{tabular}{|c|l|l|l|l|}
\hline Date & $\begin{array}{l}\text { Type of } \\
\text { media }\end{array}$ & $\begin{array}{l}\text { Galactose } \\
\text { concentration }\end{array}$ & $\begin{array}{l}\text { Culturing } \\
\text { time }\end{array}$ & \multicolumn{1}{c|}{ Purpose } \\
\hline $\begin{array}{l}\text { Marc } \\
\mathrm{h} 28, \\
2012\end{array}$ & $\begin{array}{l}\text { Complex } \\
\text { media }\end{array}$ & $\begin{array}{l}\text { YPGal. } \\
\mathrm{mg} / \mathrm{mL} / \mathrm{v})-10\end{array}$ & 28 hours & $\begin{array}{l}\text { Measure } K \text {. lactis growth, galactose concentration, and recombinant } \\
\text { Cel7B enzyme activity in complex media YPGal with } 1 \%(\mathrm{w} / \mathrm{v}) \\
\text { galactose concentration }\end{array}$ \\
\hline $\begin{array}{l}\text { Marc } \\
\mathrm{h} 28,\end{array}$ & $\begin{array}{l}\text { Minimal } \\
\text { media }\end{array}$ & $\begin{array}{l}1 \%(\mathrm{w} / \mathrm{v})-10 \\
\mathrm{mg} / \mathrm{mL}\end{array}$ & 25 hours & $\begin{array}{l}\text { Measure } K \text {. lactis growth, galactose concentration, and recombinant } \\
\text { Cel7B enzyme activity in minimal media YBC with } 1 \%(\mathrm{w} / \mathrm{v}) \text { galactose } \\
\text { concentration }\end{array}$ \\
\hline
\end{tabular}

Table A-12 Measurement of Galactose Concentration by using CMC/DNS assay into Galactose standard samples (March 28, 2012)

\begin{tabular}{|l|l|l|l|l|l|l|l|l|l|l|}
\hline S \# & $\begin{array}{l}\text { Sample } \\
\text { name }\end{array}$ & $\begin{array}{l}\text { Gal. } \\
\text { conc. } \\
(\mathrm{mg} / \mathrm{ml})\end{array}$ & $\begin{array}{l}\text { Gal. } \\
\text { perc. } \\
(\%)\end{array}$ & $\begin{array}{l}\text { Sample } \\
\text { vol. } \\
(\mathrm{ml})\end{array}$ & $\begin{array}{l}\mathrm{CMC} \\
(2 \%) \text { vol. } \\
(\mathrm{ml})\end{array}$ & $\begin{array}{l}\text { Citrate } \\
\text { buffer }(1 \mathrm{M}) \\
\text { vol. }(\mathrm{ml})\end{array}$ & $\begin{array}{l}\mathrm{dH}_{2} \mathrm{O} \\
\text { vol. } \\
(\mathrm{ml})\end{array}$ & $\begin{array}{l}\mathrm{DNS} \\
\text { vol. } \\
(\mathrm{ml})\end{array}$ & $\begin{array}{l}\mathrm{dH}_{2} \mathrm{O} \\
\text { vol. } \\
(\mathrm{ml})\end{array}$ & $\begin{array}{l}\mathrm{A} \\
540 \mathrm{~nm} \\
(\mathrm{O} . \mathrm{D})\end{array}$ \\
\hline 1 & GS $20 \mathrm{mg} / \mathrm{ml}$ & 20 & 2 & 0.45 & 0 & 0.05 & 0.5 & 3 & 20 & 1.999 \\
\hline 2 & GS $10 \mathrm{mg} / \mathrm{m}$ & 10 & 1 & 0.45 & 0 & 0.05 & 0.5 & 3 & 20 & 1.999 \\
\hline 3 & GS $5 \mathrm{mg} / \mathrm{ml}$ & 5 & 0.5 & 0.45 & 0 & 0.05 & 0.5 & 3 & 20 & 1.62 \\
\hline 4 & GS $2 \mathrm{mg} / \mathrm{ml}$ & 2 & 0.2 & 0.45 & 0 & 0.05 & 0.5 & 3 & 20 & 0.726 \\
\hline 5 & GS $1 \mathrm{mg} / \mathrm{ml}$ & 1 & 0.1 & 0.45 & 0 & 0.05 & 0.5 & 3 & 20 & 0.243 \\
\hline 6 & GS $0 \mathrm{mg} / \mathrm{ml}$ & 0 & 0 & 0 & 0 & 0.05 & 0.95 & 3 & 20 & 0.032 \\
\hline
\end{tabular}




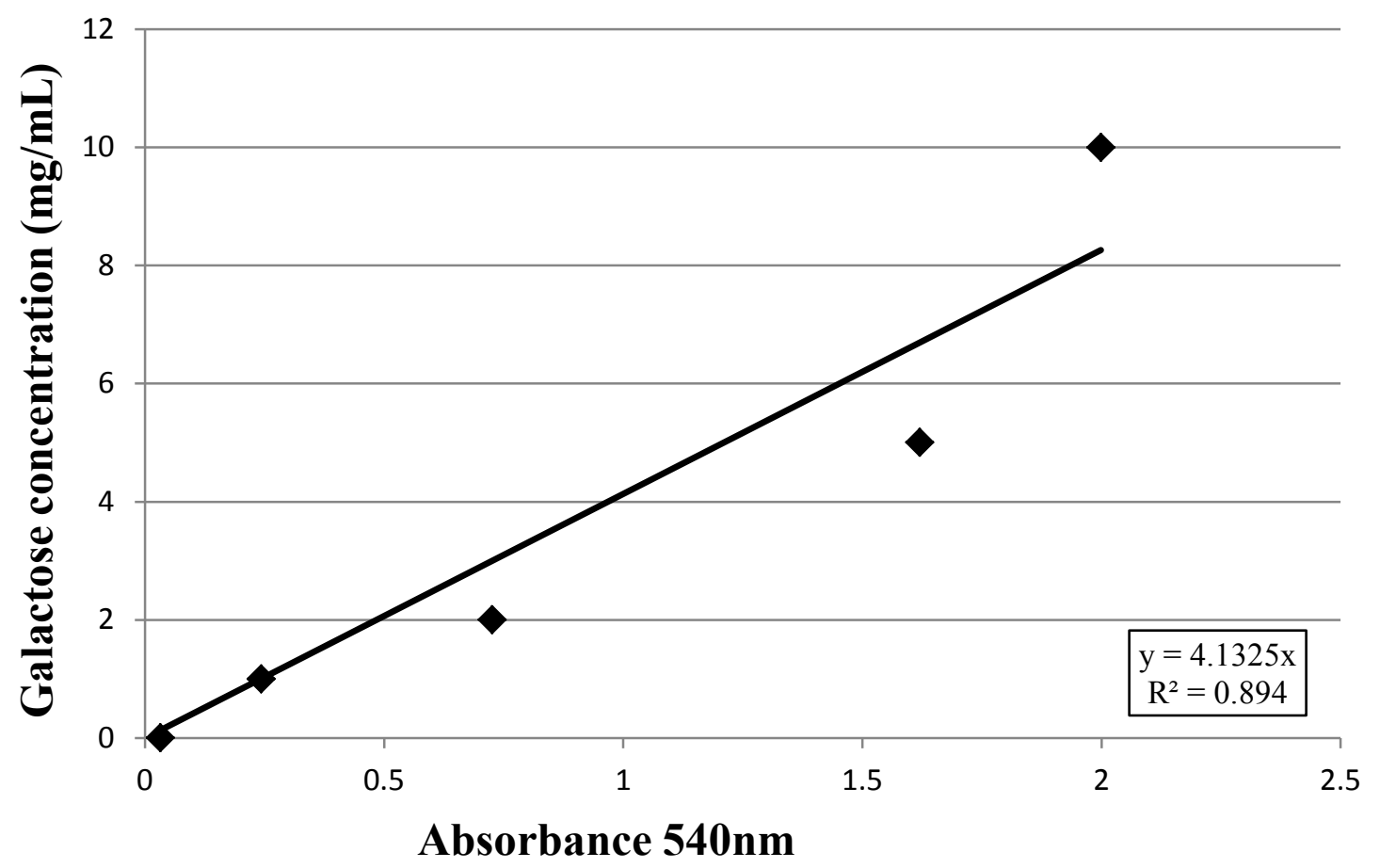

Figure A-9 Galactose calibration standard using the DNS assay, March 28, 2012

Table A-13 Measurement of yeast growth density into YBC-1\% Galactose samples and YPGal.-1\% Galactose samples (Day) by using spectrometer (absorbance) at 600 nm (March 28, 2012)

\begin{tabular}{|l|l|l|l|}
\hline YPGal.-1\% Gal. & YBC-1\% Gal. \\
\hline sample's time(day) & $\begin{array}{l}\text { Absorbance (O.D) } \\
@ 600 \mathrm{~nm}\end{array}$ & sample's time(day) & $\begin{array}{l}\text { Absorbance (O.D) } \\
@ \text { 600nm }\end{array}$ \\
\hline Just YPGal. & 0 & just YNB & 0 \\
\hline 0 & 0.001 & 0 & 0 \\
\hline 1 & 1.363 & 1 & 1.4 \\
\hline 2 & 1.633 & 2 & 1.58 \\
\hline 3 & 1.653 & 3 & 1.63 \\
\hline
\end{tabular}




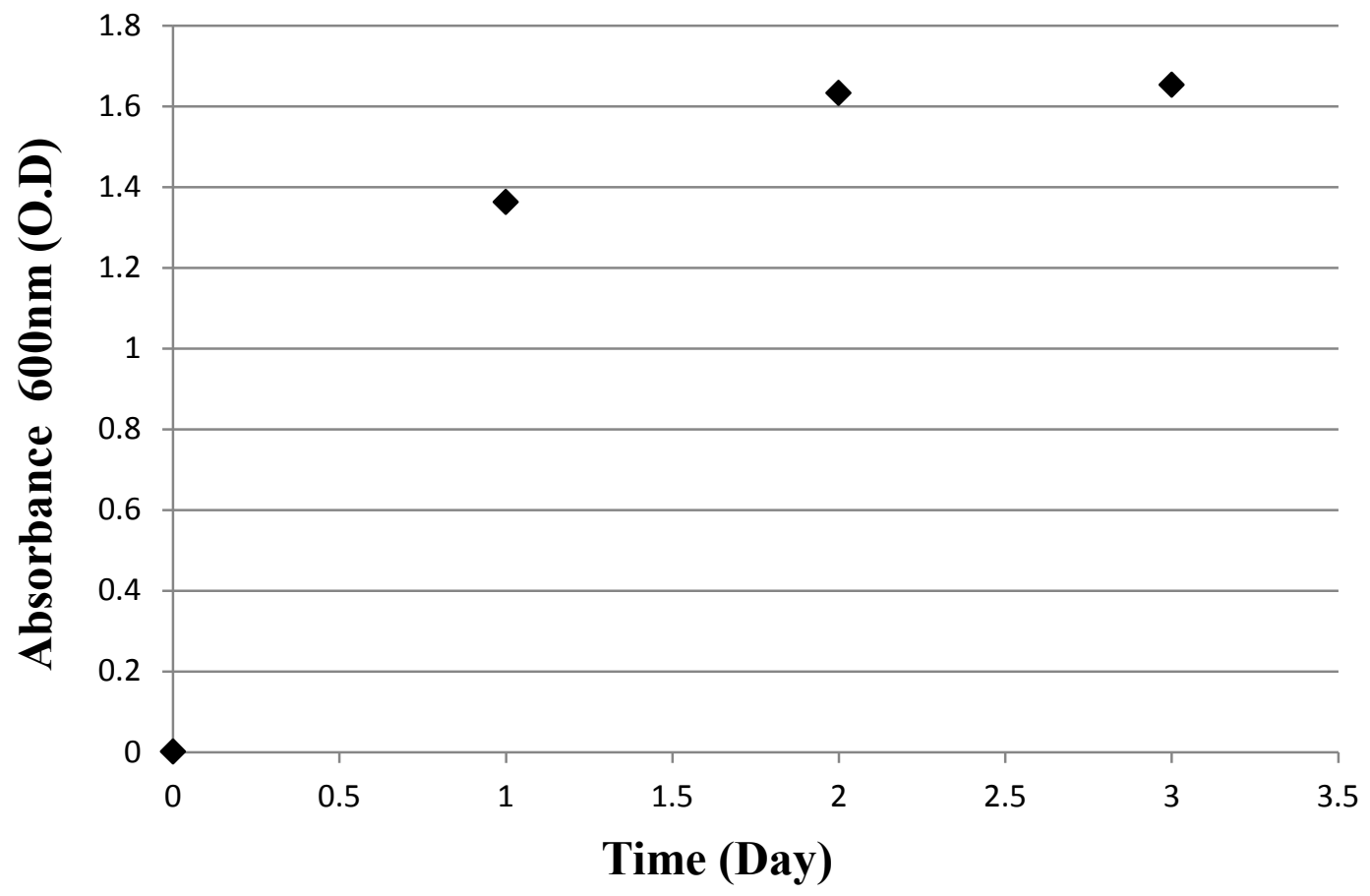

Figure A-10 K. lactis- Cel7B yeast growth density into YPGal-1\% Galactose samples (Day) "Shake Flask-Small Scale", March 27, 2012 


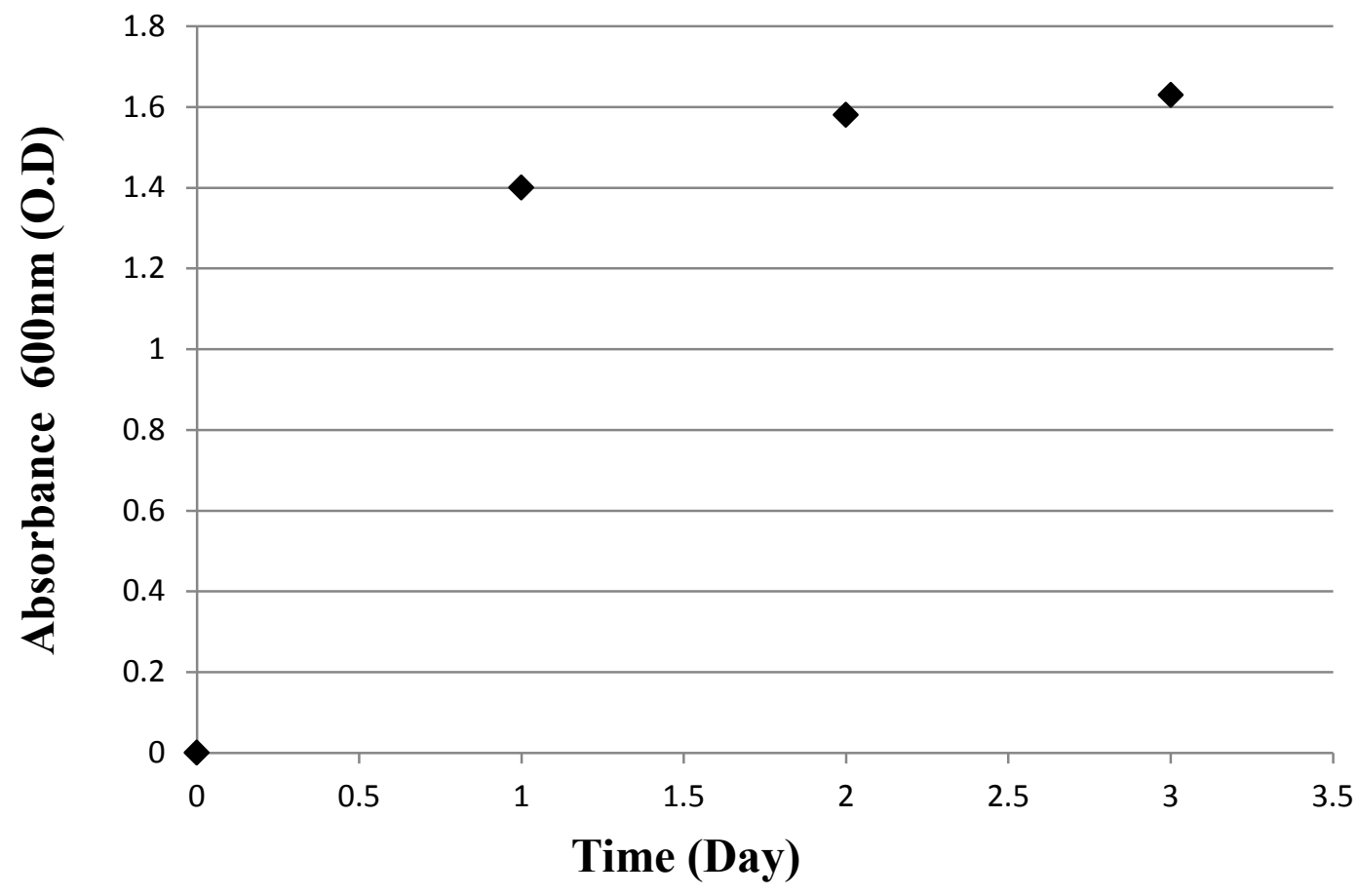

Figure A-11 K. lactis-Cel7B yeast growth density into YBC-1\% Galactose samples (Day) "Shake Flask-Small Scale", March 27, 2012

Table A-14 Measurement of yeast growth density into YBC-1\% Galactose samples and YPGal.-1\% Galactose samples (Hour) by using spectrometer (absorbance) at $600 \mathrm{~nm}$ (March 27, 2012)

\begin{tabular}{|l|l|l|l|l|l|}
\hline \multicolumn{5}{|l|}{ YPGal.-1\% Gal. } & \multicolumn{2}{l|}{ YBC-1\% Gal. } \\
\hline sample's time(hours) & \multicolumn{2}{l|}{ Absorbance (O.D)@ $600 \mathrm{~nm}$} & \multicolumn{2}{l|}{ sample's time(hours) } & \multicolumn{2}{l|}{ Absorbance (O.D)@ 600nm } \\
\hline just YPGal. & 0.043 & 0 & just YBC & 0.002 & 0 \\
\hline 0 & 0.046 & 0.003 & 0 & 0.003 & 0.001 \\
\hline 4 & 0.048 & 0.005 & 4 & 0.006 & 0.004 \\
\hline 8 & 0.055 & 0.012 & 8 & 0.043 & 0.041 \\
\hline 13 & 0.112 & 0.069 & 13 & 0.337 & 0.335 \\
\hline 25 & 1.43 & 1.387 & 25 & 1.51 & 1.508 \\
\hline 28 & 1.52 & 1.477 & 28 & 1.55 & 1.548 \\
\hline 32 & 1.58 & 1.537 & 32 & 1.62 & 1.538 \\
\hline 36 & 1.62 & 1.577 & 36 & 1.66 & 1.618 \\
\hline 50 & 1.7 & 1.657 & 50 & 1.67 & 1.658 \\
\hline 52 & 1.7 & 1.657 & 52 & 1.668 \\
\hline
\end{tabular}




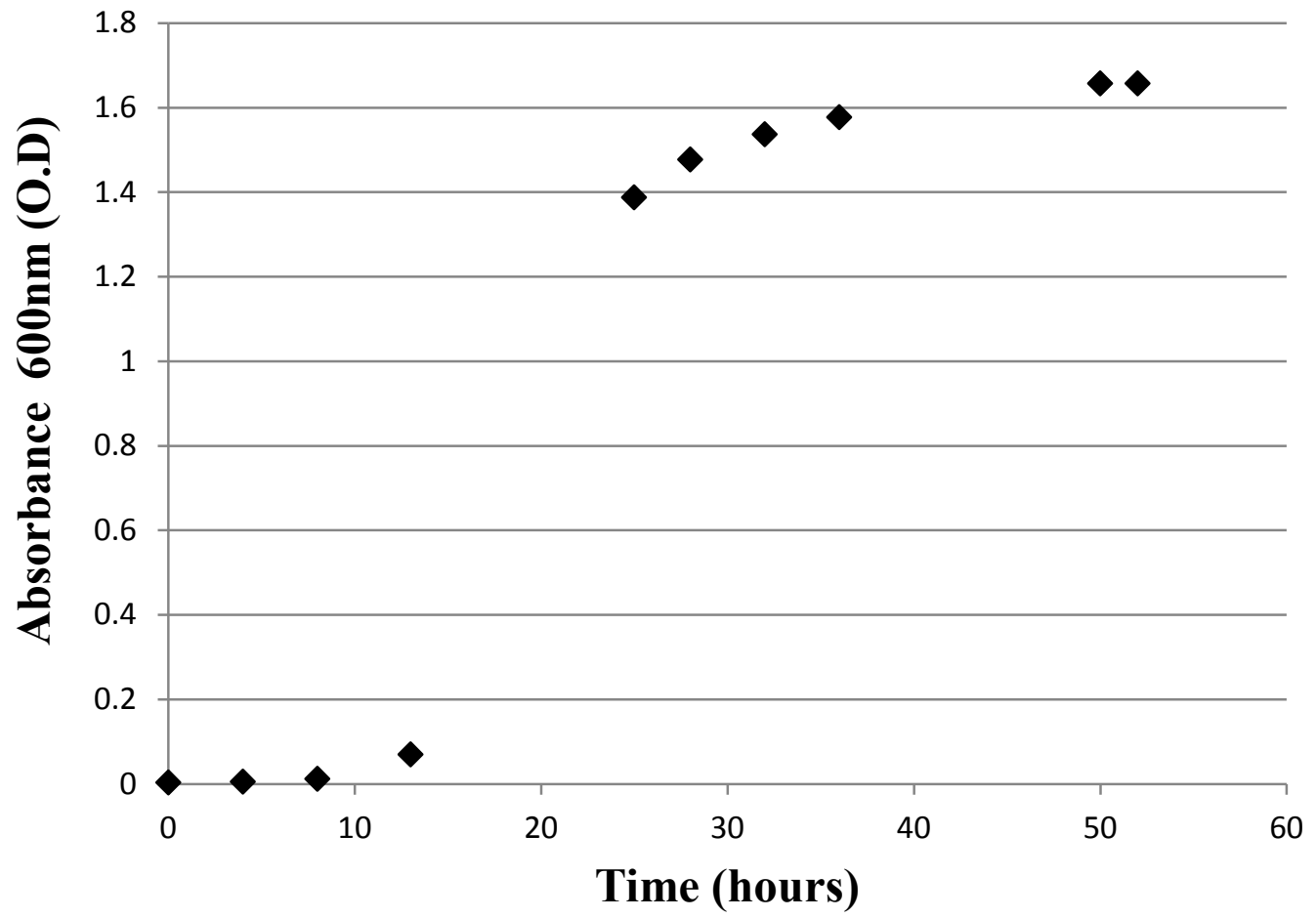

Figure A-12 K. lactis-Cel7B yeast growth density into YPGal-1\% Galactose samples (Hour) "Shake Flask-Small Scale", March 27, 2012 


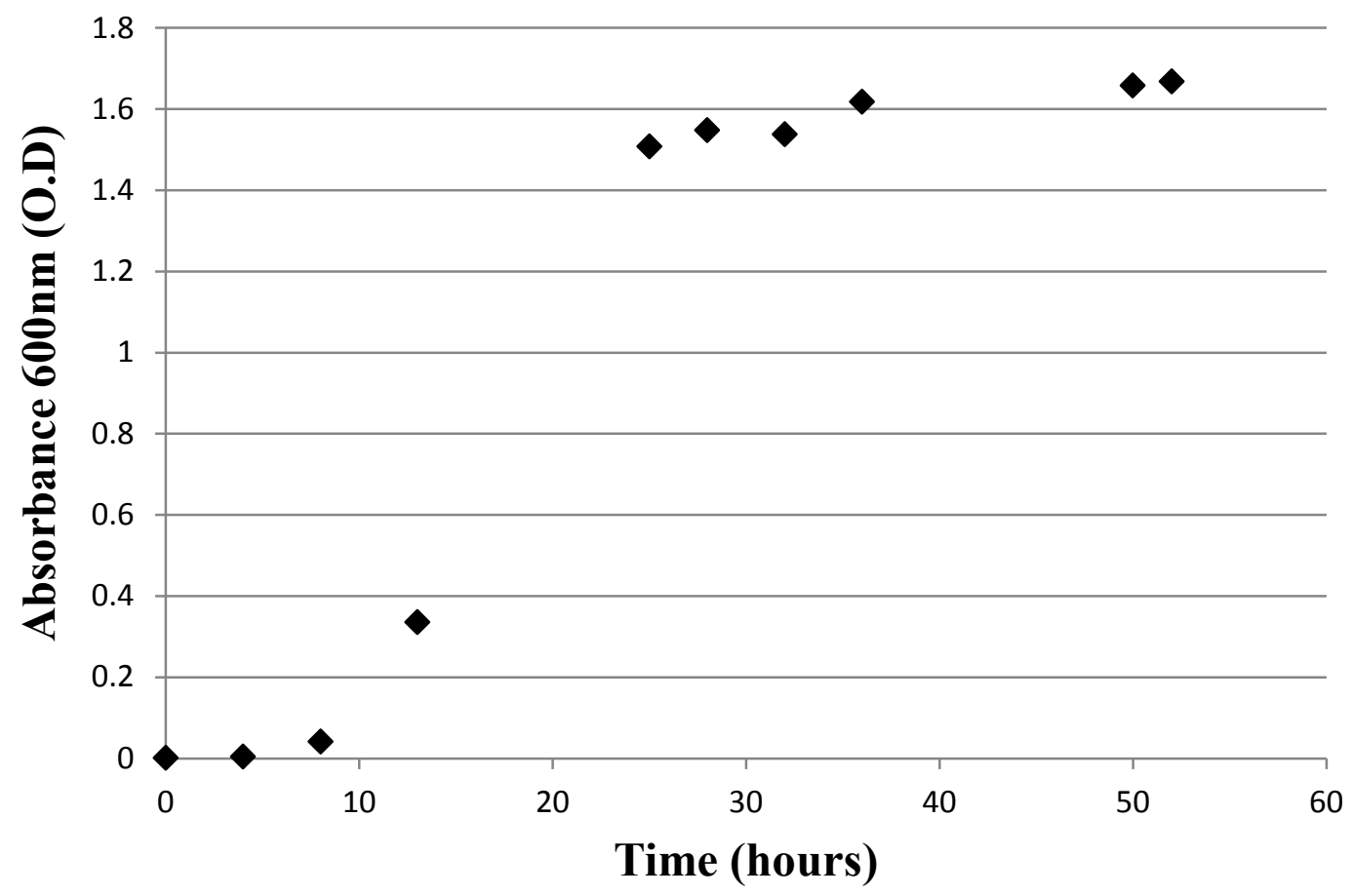

Figure A-13 K. lactis-Cel7B yeast growth density into YBC-1\% Galactose samples (Hour) "Shake Flask-Small Scale", March 27, 2012

Table A-15 Samples Sheet for CMC/DNS assay experiment (March 28, 2012)

\begin{tabular}{|l|l|l|l|l|l|l|l|l|}
\hline $\begin{array}{l}\text { Sample } \\
\text { number }\end{array}$ & $\begin{array}{l}\text { Sample } \\
\text { name }\end{array}$ & $\begin{array}{l}\text { Time } \\
\text { (hour) }\end{array}$ & $\begin{array}{l}\text { Sample's } \\
\text { volume } \\
(\mathrm{ml})\end{array}$ & $\begin{array}{l}\text { CMC's } \\
(2 \%) \\
\text { volume(ml) }\end{array}$ & $\begin{array}{l}\text { Citrate } \\
\text { buffer(1M) } \\
\text { volume(ml) }\end{array}$ & $\begin{array}{l}\text { dH2O's } \\
\text { volume } \\
(\mathrm{ml})\end{array}$ & $\begin{array}{l}\text { DNS's } \\
\text { volume } \\
(\mathrm{ml})\end{array}$ & $\begin{array}{l}\text { dH2O } \\
\text { volume } \\
(\mathrm{ml})\end{array}$ \\
\hline 1 & YPGal. & 0 & 0.45 & 0.5 & 0.05 & 0 & 3 & 20 \\
\hline 2 & YPGal. & 0 & 0.45 & 0 & 0.05 & 0.5 & 3 & 20 \\
\hline 3 & YPGal. & 4 & 0.45 & 0.5 & 0.05 & 0 & 3 & 20 \\
\hline 4 & YPGal. & 4 & 0.45 & 0 & 0.05 & 0.5 & 3 & 20 \\
\hline 5 & YPGal. & 8 & 0.45 & 0.5 & 0.05 & 0 & 3 & 20 \\
\hline 6 & YPGal. & 8 & 0.45 & 0 & 0.05 & 0.5 & 3 & 20 \\
\hline 7 & YPGal. & 13 & 0.45 & 0.5 & 0.05 & 0 & 3 & 20 \\
\hline 8 & YPGal. & 13 & 0.45 & 0 & 0.05 & 0.5 & 3 & 20 \\
\hline 9 & YPGal. & 25 & 0.45 & 0.5 & 0.05 & 0 & 3 & 20 \\
\hline 10 & YPGal. & 25 & 0.45 & 0 & 0.05 & 0.5 & 3 & 20 \\
\hline 11 & YPGal. & 28 & 0.45 & 0.5 & 0.05 & 0 & 3 & 20 \\
\hline
\end{tabular}




\begin{tabular}{|c|c|c|c|c|c|c|c|c|}
\hline 12 & YPGal. & 28 & 0.45 & 0 & 0.05 & 0.5 & 3 & 20 \\
\hline 13 & YPGal. & 32 & 0.45 & 0.5 & 0.05 & 0 & 3 & 20 \\
\hline 14 & YPGal. & 32 & 0.45 & 0 & 0.05 & 0.5 & 3 & 20 \\
\hline 15 & YPGal. & 36 & 0.45 & 0.5 & 0.05 & 0 & 3 & 20 \\
\hline 16 & YPGal. & 36 & 0.45 & 0 & 0.05 & 0.5 & 3 & 20 \\
\hline 17 & YPGal. & 50 & 0.45 & 0.5 & 0.05 & 0 & 3 & 20 \\
\hline 18 & YPGal. & 50 & 0.45 & 0 & 0.05 & 0.5 & 3 & 20 \\
\hline 19 & YPGal. & 52 & 0.45 & 0.5 & 0.05 & 0 & 3 & 20 \\
\hline 20 & YPGal. & 52 & 0.45 & 0 & 0.05 & 0.5 & 3 & 20 \\
\hline $\begin{array}{l}\text { Sample } \\
\text { number }\end{array}$ & $\begin{array}{l}\text { Sample } \\
\text { name }\end{array}$ & $\begin{array}{l}\text { Time } \\
\text { (hour) }\end{array}$ & $\begin{array}{l}\text { Sample's } \\
\text { volume } \\
(\mathrm{ml})\end{array}$ & $\begin{array}{l}\text { CMC's } \\
(2 \%) \\
\text { volume }(\mathrm{ml})\end{array}$ & $\begin{array}{l}\text { Citrate } \\
\text { buffer(1M) } \\
\text { volume }(\mathrm{ml})\end{array}$ & $\begin{array}{l}\text { dH2O’s } \\
\text { volume } \\
(\mathrm{ml})\end{array}$ & $\begin{array}{l}\text { DNS's } \\
\text { volume } \\
(\mathrm{ml})\end{array}$ & $\begin{array}{l}\mathrm{dH} 2 \mathrm{O} \\
\text { volume } \\
(\mathrm{ml})\end{array}$ \\
\hline 21 & YBC & 0 & 0.45 & 0.5 & 0.05 & 0 & 3 & 20 \\
\hline 22 & YBC & 0 & 0.45 & 0 & 0.05 & 0.5 & 3 & 20 \\
\hline 23 & YBC & 4 & 0.45 & 0.5 & 0.05 & 0 & 3 & 20 \\
\hline 24 & YBC & 4 & 0.45 & 0 & 0.05 & 0.5 & 3 & 20 \\
\hline 25 & YBC & 8 & 0.45 & 0.5 & 0.05 & 0 & 3 & 20 \\
\hline 26 & YBC & 8 & 0.45 & 0 & 0.05 & 0.5 & 3 & 20 \\
\hline 27 & YBC & 13 & 0.45 & 0.5 & 0.05 & 0 & 3 & 20 \\
\hline 28 & YBC & 13 & 0.45 & 0 & 0.05 & 0.5 & 3 & 20 \\
\hline 29 & YBC & 25 & 0.45 & 0.5 & 0.05 & 0 & 3 & 20 \\
\hline 30 & YBC & 25 & 0.45 & 0 & 0.05 & 0.5 & 3 & 20 \\
\hline 31 & YBC & 28 & 0.45 & 0.5 & 0.05 & 0 & 3 & 20 \\
\hline 32 & YBC & 28 & 0.45 & 0 & 0.05 & 0.5 & 3 & 20 \\
\hline 33 & YBC & 32 & 0.45 & 0.5 & 0.05 & 0 & 3 & 20 \\
\hline 34 & YBC & 32 & 0.45 & 0 & 0.05 & 0.5 & 3 & 20 \\
\hline 35 & YBC & 36 & 0.45 & 0.5 & 0.05 & 0 & 3 & 20 \\
\hline 36 & YBC & 36 & 0.45 & 0 & 0.05 & 0.5 & 3 & 20 \\
\hline 37 & YBC & 50 & 0.45 & 0.5 & 0.05 & 0 & 3 & 20 \\
\hline 38 & YBC & 50 & 0.45 & 0 & 0.05 & 0.5 & 3 & 20 \\
\hline 39 & YBC & 52 & 0.45 & 0.5 & 0.05 & 0 & 3 & 20 \\
\hline 40 & YBC & 52 & 0.45 & 0 & 0.05 & 0.5 & 3 & 20 \\
\hline 41 & no-Enz. & & 0 & 0.5 & 0.05 & 0.45 & 3 & 20 \\
\hline 42 & no-Enz. & & 0 & 0 & 0.05 & 0.95 & 3 & 20 \\
\hline 43 & $7 \mathrm{~B}$ & & 0.05 & 0.5 & 0.05 & 0.4 & 3 & 20 \\
\hline 44 & $7 \mathrm{~B}$ & & 0.05 & 0 & 0.05 & 0.9 & 3 & 20 \\
\hline
\end{tabular}




\begin{tabular}{|l|l|l|l|l|l|l|l|l|}
\hline 45 & GS 20mg/ml & & 0.45 & 0 & 0.05 & 0.5 & 3 & 20 \\
\hline 46 & GS $10 \mathrm{mg} / \mathrm{m}$ & & 0.45 & 0 & 0.05 & 0.5 & 3 & 20 \\
\hline 47 & GS $5 \mathrm{mg} / \mathrm{ml}$ & & 0.45 & 0 & 0.05 & 0.5 & 3 & 20 \\
\hline 48 & GS $2 \mathrm{mg} / \mathrm{ml}$ & & 0.45 & 0 & 0.05 & 0.5 & 3 & 20 \\
\hline 49 & GS $1 \mathrm{mg} / \mathrm{ml}$ & & 0.45 & 0 & 0.05 & 0.5 & 3 & 20 \\
\hline 50 & GS $0 \mathrm{mg} / \mathrm{ml}$ & & 0 & 0 & 0.05 & 0.95 & 3 & 20 \\
\hline
\end{tabular}


Table A-16 Measurement of Galactose Concentration and Net activity of enzyme into YPGal-1\% Galactose samples by using CMC/DNS tool (March 28, 2012)

\begin{tabular}{|c|c|c|c|c|c|c|c|c|}
\hline $\begin{array}{l}\text { Sample } \\
\text { number }\end{array}$ & $\begin{array}{l}\text { Sample } \\
\text { name }\end{array}$ & $\begin{array}{l}\text { Time } \\
\text { (hours) }\end{array}$ & A@54 & & $\begin{array}{l}\text { Net } \\
\text { A540nm } \\
\text { (O.D) }\end{array}$ & $\begin{array}{l}\text { Gal. } \\
\text { Conc. } \\
(\mathrm{mg} / \mathrm{ml})\end{array}$ & $\begin{array}{l}\text { Net Gal. } \\
\text { Conc. } \\
(\mathrm{mg} / \mathrm{ml})\end{array}$ & $\begin{array}{l}\text { Volumetric } \\
\text { Activity } \\
\left(\mathrm{mg} / \mathrm{mL}^{*} \mathrm{~h}\right)\end{array}$ \\
\hline 1 & YPGal. & 0 & 1.999 & 1.965 & 0 & & 0 & 0 \\
\hline 3 & YPGal. & 4 & 1.999 & 1.965 & 0 & & 0 & 0 \\
\hline 5 & YPGal. & 8 & 1.999 & 1.965 & 0 & & 0 & 0 \\
\hline 7 & YPGal. & 13 & 1.999 & 1.965 & 0 & & 0 & 0 \\
\hline 9 & YPGal. & 25 & 0.667 & 0.633 & 0.046 & & 0.19 & 0.19 \\
\hline 11 & YPGal. & 28 & 0.135 & 0.101 & 0.094 & & 0.38 & 0.38 \\
\hline 13 & YPGal. & 32 & 0.116 & 0.082 & 0.075 & & 0.30 & 0.30 \\
\hline 15 & YPGal. & 36 & 0.11 & 0.076 & 0.068 & & 0.28 & 0.28 \\
\hline 17 & YPGal. & 50 & 0.147 & 0.113 & 0.105 & & 0.43 & 0.43 \\
\hline 19 & YPGal. & 52 & 0.16 & 0.126 & 0.121 & & 0.50 & 0.50 \\
\hline 43 & $7 \mathrm{~B}$ & 0 & 0.509 & 0.475 & 0.473 & & 1.95 & 1.95 \\
\hline 41 & no-Enz. & 0 & 0.034 & 0 & 0 & & 0 & 0 \\
\hline 2 & YPGal. & 0 & 1.999 & 1.965 & & 8.12 & & \\
\hline 4 & YPGal. & 4 & 1.999 & 1.965 & & 8.12 & & \\
\hline 6 & YPGal. & 8 & 1.999 & 1.965 & & 8.12 & & \\
\hline 8 & YPGal. & 13 & 1.999 & 1.965 & & 8.12 & & \\
\hline 10 & YPGal. & 25 & 0.621 & 0.587 & & 2.42 & & \\
\hline 12 & YPGal. & 28 & 0.041 & 0.007 & & 0.028 & & \\
\hline 14 & YPGal. & 32 & 0.041 & 0.007 & & 0.028 & & \\
\hline 16 & YPGal. & 36 & 0.042 & 0.008 & & 0.033 & & \\
\hline 18 & YPGal. & 50 & 0.042 & 0.008 & & 0.033 & & \\
\hline 20 & YPGal. & 52 & 0.039 & 0.005 & & 0.020 & & \\
\hline 44 & $7 \mathrm{~B}$ & 0 & 0.036 & 0.002 & & 0.008 & & \\
\hline 42 & no-Enz. & 0 & 0.034 & 0 & & 0 & & \\
\hline
\end{tabular}


Table A-17 Measurement of Galactose Concentration and Net activity of enzyme into YBC-1\% Galactose samples by using CMC/DNS tool (March 28, 2012)

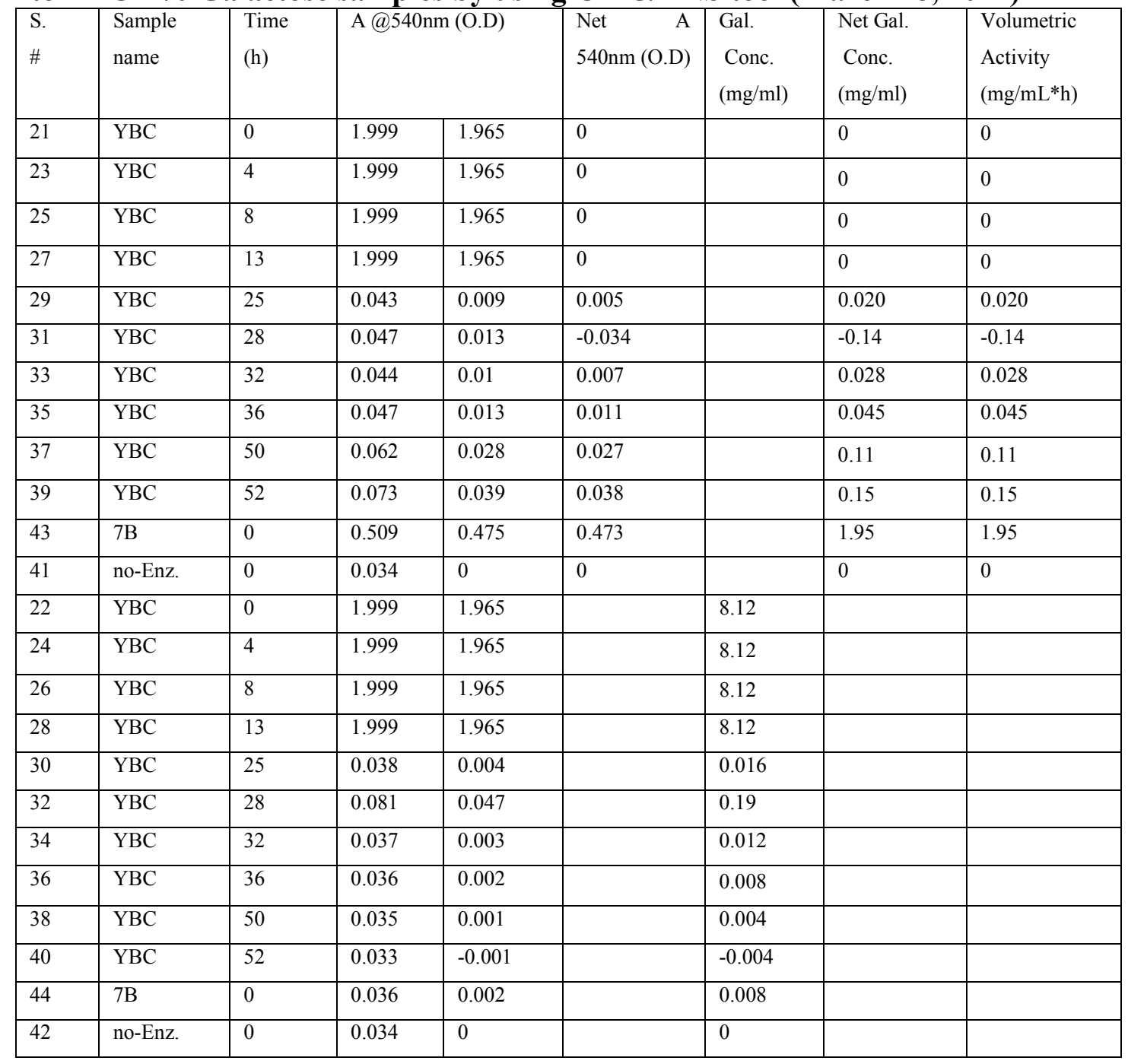


Experiment: YPGal-1\% Galactose "Shake Flask-Small Scale"

Date: July 9, 2012

Table A-18 Experiment Conducted in Small-Scale Culture of K. lactis Cel7B

\begin{tabular}{|c|l|l|l|l|}
\hline Date & $\begin{array}{l}\text { Type of } \\
\text { media }\end{array}$ & $\begin{array}{l}\text { Galactose } \\
\text { concentrati } \\
\text { on }\end{array}$ & $\begin{array}{l}\text { Culturing } \\
\text { time }\end{array}$ & \multicolumn{1}{c|}{ Purpose } \\
\hline $\begin{array}{l}\text { Jul 9, } \\
2012\end{array}$ & $\begin{array}{l}\text { Complex } \\
\text { media } \\
\text { YPGal. }\end{array}$ & $\begin{array}{l}1 \%(\mathrm{w} / \mathrm{v})- \\
10 \mathrm{mg} / \mathrm{mL}\end{array}$ & 28 hours & $\begin{array}{l}\text { Measure } \text { K. lactis growth, galactose concentration, and recombinant } \\
\text { Cel7B enzyme activity in complex media YPGal. with 1\% (w/v) } \\
\text { galactose concentration }\end{array}$ \\
\hline
\end{tabular}

Table A-19 Measurement of Galactose Concentration by using CMC/DNS assay into Galactose standard samples (July 9, 2012)

\begin{tabular}{|l|l|l|l|l|l|}
\hline S\# & Sample name & Gal. conc. (mg/ml) & Gala. (\%) & A @ 540nm (O.D) & Final A@540nm (O.D) \\
\hline 1 & GS 20 & 20 & 2 & 1.999 & 1.981 \\
\hline 2 & GS 10 & 10 & 1 & 1.46 & 1.442 \\
\hline 3 & GS 5 & 5 & 0.5 & 0.782 & 0.764 \\
\hline 4 & GS 2 & 2 & 0.2 & 0.328 & 0.31 \\
\hline 5 & GS 1 & 1 & 0.1 & 0.127 & 0.109 \\
\hline 6 & GS 0 & 0 & 0 & 0.018 & 0 \\
\hline
\end{tabular}




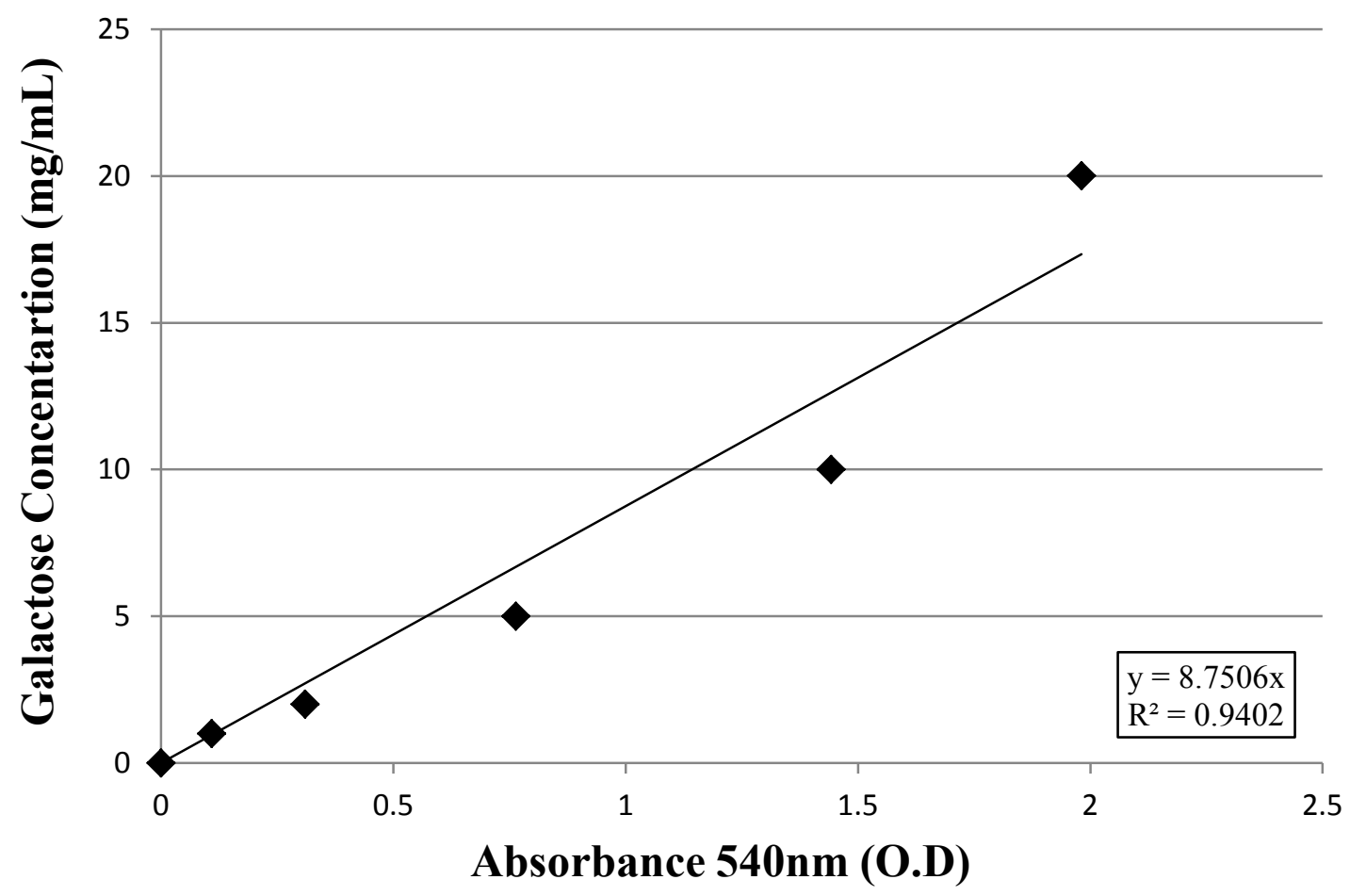

Figure A-14 Galactose Standard Curve into experiment of growing yeast Cel7B into YPGal-1\% Galactose "Shake Flask-Small Scale", July 9, 2012

Table A-20 Measurement of yeast growth density into YPGal.-1\% Galactose samples by using spectrometer A600 nm (July 9, 2012)

\begin{tabular}{|l|l|l|l|l|l|}
\hline YPGal.-1\%Gal. Sample & Time(h) & A600nm(O.D) & $\begin{array}{l}\text { Calculated A } \\
600 \mathrm{~nm} \text { (O.D) }\end{array}$ & Dilution (1:10) & final A600nm (O.D) \\
\hline inoculums & & 0.954 & & & 0.068 \\
\hline YPGal.- 1\% Gal. & 0 & 0.068 & 0 & & 0.088 \\
\hline YPGal.- 1\% \#1 & 0 & 0.088 & 0.02 & 0.094 \\
\hline YPGal.- 1\% \#2 & 2 & 0.094 & 0.026 & 0.196 \\
\hline YPGal.- 1\%\#3 & 6 & 0.196 & 0.128 & 0.286 & 0.354 \\
\hline YPGal.- 1\% \#4 & 10 & 0.354 & 1.522 & 0.548 & 4.37 \\
\hline YPGal.- 1\% \#5 & 21 & 1.59 & 1.632 & 0.66 & 5.48 \\
\hline YPGal.- 1\% \#6 & 24 & 1.7 & 1.672 & 6.6 \\
\hline YPGal.- 1\% \#7 & 28 & 1.74 & & & 0.437 \\
\hline
\end{tabular}




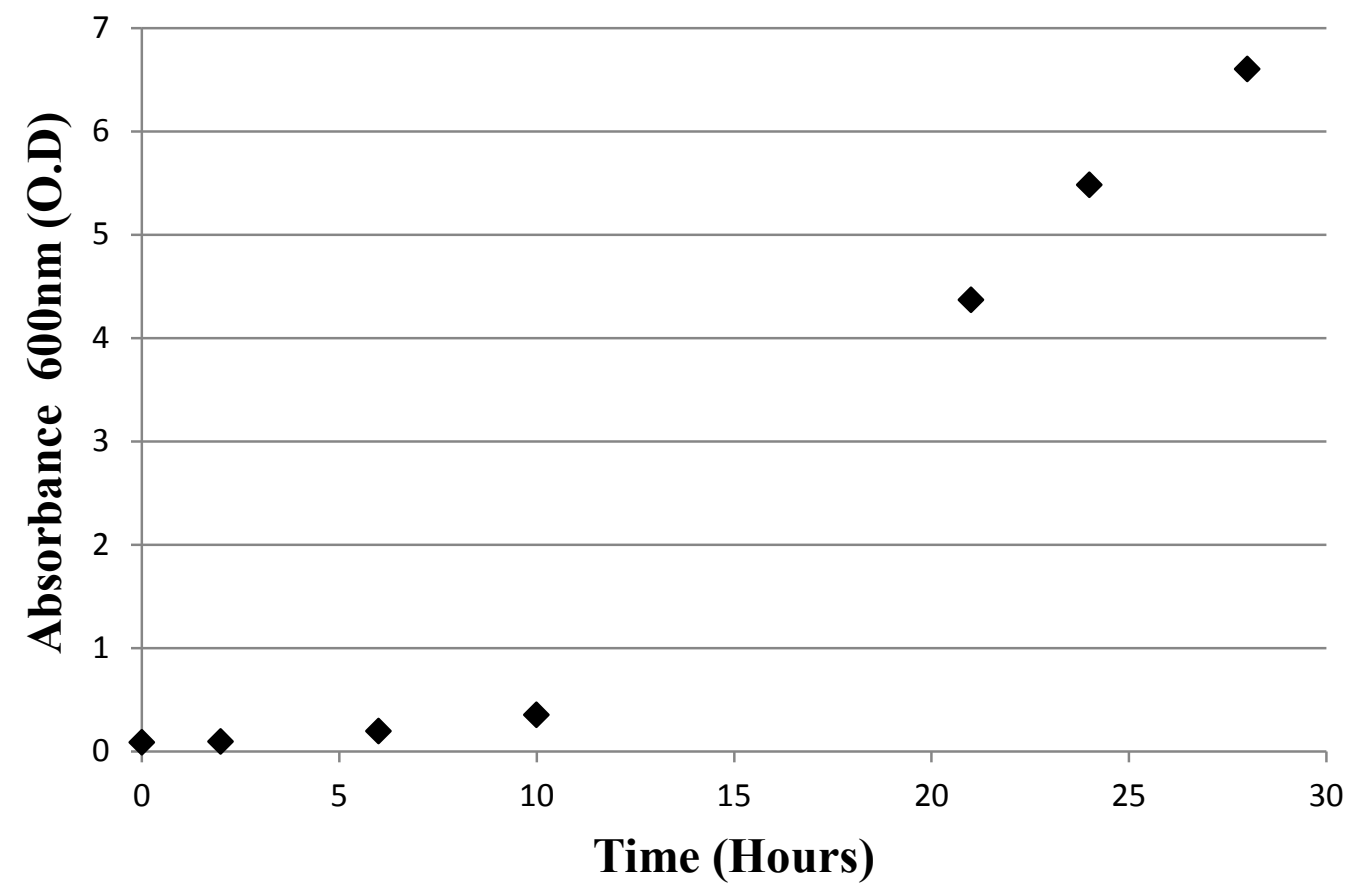

Figure A-15 K. lactis-Cel7B yeast growth density into YPGal-1\% Galactose samples "Shake Flask-Small Scale", July 9, 2012 
Table A-21 Measurement of Galactose Concentration and Net activity of enzyme into YPGal-1\% Galactose samples by using CMC/DNS tool (July 9, 2012)

\begin{tabular}{|c|c|c|c|c|c|c|c|c|c|}
\hline S.\# & $\begin{array}{l}\text { Sample } \\
\text { name }\end{array}$ & $\begin{array}{l}\text { Time } \\
\text { (h) }\end{array}$ & $\begin{array}{l}\text { A540nm } \\
\text { (O.D) }\end{array}$ & $\begin{array}{l}\text { Net } \\
\text { A540nm } \\
\text { (O.D) }\end{array}$ & $\begin{array}{l}\text { Final } \\
\text { A540nm } \\
\text { (O.D) }\end{array}$ & $\begin{array}{l}\text { Net } \\
\text { A540nm } \\
\text { (O.D) }\end{array}$ & $\begin{array}{l}\text { Galactose } \\
\text { conc. } \\
(\mathrm{mg} / \mathrm{ml})\end{array}$ & $\begin{array}{l}\text { Net } \\
\text { Galactose } \\
\text { conc. } \\
(\mathrm{mg} / \mathrm{ml})\end{array}$ & $\begin{array}{l}\text { Volumetric } \\
\text { Activity } \\
\left(\mathrm{mg} / \mathrm{mL}^{*} \mathrm{~h}\right)\end{array}$ \\
\hline 1 & Just YPGal. & & 1.165 & 1.147 & 0.79 & 0.057 & & 0.49 & 0.49 \\
\hline 3 & YPGal. & 0 & 1.11 & 1.092 & 0.7 & -0.053 & & -0.46 & -0.46 \\
\hline 5 & YPGal. & 2 & 1.215 & 1.197 & 0.78 & 0.042 & & 0.36 & 0.36 \\
\hline 7 & YPGal. & 6 & 1.17 & 1.152 & 0.76 & -0.088 & & -0.77 & -0.77 \\
\hline 9 & YPGal. & 10 & 1.21 & 1.192 & 0.9 & 0.082 & & 0.71 & 0.71 \\
\hline 11 & YPGal. & 21 & 0.235 & 0.217 & 0.16 & 0.057 & & 0.49 & 0.49 \\
\hline 13 & YPGal. & 24 & 0.112 & 0.094 & 0.09 & 0.08 & & 0.70 & 0.70 \\
\hline 15 & YPGal. & 28 & 0.11 & 0.092 & 0.06 & 0.082 & & 0.71 & 0.71 \\
\hline 17 & $7 \mathrm{~B}$ & & 0.52 & 0.502 & 0.36 & 0.5 & & 4.37 & 4.37 \\
\hline 19 & no-Enz. & & 0.018 & 0 & 0 & 0 & & 0 & 0 \\
\hline 2 & Just YPGal. & & 1.11 & 1.09 & 0.75 & & 6.56 & & \\
\hline 4 & YPGal. & 0 & 1.165 & 1.145 & 0.78 & & 6.82 & & \\
\hline 6 & YPGal. & 2 & 1.175 & 1.155 & 0.76 & & 6.65 & & \\
\hline 8 & YPGal. & 6 & 1.26 & 1.24 & 0.81 & & 7.08 & & \\
\hline 10 & YPGal. & 10 & 1.13 & 1.11 & 0.8 & & 7.00 & & \\
\hline 12 & YPGal. & 21 & 0.18 & 0.16 & 0.12 & & 1.05 & & \\
\hline 14 & YPGal. & 24 & 0.034 & 0.014 & 0.03 & & 0.26 & & \\
\hline 16 & YPGal. & 28 & 0.03 & 0.01 & 0.02 & & 0.17 & & \\
\hline 18 & $7 \mathrm{~B}$ & & 0.022 & 0.002 & 0.01 & & 0.087 & & \\
\hline 20 & no-Enz. & & 0.02 & 0 & 0 & & 0 & & \\
\hline
\end{tabular}




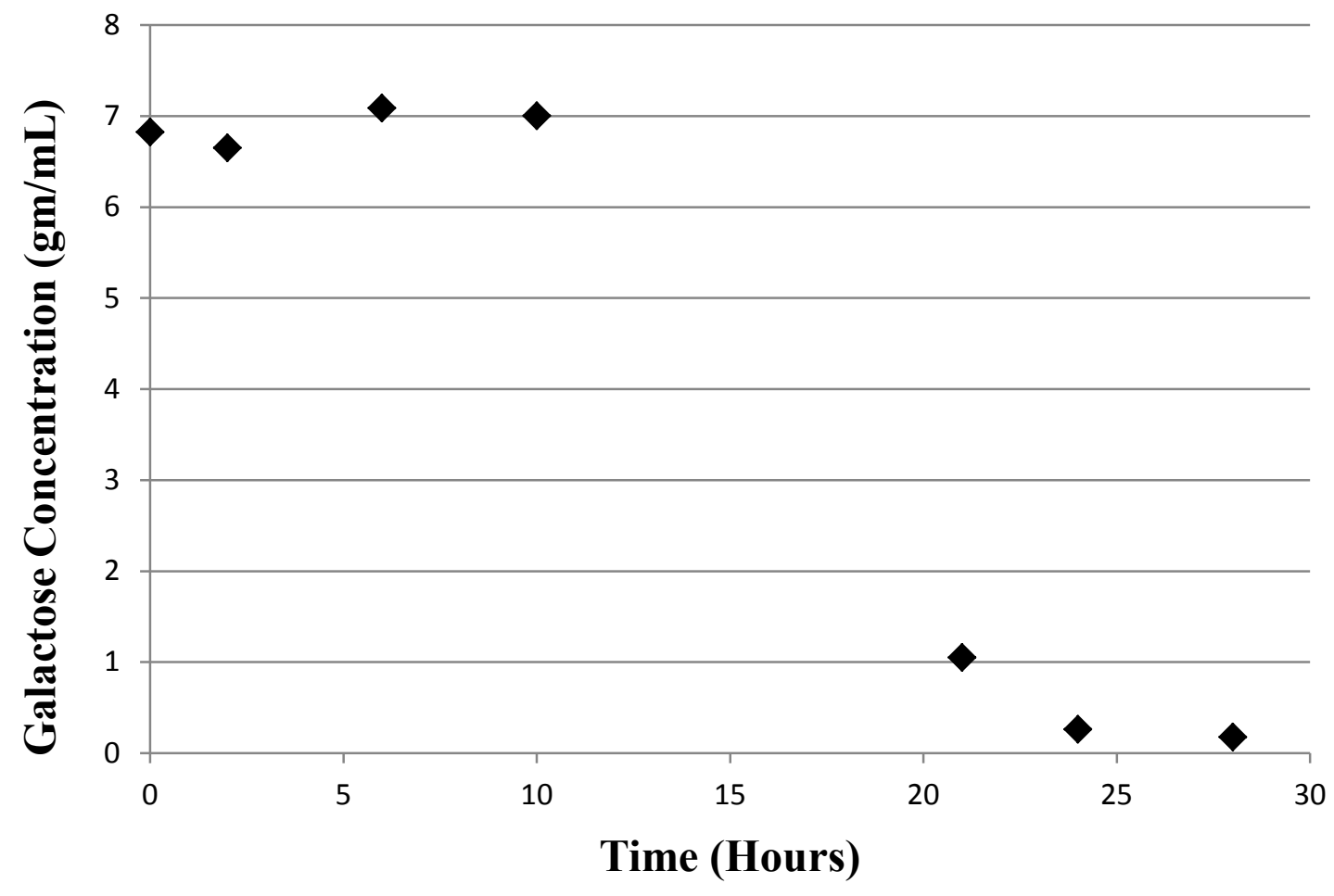

Figure A-16 Galactose concentration into YPGal.-1\% Galactose samples by using CMC/DNS assay (July 9, 2012) 


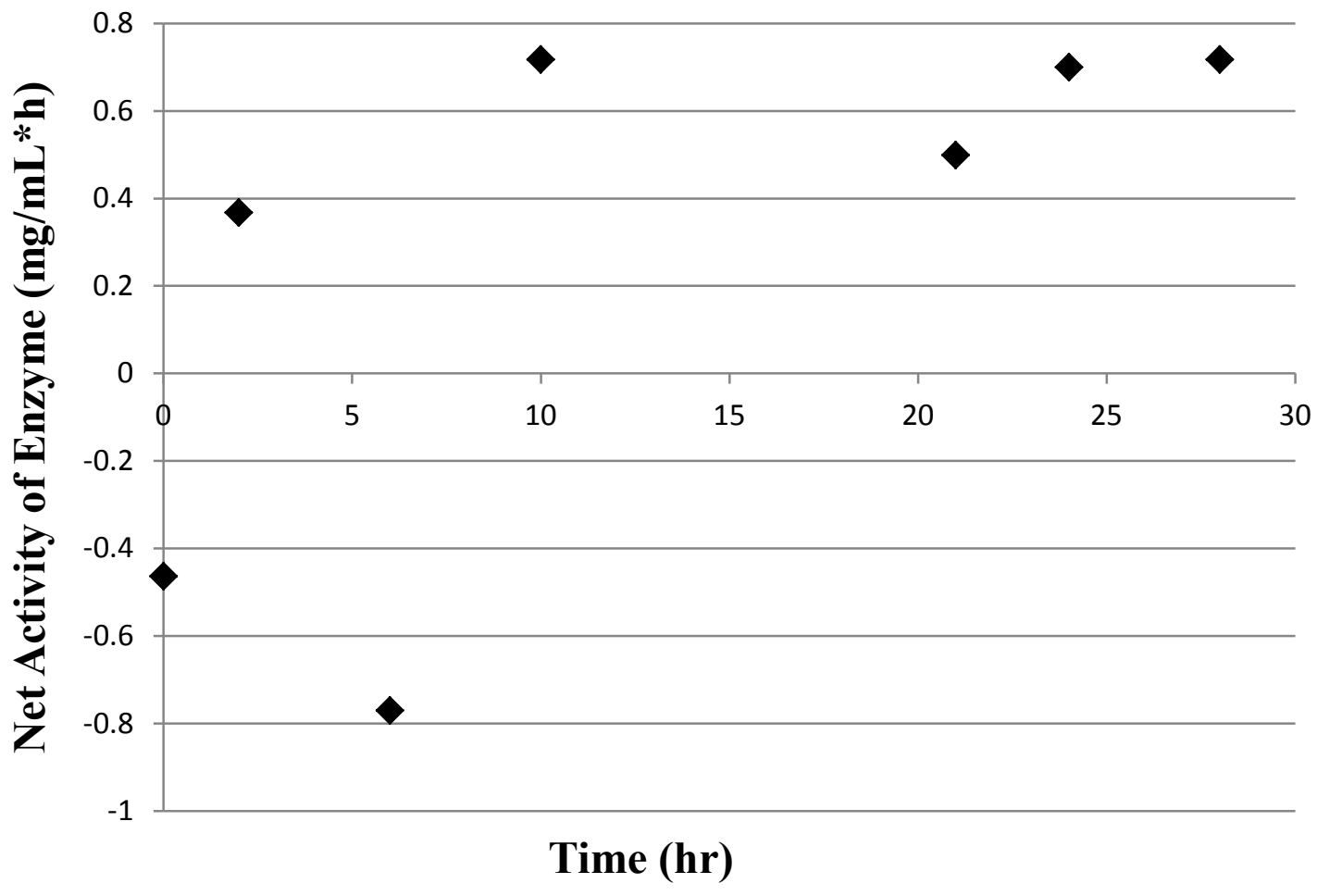

Figure A-17 Volumetric activity of enzyme into YPGal.-1\% Galactose samples by using CMC/DNS assay (July 9, 2012) 
Experiment: Comparison between growth density of $K$. lactis into YPGal-1\% Galactose, YBC-1\% Galactose, YNB-2\% Galactose, YBC-2\% Galactose and YPGal.-2\% Galactose "Shake Flask-Small Scale"

See table 3-1 in chapter 3

Table A-22 Measurement of yeast growth density into YBC-1\% Galactose and YPGal.-1\% Galactose by using spectrometer (absorbance) at $600 \mathrm{~nm}$.

\begin{tabular}{|l|l|l|l|l|l|l|l|l|l|}
\hline $\begin{array}{l}\text { YNB- } \\
\text { Gal. }\end{array}$ & 9-Jan-12 & $\begin{array}{l}\text { YPGal- } \\
2 \% \text { Gal. }\end{array}$ & $\begin{array}{l}\text { 9-Jan- } \\
12\end{array}$ & $\begin{array}{l}\text { YBC-2\% } \\
\text { Gal. }\end{array}$ & 6-Mar-12 & $\begin{array}{l}\text { YPGal- } \\
1 \% \text { Gal. }\end{array}$ & $\begin{array}{l}\text { 28-Mar- } \\
12\end{array}$ & $\begin{array}{l}\text { YBC-1\% } \\
\text { Gal. }\end{array}$ & 28-Mar-12 \\
\hline $\begin{array}{l}\text { Time } \\
(\mathrm{h})\end{array}$ & $\begin{array}{l}\text { A600 } \\
\mathrm{nm}\end{array}$ & Time (h) & $\begin{array}{l}\text { A600 } \\
\mathrm{nm}\end{array}$ & Time (h) & A600 nm & Time (h) & $\begin{array}{l}\text { A600 } \\
\mathrm{nm}\end{array}$ & $\begin{array}{l}\text { Time } \\
\text { (h) }\end{array}$ & A600 nm \\
\hline 0 & 0.003 & 0 & 0.06 & 0 & 0.009 & 0 & 0.003 & 0 & 0.001 \\
\hline 2 & 0 & 2 & 0.059 & 4 & 0.022 & 4 & 0.005 & 4 & 0.004 \\
\hline 4 & 0.018 & 4 & 0.075 & 8 & 0.118 & 8 & 0.012 & 8 & 0.041 \\
\hline 22 & 1.034 & 22 & 1.46 & 12 & 0.568 & 13 & 0.069 & 13 & 0.335 \\
\hline 24 & 1.13 & 24 & 1.51 & 24 & 1.58 & 25 & 1.387 & 25 & 1.508 \\
\hline 26 & 1.22 & 26 & 1.61 & 28 & 1.63 & 28 & 1.477 & 28 & 1.548 \\
\hline 28 & 1.27 & 28 & 1.62 & 32 & 1.65 & 32 & 1.537 & 32 & 1.538 \\
\hline 46 & 1.375 & 46 & 1.74 & 36 & 1.66 & 36 & 1.577 & 36 & 1.618 \\
\hline & & & & 48 & 1.68 & 50 & 1.657 & 50 & 1.658 \\
\hline
\end{tabular}




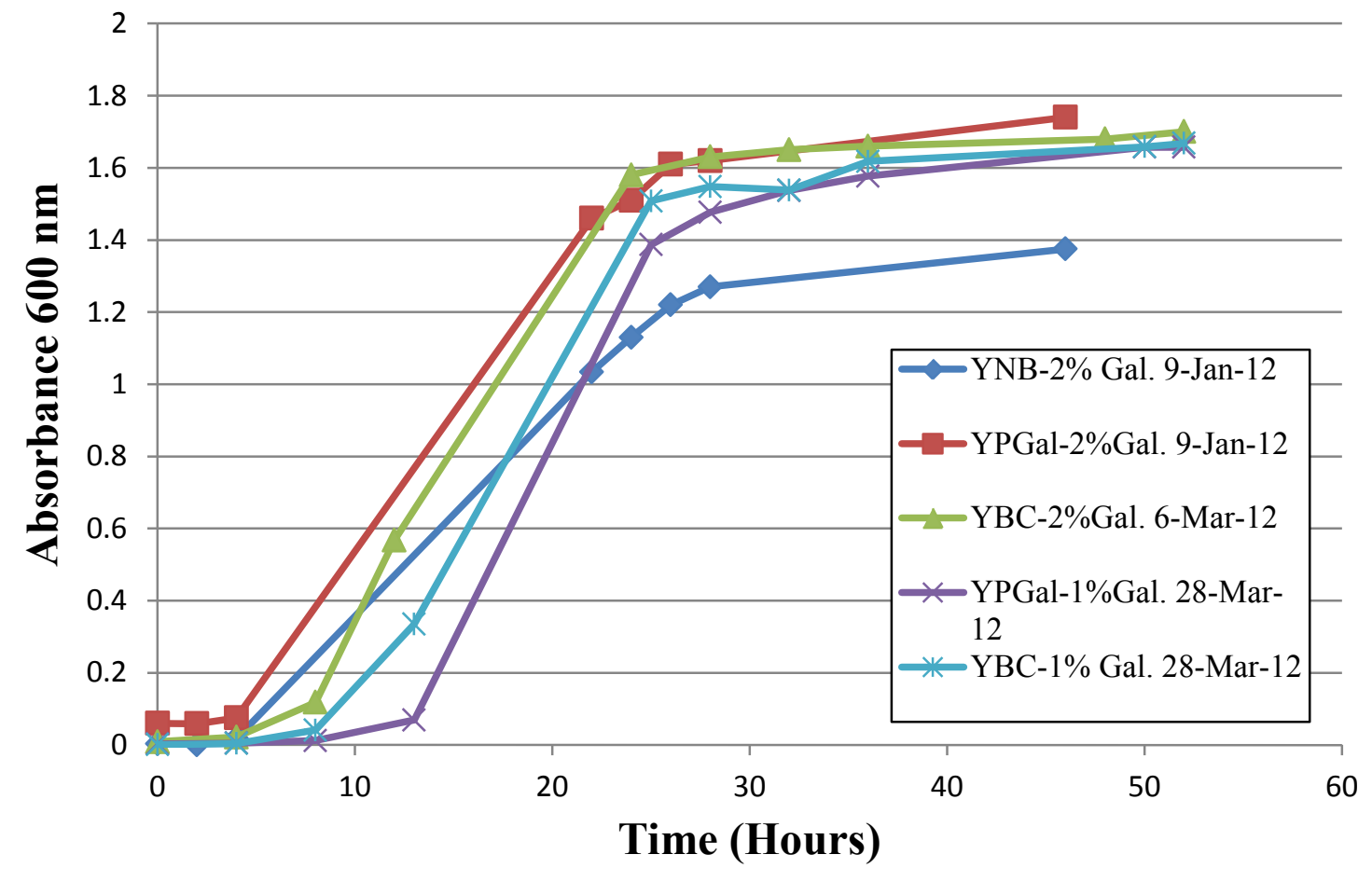

Figure A-18 Comparison between growth densities of $K$. lactis-Cel7B yeast into different medum: YNB-2\% Gal., YPGal-2\% Gal., YBC-2\% Gal., YPGal-1\% Gal., and YBC-1\% Gal. 


\section{Appendix B: Large Scale "Bioreactor/Fermenter" Experiments}

The experiments follow a sequential order

Experiment: YPGal-1\% Galactose "Bioreactor (3.5liters)-Large Scale"

Date: May 23, 2012

See table $4-1$ in chapter 4

Table B-1 Measurement of Galactose Concentration by using CMC/DNS assay into Galactose standard samples (May 23, 2012)

\begin{tabular}{|l|l|l|l|l|}
\hline S\# & Sample Name & $\begin{array}{l}\text { Galactose } \\
\text { Concentration } \\
(\mathrm{mg} / \mathrm{ml})\end{array}$ & $\begin{array}{l}\text { Galactose } \\
\text { percentage (\%) }\end{array}$ & A @ 540nm (O.D) \\
\hline 1 & GS $20 \mathrm{mg} / \mathrm{ml}$ & 20 & 2 & 1.98 \\
\hline 2 & GS $10 \mathrm{mg} / \mathrm{m}$ & 10 & 1 & 1.34 \\
\hline 3 & GS $5 \mathrm{mg} / \mathrm{ml}$ & 5 & 0.5 & 0.91 \\
\hline 4 & GS $2 \mathrm{mg} / \mathrm{ml}$ & 2 & 0.2 & 0.337 \\
\hline 5 & GS $1 \mathrm{mg} / \mathrm{ml}$ & 1 & 0.1 & 0.169 \\
\hline 6 & GS $0 \mathrm{mg} / \mathrm{ml}$ & 0 & 0 & 0.023 \\
\hline
\end{tabular}




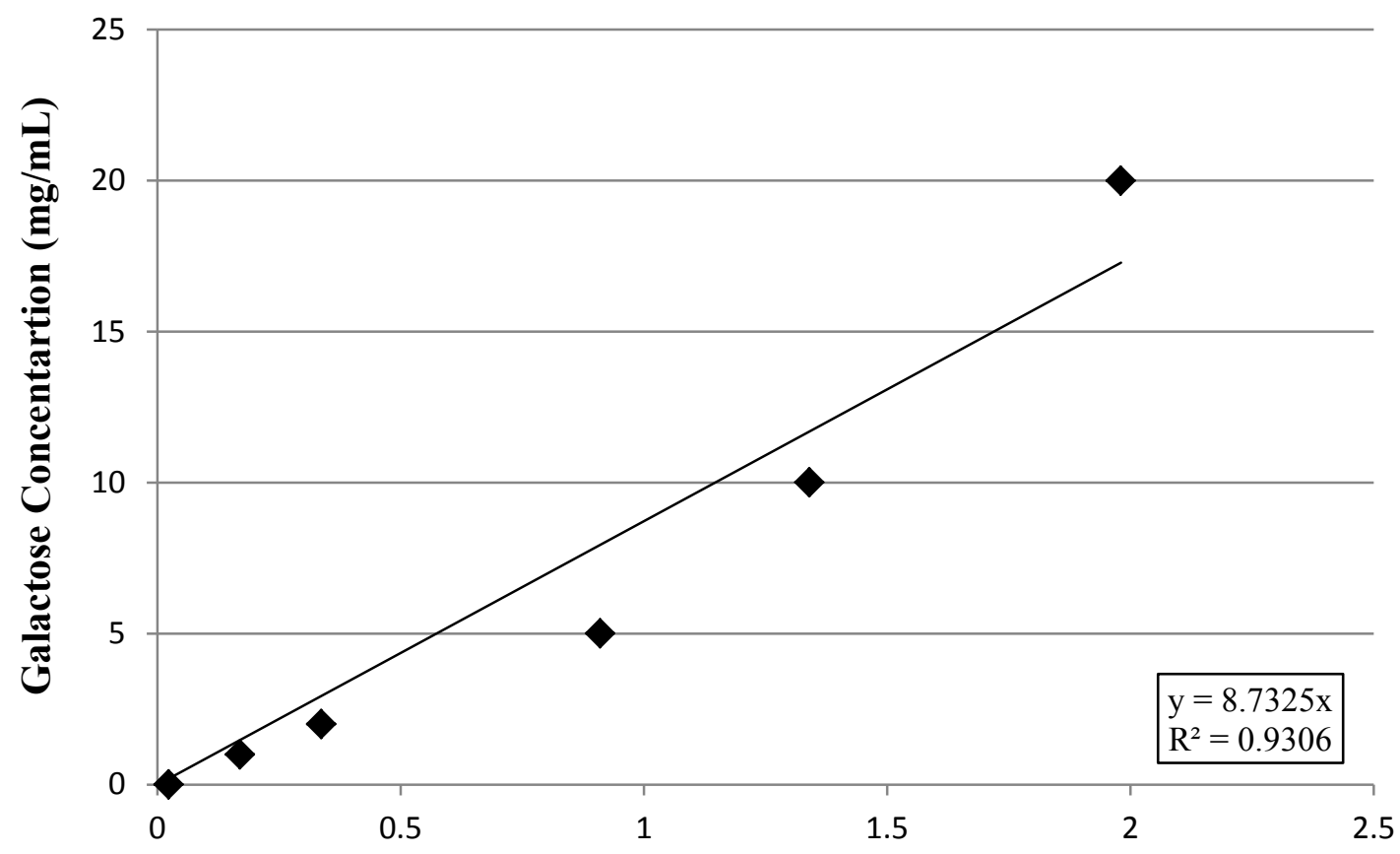

Absorbance 540nm (O.D)

Figure B-1 Galactose Standard Curve into experiment into YPGal.-1\% Galactose, (May 23, 2012)

Table B-2 Measurement of yeast growth density into YPGal.-1\% Galactose samples by using spectrometer (absorbance) at $600 \mathrm{~nm}$ (May 23, 2012)

\begin{tabular}{|l|l|l|}
\hline YPGal Sample & Time(h) & Absorbance@600nm \\
\hline YPGal- $1 \%$ Gal. & & 0 \\
\hline 1 & 0 & 0.039 \\
\hline 2 & 2 & 0.084 \\
\hline 3 & 4 & 0.182 \\
\hline 4 & 6 & 0.464 \\
\hline 5 & 18 & 6.74 \\
\hline 6 & 20 & 7.36 \\
\hline 7 & 22 & 7.18 \\
\hline 8 & 24 & 7.14 \\
\hline 9 & 28 & 7.48 \\
\hline 10 & 41 & 8.32 \\
\hline
\end{tabular}


Table B-3 Measurement of Galactose Concentration and Net activity of enzyme into YPGal-1\% Galactose samples by using CMC/DNS tool (May 23, 2012)

\begin{tabular}{|c|c|c|c|c|c|c|c|}
\hline S.\# & $\begin{array}{l}\text { Sample } \\
\text { name }\end{array}$ & $\begin{array}{l}\text { Time } \\
\text { (h) }\end{array}$ & $\begin{array}{l}\text { A540nm } \\
\text { (O.D) }\end{array}$ & $\begin{array}{l}\text { Net } \\
\text { A540nm (O.D) }\end{array}$ & $\begin{array}{l}\text { Galactose } \\
\text { Concentration } \\
(\mathrm{mg} / \mathrm{ml})\end{array}$ & $\begin{array}{l}\text { Net Gal. } \\
\text { Conc. } \\
(\mathrm{mg} / \mathrm{ml})\end{array}$ & $\begin{array}{l}\text { Volumetric } \\
\text { Activity } \\
\text { of Enzyme } \\
\left(\mathrm{mg} / \mathrm{mL}^{*} \mathrm{~h}\right)\end{array}$ \\
\hline 7 & YPGal.-1\% Gal. & 0 & 0.565 & -0.145 & & -1.26 & -1.26 \\
\hline 8 & YPGal. & 0 & 0.928 & 0.17 & & 1.48 & 1.48 \\
\hline 9 & YPGal. & 2 & 0.978 & 0.26 & & 2.27 & 2.27 \\
\hline 10 & YPGal. & 4 & 0.986 & 0.188 & & 1.64 & 1.64 \\
\hline 11 & YPGal. & 6 & 0.728 & 0 & & 0 & 0 \\
\hline 12 & YPGal. & 18 & 0.205 & 0.094 & & 0.82 & 0.82 \\
\hline 13 & YPGal. & 20 & 0.265 & 0.089 & & 0.77 & 0.77 \\
\hline 14 & YPGal. & 22 & 0.262 & 0.156 & & 1.36 & 1.36 \\
\hline 15 & YPGal. & 24 & 0.264 & 0.185 & & 1.61 & 1.61 \\
\hline 16 & YPGal. & 28 & 0.28 & 0.187 & & 1.63 & 1.63 \\
\hline 17 & YPGal & 41 & 0.175 & 0.088 & & 0.76 & 0.76 \\
\hline 31 & $7 \mathrm{~B}$ & 0 & 0.265 & 0.249 & & 2.17 & 2.17 \\
\hline 29 & no-Enz. & 0 & 0 & 0 & & 0 & 0 \\
\hline 18 & YPGal.-1\% Gal & 0 & 0.71 & & 6.20 & & \\
\hline 19 & YPG: $0 \mathrm{H}$ & 0 & 0.758 & & 6.61 & & \\
\hline 20 & YPGal. & 2 & 0.718 & & 6.26 & & \\
\hline 21 & YPGal. & 4 & 0.798 & & 6.96 & & \\
\hline 22 & YPGal. & 6 & 0.728 & & 6.35 & & \\
\hline 23 & YPGal. & 18 & 0.111 & & 0.96 & & \\
\hline 24 & YPGal. & 20 & 0.176 & & 1.53 & & \\
\hline 25 & YPGal. & 22 & 0.106 & & 0.92 & & \\
\hline 26 & YPGal. & 24 & 0.079 & & 0.68 & & \\
\hline 27 & YPGal. & 28 & 0.093 & & 0.81 & & \\
\hline 28 & YPGal. & 41 & 0.087 & & 0.75 & & \\
\hline 32 & $7 \mathrm{~B}$ & 0 & 0.016 & & 0.13 & & \\
\hline 30 & no-Enz. & 0 & 0 & & 0 & & \\
\hline
\end{tabular}


Experiment: YPGal-1\% Galactose "Bioreactor (3.5liters)-Large Scale"

Date: June 13, 2012

See table $4-1$ in chapter 4

Table B-4 Measurement of Galactose Concentration by using CMC/DNS assay into Galactose standard samples (June 13, 2012)

\begin{tabular}{|l|l|l|l|l|l|l|l|l|l|l|}
\hline $\begin{array}{l}\text { Sample } \\
\#\end{array}$ & $\begin{array}{l}\text { Sample } \\
\text { name }\end{array}$ & $\begin{array}{l}\text { Gal. } \\
\text { conc. } \\
(\mathrm{mg} / \mathrm{ml})\end{array}$ & $\begin{array}{l}\text { Gal. } \\
\text { percentage } \\
(\%)\end{array}$ & $\begin{array}{l}\text { Sample } \\
\text { volume } \\
(\mathrm{ml})\end{array}$ & $\begin{array}{l}\mathrm{CMC} \\
(2 \%) \\
\text { vol.(ml) }\end{array}$ & $\begin{array}{l}\text { Citrate } \\
\text { buffer(1M) } \\
\text { vol.(ml) }\end{array}$ & $\begin{array}{l}\mathrm{dH}_{2} \mathrm{O} \\
\text { vol. } \\
(\mathrm{ml})\end{array}$ & $\begin{array}{l}\mathrm{DNS} \\
\text { vol. } \\
(\mathrm{ml})\end{array}$ & $\begin{array}{l}\mathrm{dH}_{2} \mathrm{O} \\
\text { vol. } \\
(\mathrm{ml})\end{array}$ & $\begin{array}{l}\mathrm{A} \\
540 \mathrm{~nm} \\
(\mathrm{O} . \mathrm{D})\end{array}$ \\
\hline 1 & GS $10 \mathrm{mg} / \mathrm{m}$ & 10 & 1 & 0.45 & 0 & 0.05 & 0.5 & 3 & 20 & 1.6 \\
\hline 2 & GS $5 \mathrm{mg} / \mathrm{ml}$ & 5 & 0.5 & 0.45 & 0 & 0.05 & 0.5 & 3 & 20 & 0.96 \\
\hline 3 & GS $2 \mathrm{mg} / \mathrm{ml}$ & 2 & 0.2 & 0.45 & 0 & 0.05 & 0.5 & 3 & 20 & 0.3335 \\
\hline 4 & GS $1 \mathrm{mg} / \mathrm{ml}$ & 1 & 0.1 & 0.45 & 0 & 0.05 & 0.5 & 3 & 20 & 0.1695 \\
\hline 5 & GS $0 \mathrm{mg} / \mathrm{ml}$ & 0 & 0 & 0 & 0 & 0.05 & 0.95 & 3 & 20 & 0.019 \\
\hline
\end{tabular}

Table B-5 Measurement of yeast growth density into YPGal.-1\% Galactose samples by using spectrometer (absorbance) at $600 \mathrm{~nm}$ (June 13, 2012)

\begin{tabular}{|l|l|l|l|l|}
\hline YPGal-1\% Galactose Sample & Time(h) & \multicolumn{2}{l|}{ Absorbance@600nm } & 0 \\
\hline YPGal.- 1\% Gal. & 0 & 0.04 & 0.04 & 0.145 \\
\hline YPGal.- 1\% \#1 & 0 & 0.185 & 0.185 & 0.197 \\
\hline YPGal.- 1\% \#2 & 2 & 0.237 & 0.237 & 0.354 \\
\hline YPGal.- 1\% \#3 & 4 & 0.394 & 0.394 & 0.455 \\
\hline YPGal.- 1\% \#4 & 6 & 0.495 & 0.495 & 0.736 \\
\hline YPGal.- 1\% \#5 & 8 & 0.776 & 0.776 & 3.56 \\
\hline YPGal.- 1\% \#6 & 12 & & 3.6 & 7.06 \\
\hline YPGal.- 1\%\#7 & 16 & 1.8 & 7.1 & 7.76 \\
\hline YPGal.- 1\% \#8 & 20 & 1.84 & 7.8 & 7.74 \\
\hline YPGal.- 1\% \#9 & 24 & 1.84 & 7.78 & 7.96 \\
\hline YPGal.- 1\% \#10 & 30 & 1.88 & 8 & \\
\hline
\end{tabular}


Table B-6 Measurement of Galactose Concentration and Net activity of enzyme into YPGal-1\% Galactose samples by using CMC/DNS tool (June 13, 2012)

\begin{tabular}{|c|c|c|c|c|c|c|c|}
\hline S.\# & $\begin{array}{l}\text { Sample } \\
\text { name }\end{array}$ & $\begin{array}{l}\text { Time } \\
\text { (h) }\end{array}$ & $\begin{array}{l}\text { A540nm } \\
\text { (O.D) }\end{array}$ & $\begin{array}{l}\text { Net } \\
\text { A540nm (O.D) }\end{array}$ & $\begin{array}{l}\text { Gal. } \\
\text { Conc. } \\
(\mathrm{mg} / \mathrm{ml})\end{array}$ & $\begin{array}{l}\text { Net Galactose } \\
\text { Concentration } \\
(\mathrm{mg} / \mathrm{ml})\end{array}$ & $\begin{array}{l}\text { Volumetric } \\
\text { activity } \\
\left(\mathrm{mg} / \mathrm{mL}^{*} \mathrm{~h}\right)\end{array}$ \\
\hline 1 & YPG-1\% Gal. & 0 & 1.353 & -0.069 & & -0.41 & -0.41 \\
\hline 3 & YPGal. & 0 & 1.383 & 0.061 & & 0.36 & 0.36 \\
\hline 5 & YPGal. & 2 & 1.303 & -0.029 & & -0.17 & -0.17 \\
\hline 7 & YPGal. & 4 & 0.963 & -0.264 & & -1.57 & -1.57 \\
\hline 9 & YPGal. & 6 & 1.093 & -0.029 & & -0.17 & -0.17 \\
\hline 11 & YPGal. & 8 & 0.945 & -0.021 & & -0.12 & -0.12 \\
\hline 13 & YPGal. & 12 & 0.549 & 0.047 & & 0.28 & 0.28 \\
\hline 15 & YPGal. & 16 & 0.087 & 0.084 & & 0.50 & 0.50 \\
\hline 17 & YPGal. & 20 & 0.107 & 0.103 & & 0.61 & 0.61 \\
\hline 19 & YPGal. & 24 & 0.137 & 0.136 & & 0.81 & 0.81 \\
\hline 21 & YPGal & 30 & 0.157 & 0.155 & & 0.92 & 0.92 \\
\hline 25 & $7 \mathrm{~B}$ & 0 & 0.423 & 0.413 & & 2.46 & 2.46 \\
\hline 23 & no-Enz. & 0 & 0 & 0 & & 0 & 0 \\
\hline 2 & YPG-1\% Gal & 0 & 1.422 & & 8.49 & & \\
\hline 4 & YPGal. & 0 & 1.322 & & 7.89 & & \\
\hline 6 & YPGal. & 2 & 1.332 & & 7.95 & & \\
\hline 8 & YPGal. & 4 & 1.227 & & 7.32 & & \\
\hline 10 & YPGal. & 6 & 1.122 & & 6.70 & & \\
\hline 12 & YPGal. & 8 & 0.966 & & 5.77 & & \\
\hline 14 & YPGal. & 12 & 0.502 & & 2.99 & & \\
\hline 16 & YPGal. & 16 & 0.003 & & 0.017 & & \\
\hline 18 & YPGal. & 20 & 0.004 & & 0.023 & & \\
\hline 20 & YPGal. & 24 & 0.001 & & 0.005 & & \\
\hline 22 & YPGal. & 30 & 0.002 & & 0.011 & & \\
\hline 26 & $7 \mathrm{~B}$ & 0 & 0.01 & & 0.059 & & \\
\hline 24 & no-Enz. & 0 & 0 & & 0 & & \\
\hline
\end{tabular}




\section{Appendix C: Tools and devices were used in this study research}

The original yeast "Kluyveromyces lactis" used in this research was developed at New England Biolabs, Inc. and DSM Biologics Company B.V. The shaker table used in these experiments was a Lab-Line ${ }^{\circledR}$ Orbit Environ-shaker (model 3528-5). The autoclave used in this work was a New Brunswick Scientific autoclave (model AC-48). The spectrometer used in this research was a Milton Roy Spectrometer (model Spectronic 21D UV). The power source for gel electrophoresis was VWR 300V Power Source (model G82428). The balance in this lab was METTLED TOLEDO Scalar (model VIPER). The bioreactors were BioFlo3000 and BioFlo5000. The microscope used in this research study was an Olympus-BX40 (Leeds Precision Instruments). The side-arm flasks from Bellco and other glassware used in this lab were mostly from Fisher Scientific. All these devices and tools were located in and all the experiments done in Dr. David R. Shonnard's laboratory, in the Chemical Engineering Department of Michigan Technological University.

Some of the lab tools photo: 


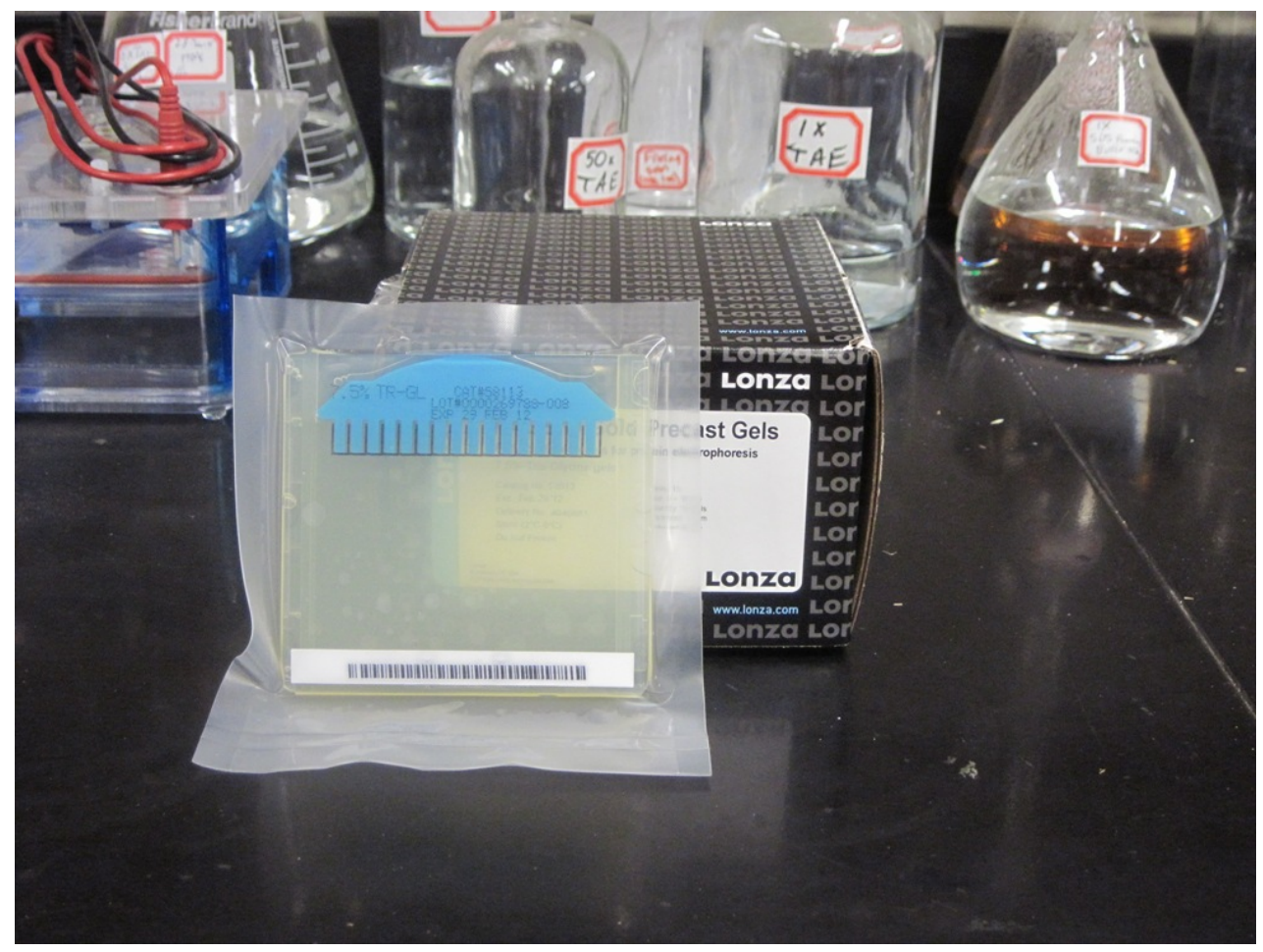

Figure C-1 Gel electrophoresis for the SDS-PAGE

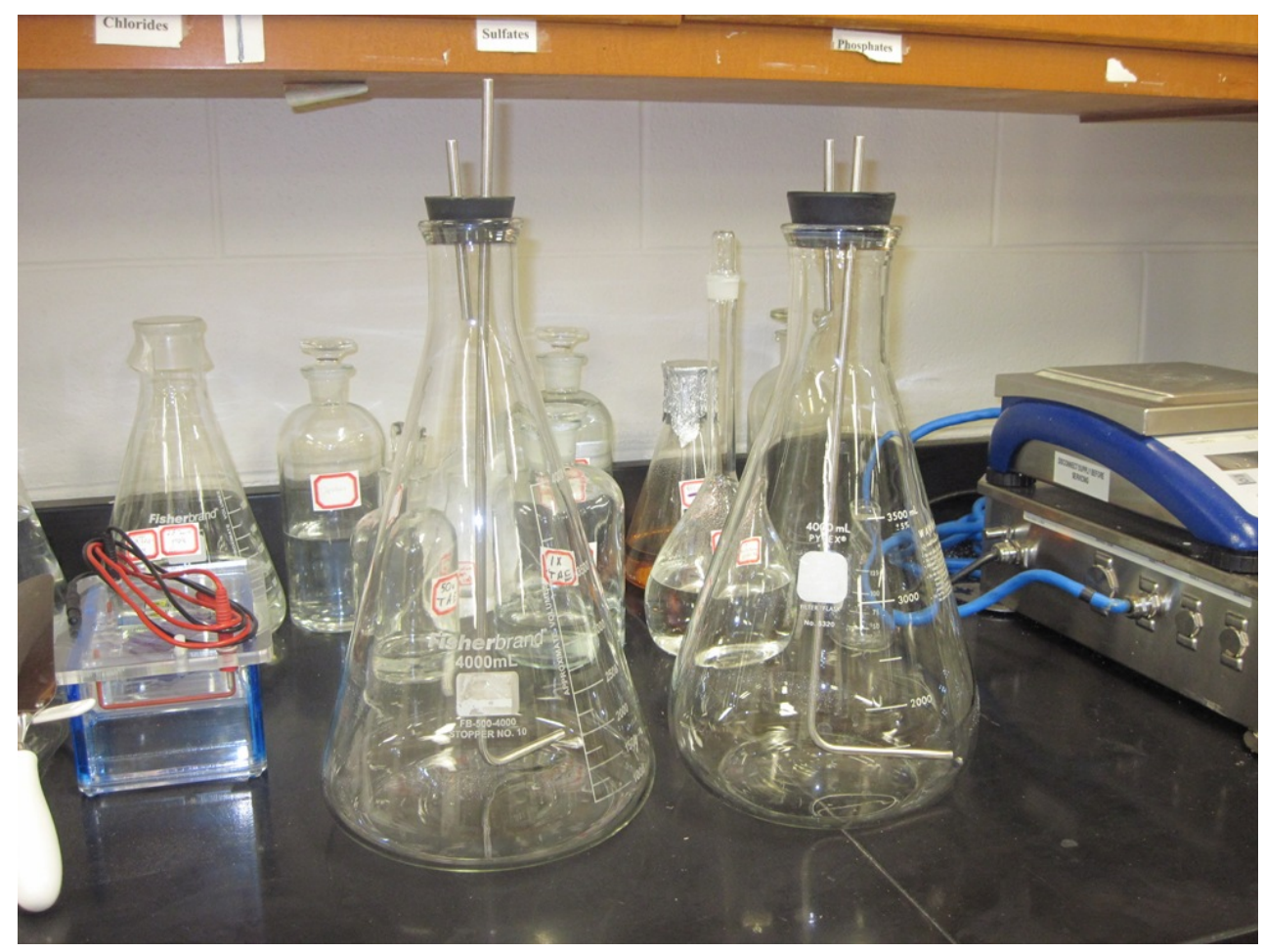

Figure C-2 Large flasks (4L) were used to transfer YPGal 1\% media in this research into a pre-sterilized BioFlo3000 bioreactor 


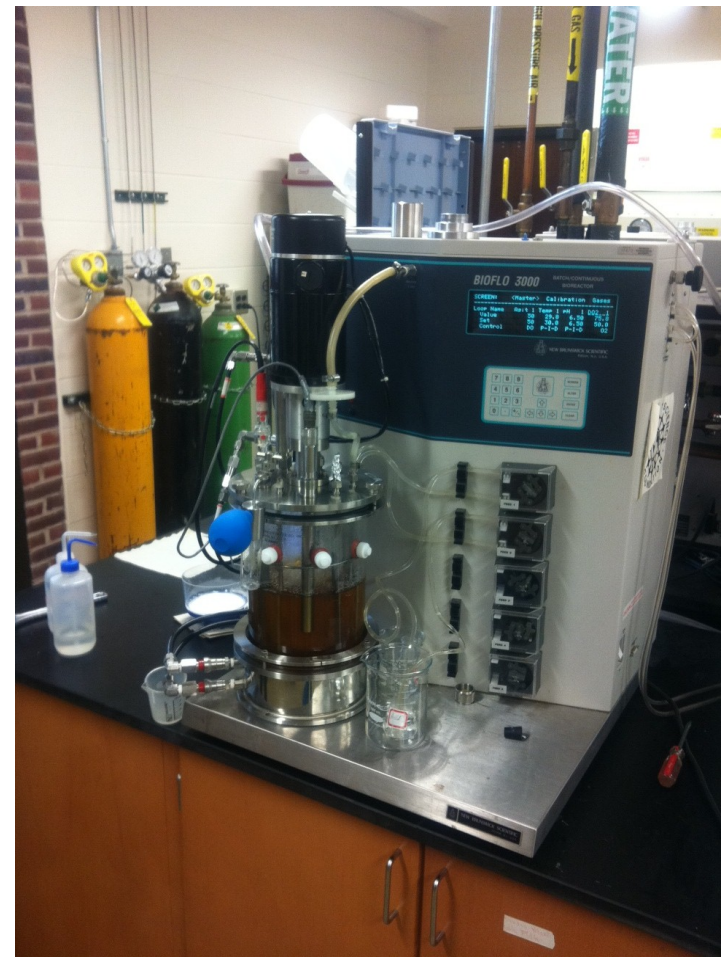

Figure C-3 BIOFLO 3000 reactor 


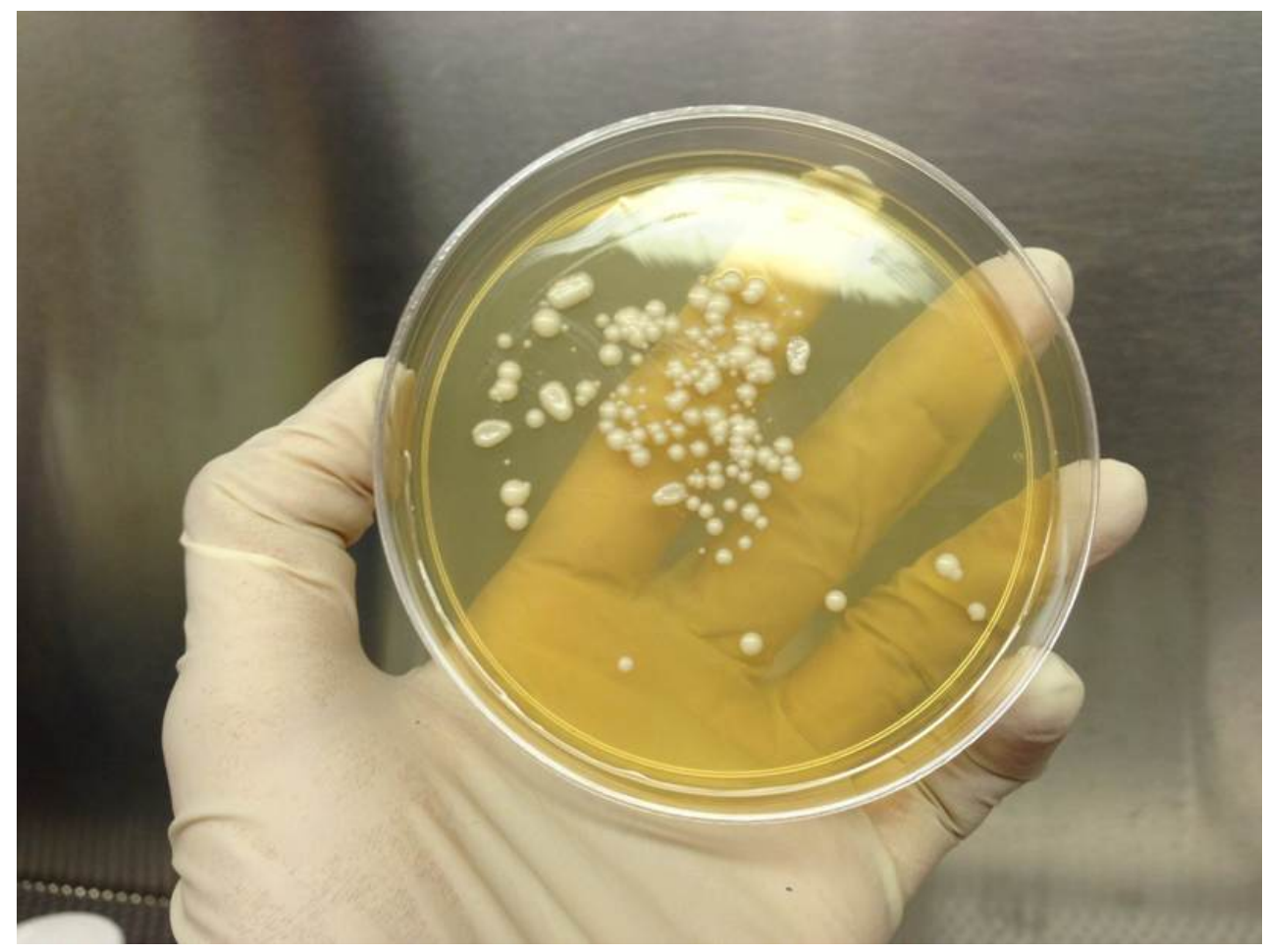

Figure C-4 YPD agar media plate with many single colonies of $\mathrm{K}$. lactis-Cel7B

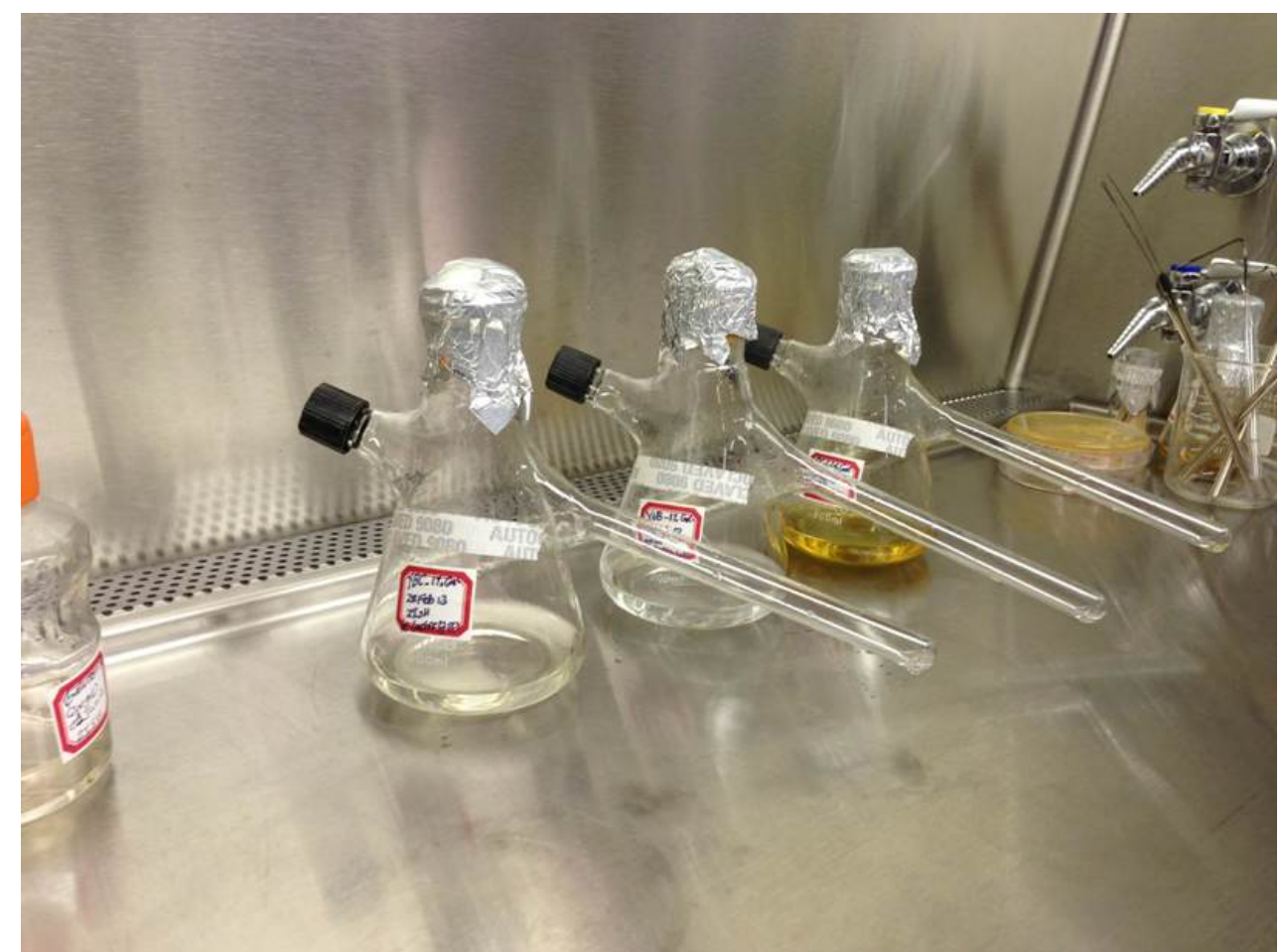

Figure C-5 Side-arm flasks (small scale) with different medium: YPGal, YNB, and YBC 


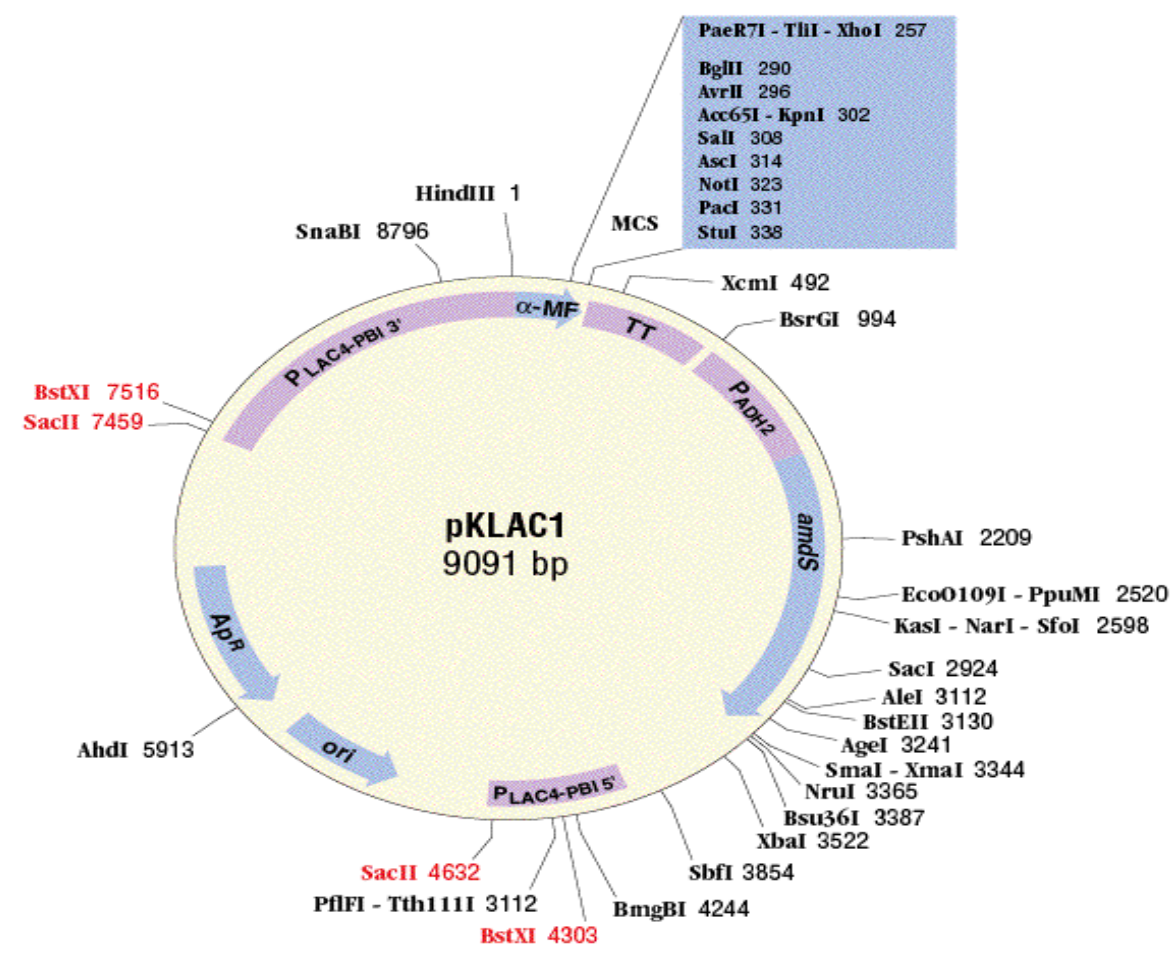

Figure C-6 The original yeast "Kluyveromyces lactis" was developed at New England Biolabs, Inc. and DSM Biologics Company B.V T. reeseigrowth
and induction $\rightarrow$ mRNA isolation $\rightarrow \begin{aligned} & \text { cDNA reverse } \\ & \text { transcription }\end{aligned}$

$\rightarrow \begin{aligned} & \text { PCR amplification } \\ & \text { of target genes }\end{aligned} \rightarrow \begin{aligned} & \text { Digestion/ligation } \\ & \text { into plasmid }\end{aligned} \rightarrow$ E. colitransformation

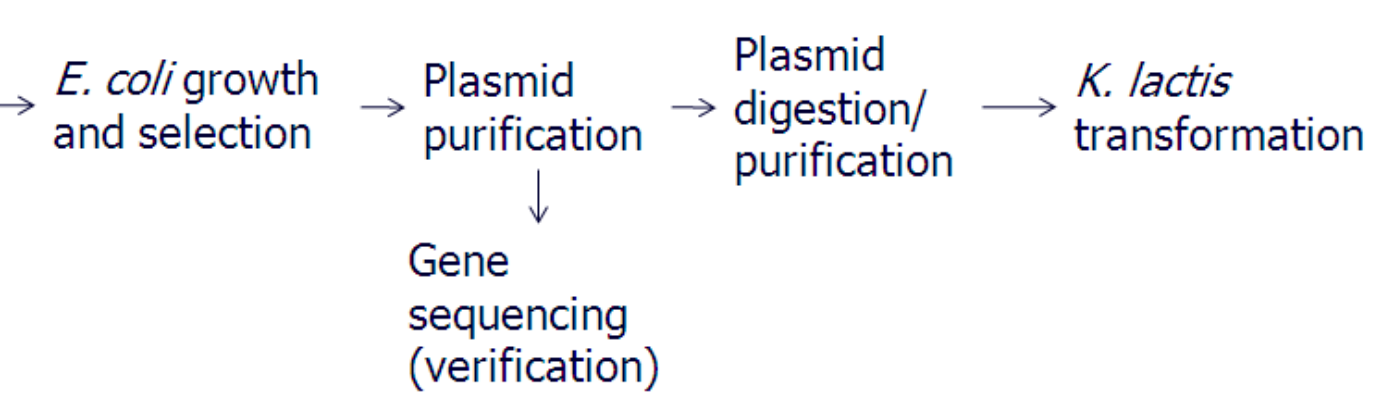

Figure C-7 The transformed yeast "Kluyveromyces lactis" Cel7B was developed by (Brodeur-Campbel 2012) 